\title{
Revision of the
}

\section{Niagara Railway Arch Bridge}

\author{
by \\ CHARLES EVAN FOWLER
}

\begin{tabular}{l|} 
SPCL \\
$F C$ \\
3160 \\
.67 \\
$N 54$ \\
1920
\end{tabular}




$$
\begin{gathered}
\text { LIBRARY } \\
\text { BROCK UNTTVERSITY }
\end{gathered}
$$


$=$ 
Digitized by the Internet Archive in 2012 with funding from

Brock University - University of Toronto Libraries 


\section{AMERICAN SOCIETY}

OF

\section{CIVIL ENGINEERS}

\section{REVISION OF}

THE NIAGARA RAILWAY ARCH BRIDGE

Charles Evan Fowler, M. Am. Soc. C. E. WITH DISCUSSION BY

MessRs. O. H. AMMANN, C. BENTHAM, J. A. L. WADDELL, THEODORE BELZNER, F. E. SCHMITT, P. G. LANG, JR., JAMES E. HOWARD, CLYDE T. MORRIS, ALMON H. FULLER, AND CHARLES EVAN FOWLER.

Reprinted from Transactions, Vol. LXXXIII, p. 1919 (1920). 



\section{AMERICAN SOCIETY OF OIVIL ENGINEERS}

\section{N S T T U T E D 1852 \\ TRANSACTIONS}

This Society is not responsible for any statement made or opinion expressed in its publications.

\section{Paper No. 1460}

REVISION OF

THE NIAGARA RAILWAY ARCH BRIDGE*

By Charles Evan Fowler, M. Am. Soc. C. E.

With Discussion by Messrs. O. H. Ammann, C. Benthali, J. A. L. Waddell, Theodore Belzner, F. E. Schmitt, P. G. Lang, Jr.,

James E. Howard, Clyde T. Morris, Almon H.

Fuller, and Charles Evan Fowler.

\section{SYNOPSIS.}

The revision of the Niagara Railway Arch Bridge made in 1918-19, as here described, comprised first a complete investigation of live loads for railway bridges, in order to determine the probable maximum loading for such a terminal bridge-a double-track, two-hinged, 550-ft. arch over the Niagara Gorge. In 1918 an extensive series of strain-gauge readings, the methods of which are fully described, was made. The dead load stresses were investigated by jacking apart one top chord of the arch span by means of a special toggle, the center top chord dead load stress being read with the strain gauge. This resulted in the jacking open of both top chords in 1919 to change the center shims and readjust the stresses in all members of the arch trusses.

The investigations as to the proper unit stresses to adopt and the logical column formula to use for the revision, are given at some length. The strain-gauge investigation also determined the secondary stresses, and readings of stresses made during the passage of trains at various speeds were made the basis of a formula for a curve of values for impact at various speeds. The new Fuller-West strain gauge, developed as a result of the investigations, is described. 
The methods of reinforcing the sway and floor system of the arch span and of the approaches, particularly the methods of relieving dead load stress and of doing the field work, and the construction of a copperstcel salt-water protecting floor are described, also the method of grade rectification.

The method of reinforcement of an abutment 64 years old is given in some detail, as well as armored coatings of the arch skewbacks to motect them from weathering, and of skewback thrust walls to carry the sway stresses to bed-rock. Brief descriptions are given of the improvements made to the bridge entrances, and other bridge property accessories. The paper as a whole covers the work of revising the structure up to modern capacity at less than one-third the cost of a new structure.

The Niagara Railway Arch Bridge (Fig. 1) was constructed in 1896-97 from the plans of the late L. L. Buck, M. Am. Soc. C. E., to take the place of the Roebling Railway Suspension Bridge, and has already been described for the Society.* The history of the various bridges which had occupied this site is quite fully given, so that no description of them will be repeated here; but it is desirable for the full understanding of this paper to show briefly the evolution which took place from the first suspension bridge built in 1847-48.

The first bridge was built of wire cables, with no stiffening trusses, carrying a single 7 -ft. roadway. That no disaster occurred due to the heavy winds up and down the Gorge may be considered miraculous, as such a disaster did befall the Wheeling Suspension Bridge, which was built by the same engineer, Charles Ellet, whose fame resulted from his work in the development of long-span suspension bridges. Doubtless the study of the faults of this very primitive bridge over the Niagara Gorge led the late John A. Roebling, M. Am. Soc. C. E., to plan the railway suspension bridge with heavy stiffening trusses, and with guys to the cliffs as well.

That there was much competition between the suspension type and the tubular continuous girder, is evidenced by the remark in Mr. Roebling's final report to the effert that "as regards the success of your work more has been accomplished than was promised. The idea of a perfectly rigid structure, such as a tubular bridge, was never held out". 


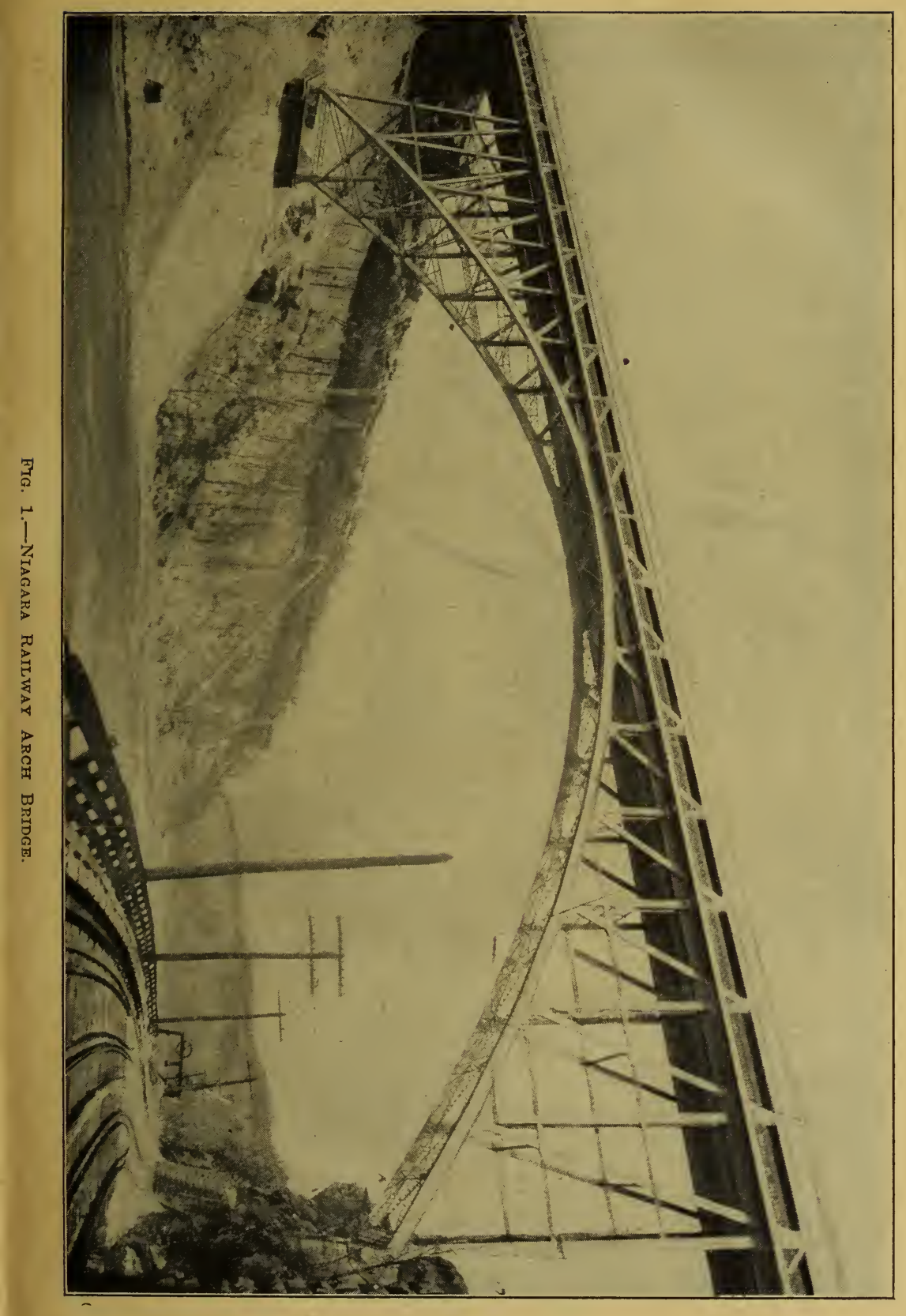



The design for a tubular continuous girder bridge for this site was made in 1850, by James Hodges. This is shown in Fig. 2, and is undoubtedly one of the most pleasing, artistic and chaste designs ever made for a bridge with wholly rectangular lines. One is also led to wonder if it would not, with some reinforcement, have been in use nearly up to the present, had it been built instead of the suspension type. The reason for its not having been adopted, as may be inferred from Mr. Roebling's remark just quoted, was due almost entirely to the question of cost. There may also be some question as to whether such heavy stone piers would long have stood so close to the water's edge, especially in view of the fact that the side slopes under water have scoured out as much as $30 \mathrm{ft}$. near this site, during the last twenty years.

The statement may be safely made, however, that if an engineer were considering the various phases of the problem of bridging the Gorge at this site to-day, the quest would soon narrow to the three-span continuous truss and a two-hinged arch such as is now in use, with the modification, however, of its being constructed as a three-hinged arch under dead load. The latter feature governed very largely the course of the writer's investigations during the summer and fall of 1918, looking toward increasing the carrying capacity of the arch structure.

The stiffened suspension bridge would now only be considered for railway use where the span was very long, or where the ratio of dead load to live load would approximate 1.8 to 1 up to 3 to 1 . There is, however, every probability that as steel becomes increasingly costly, the minimum span for suspension bridges for carrying railways will again gradually approach $1000 \mathrm{ft}$.

The process of evolution at Niagara shows also the progress from wood to stone and steel, and, later, to reinforced concrete and steel. The towers of the first suspension bridge were of wood, and although an advance was made in using stone towers for the railway suspension bridge in 1856, a still further advance was made by replacing the stone towers, which had become badly cracked and shattered, with steel ones in 1886. The use of stiffening trusses in the railway suspension bridge was a distinct advance, but they were of wood, and were later replaced with steel trusses. Both the towers and stiffening trusses were replaced under the supervision of Mr. L. L. Buck, and fully 
described for the Society.* The work carried out during 1919 on the arch, under the writer's direction, marked a still further replacement of wood with steel, and the substitution of steel or reinforced concrete for some of the stonework.

The writer was first called on in June, 1918, to make merely the regular annual inspection of the bridge, and it was supposed to be confined to the need for ordinary repairs, such as riveting and painting. However, there was found to be very serious corrosion of the top flanges of the floor-beams, stringers, and stringer laterals on the spans, and the top flanges and laterals of the six approach girder spans, from the salt water dripping from refrigerator cars and from leakage of water and injector discharge from locomotives. The studies made in developing plans for repairing this damage, where metal originally $\frac{1}{2}$ in. in thickness was corroded in some cases to a thickness of only $\frac{1}{16}$ in., soon demonstrated that the loads passing over the double-track railway deck were from 30 to $70 \%$ heavier than those for which the structure was designed.

Instructions were thereupon given to proceed with a thorough analytical study and strain-gauge analysis of the entire bridge. This was considered to be necessary by the writer on account of the 550-ft. arch span being an indeterminate type of structure; on account of the large secondary stresses that it was apparent were induced from many of the details; and from a desire to fix definitely the amount of impact. The first problem, therefore, was to study the past and probable future increase of live loads.

\section{LIVE LOADS.}

The trains crossing the Suspension Bridge at the time of its completion in 1855 were so light as to be somewhat amusing in comparison with present-day trains, but they were a serious problem to the engineer of that period. In his final report, Mr. Roebling speaks of passenger trains of 15-ton cars frequently passing over the bridge, and the average number of trips in March, 1855, as being more than 30 daily, probably including freight trains as well as passenger trains.

The loads used by Mr. Roebling in testing the Suspension Bridge are referred to in his report in several paragraphs as follows:

- Transactions, Am. Soc. C. E., Vol. X (1881), p. 195. 


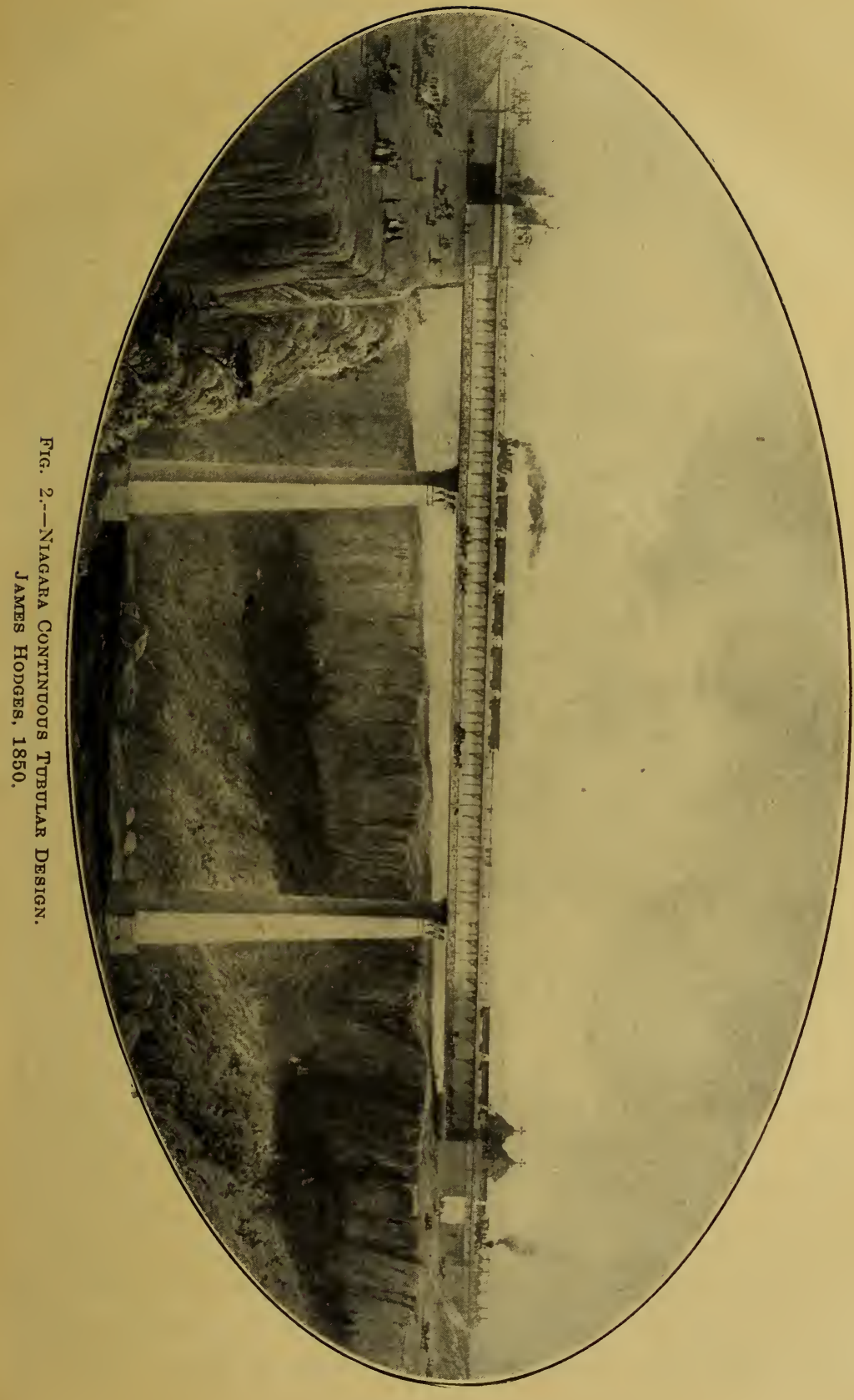



"An engine and tender of 34 tons weight, together with one passenger car, crowded with persons, making a total of about 47 tons, caused a depression in the center of $5 \frac{1}{2}$ inches." * * *

"A single engine of 23 tons weight, including tender, caused a flattening of the camber in the center of 0.3 feet." * * *

"On the last mentioned day (March 18th, 1855) the railroad floor was opened for business by passing an experimental freight train, composed of 20 full loaded cars, pushed by a 26 -ton engine, from the Canada to the New York depot. The gross weight was estimated at 326 tons."

This indicates that the total weight of each car, with load, was only 15 tons. Other tests were made with a 22-ton American engine and a 34-ton, six-driver, English built, freight engine. The locomotives used in the test trains by Mr. L. L. Buck, in testing the Arch Bridge on July 29th, 1897, weighed 90 tons each, the cars 52.5 tons each, and the total test load on the 550-ft. arch span was 1670 short tons. The engines used by the writer for load tests and deflection tests on August 30th and 31st, 1918, weighed from 177 to 221 tons each, and the test load on the 550 -ft. arch span was 2490 short tons.

The diagram, Fig. 3, shows by the lower curve the average increase in the total weight of locomotives in short tons for this locality from 1850 to 1918. This curve was established from the weights of locomotives passing over the Niagara bridges during this period and filled in by locomotives used by the writer in calculating bridge stresses in the same territory from 1887 to 1918 . It agrees quite closely with the one established by J. E. Greiner, M. Am. Soc. C. E., from the records of the Baltimore and Ohio Railway. The curve extended to 1940 indicates that the total weight of locomotives by that time might reach 365 tons, if the same rate of increase is maintained; but owing to mechanical limitations well known to locomotive builders, such as lack of space for much larger cylinders, it seems more probable that the 1940 limit for consolidation or decapod locomotives will not exceed 300 tons, as indicated by the dotted reverse curve. The total weight of the various Cooper locomotives has been located on the curve, as a means of general comparison. The investigation developed the fact, which is doubtless more or less appreciated by all railway and bridge engineers, that the Cooper loadings are out of date and should no longer be used for calculating bridge stresses. The Cooper E-65 
locomotive (and all others) is only $56 \mathrm{ft}$. in length, whereas the Grand Trunk Mikado locomotives used in the tests of 1918 on the arch weighed 221 tons, or practically the same as the E-65, but were $77 \mathrm{ft}$. long over all.

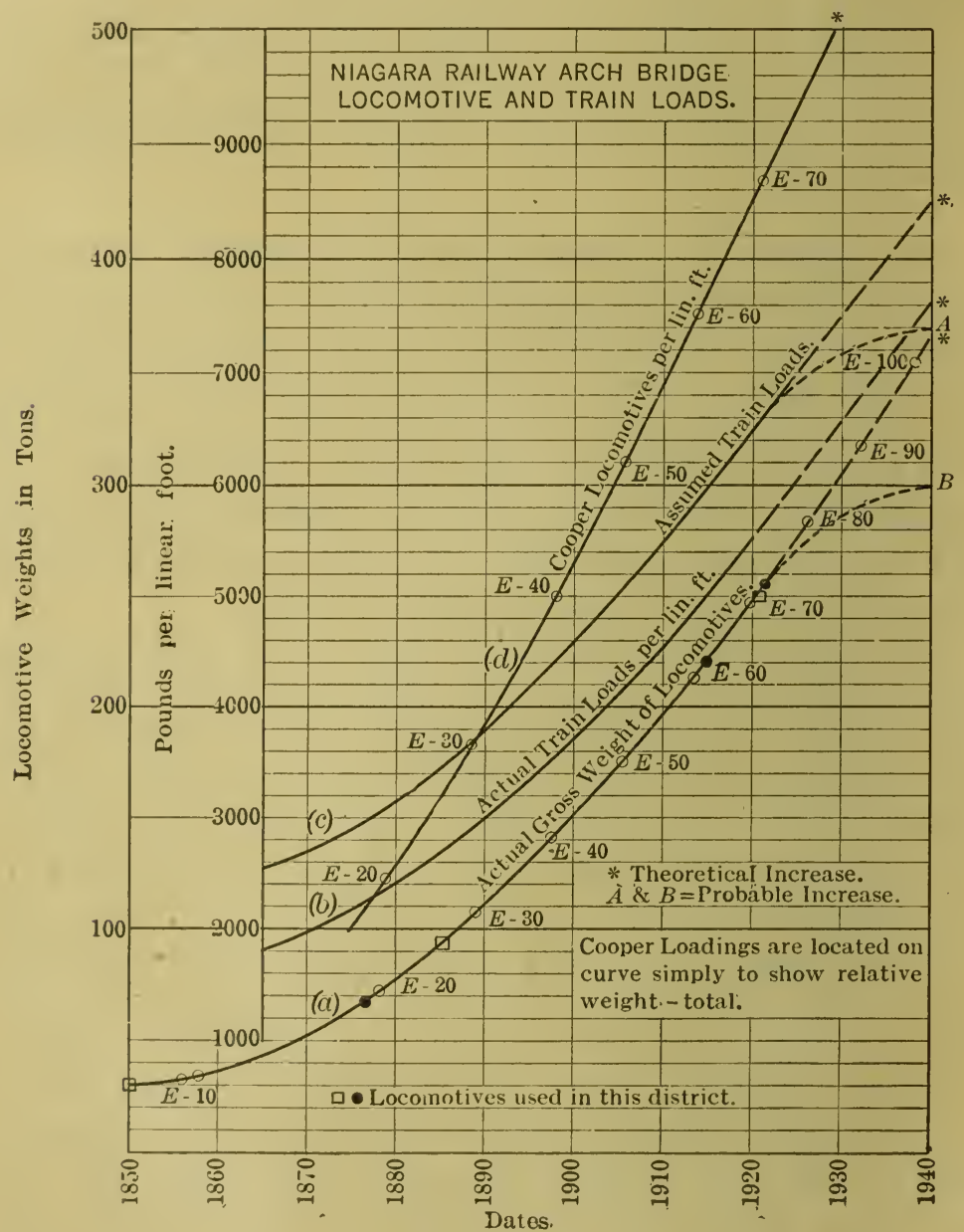

FIG. 3.

The peculiar use of the Niagara Arch as a terminal bridge, or connection between the Canadian and American yards, makes it unnecessary to provide for as heavy locomotives as would be used on a main-line structure, so that Cooper's E-60 as adopted for the arch 
and the truss spans reaching to the shores, will undoubtedly be the maximum absolutely required up to 1940 ; but to make a structure of uniform strength for modern locomotives it was necessary to use Cooper's E-70 loading for the stringers and floor-beams on the spans and the approach girders, or on spans from 20 to $52 \mathrm{ft}$. in length. Then, by stopping traffic at any time on one track, it will be possible to pass heary loads or locomotives slowly over the other track, up to about E-80 loading or its equivalent.

The logical procedure for new bridges, however, seems to be to abandon the Cooper loading entirely and adopt a table of moments (and one of end shears to correspond) similar to that given in Column 10 $(F)$ of Table 1. This was established by taking the maximum moment from Columns 1, 2, 3, and 4 for each span length, Columns 1, 2, 3, and 4 being the moments from the heaviest existing locomotives and trains, as calculated by H. T. Welty, M. Am. Soc. C. E., Structural Engineer of the New York Central Railroad. This indicates that for a logical application of the old Cooper loadings, E-70 should be used for spans from 10 to $30 \mathrm{ft}$., E-80 for spans from 30 to $100 \mathrm{ft}$., and E-60 for spans from 100 to $300 \mathrm{ft}$. and over. Should it be desired to provide for future increase, as is advisable, a percentage must be added to the values in Column $9\left(F^{\prime}\right)$, logically $25 \%$ at the present time, these values plotted, a smooth curve established comprising them, and the moments tabulated for each span length from 10 to $300 \mathrm{ft}$.

The values for moments in Column (10) $(F)$ of Table 1, and Fig. 4 , would be greater than for E-90 loading up to about a span length of $120 \mathrm{ft}$., and for spans greater than $120 \mathrm{ft}$., the $F$ moments would be less than for E-90 loading. Some of the large railway lines are already planning to use a similar scheme, and it is confidently expected that some such method will be in universal use within a few years.

The adoption of a maximum loading such as this, and approximating E-90, calls of course, for a more logical system of unit stresses, and not less than those used in the Niagara Arch revision, such as are explained in a later section of this paper. They agree well with the unit stresses used for the Hell Gate Arch and the Quebec Cantilever. The table would show the relation to the Cooper loads, and they could still be used as a reference standard for spans calculated for them.

The actual train loads for the same period are shown on Fig. 3, as Curve (b), and the assumed train loads as Curve $(c)$. These curves 


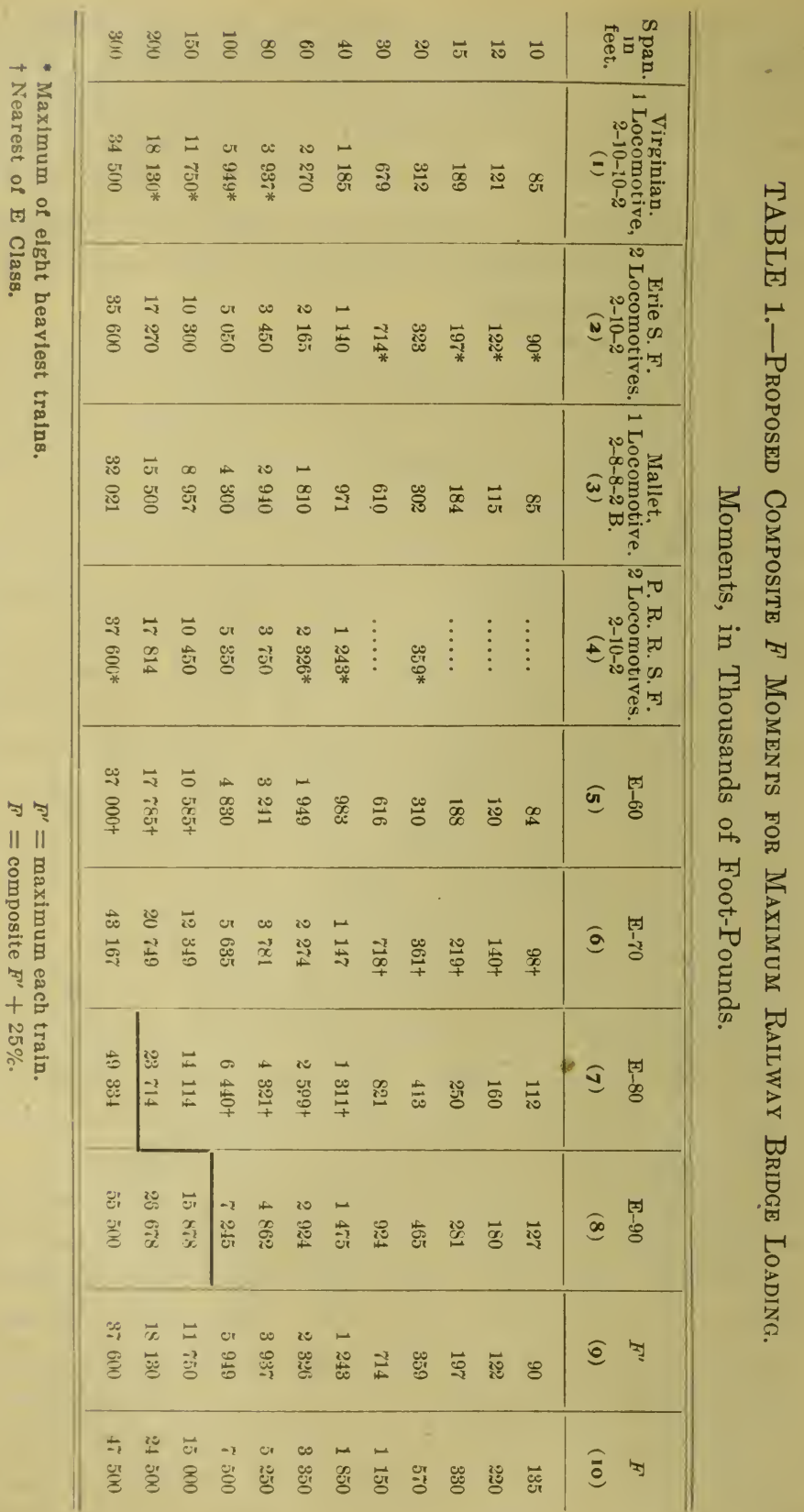




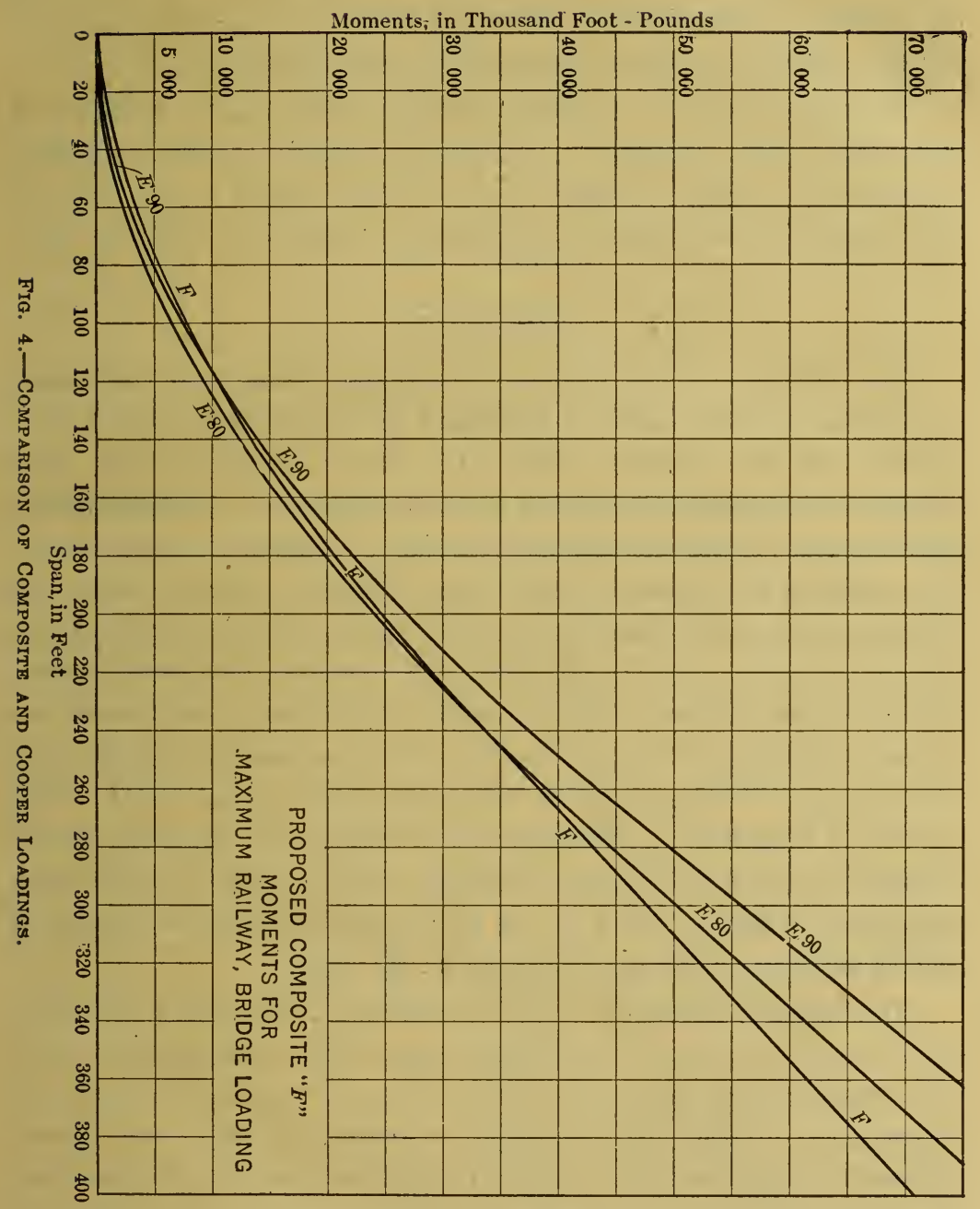


indicate that the following, or train loads, with each of the Cooper loadings E-60, E-70, and E-80, are too high and that if Cooper's loading is to be used for the future, the train load for E-60 should be $5500 \mathrm{lb}$. per lin. ft., for E-70 only $6000 \mathrm{lb}$. per lin. ft., and for E-80 only 6500 lb. per lin. ft. The weight per linear foot of Cooper locomotives is shown in Curve $(d)$ for the purpose of general comparison.

The careful study of all traffic using the Niagara Arch Bridge, and especially of that passing over it during the months that the tests were in progress in 1918, indicated that, for both tracks loaded, $90 \%$ of E-60 should be used on the arch, but $100 \%$ on the trusses of 115 -ft. span.

\section{Deflection.}

The deflection of the Roebling Suspension Bridge was very large, amounting to $5 \frac{1}{2}$ in. under a light load of 47 tons total for one locomotive and one passenger car. This always necessitated the slow speed of 5 miles per hour, and as the trains increased in weight greatly by 1896 , the deflection became alarming, amounting to about $18 \mathrm{in}$. The Schneider Cantilever Bridge near it had a deflection under the original test load of about $7 \frac{5}{16}$ in. The new arch built in 1896-97 was tested, therefore, only for the deflection under the test load of alternating engines and cars weighing a total of 1670 tons, and a maximum vertical deflection of $\frac{13}{1} \frac{3}{6}$ in. resulted. The calculated deflection for the full load on both decks of $10000 \mathrm{lb}$. per lin. ft. was $1 \frac{15}{16} \mathrm{in}$. This was for a total load on the arch span of 2750 tons, while the load of 2490 tons used by the writer on August 30th and 31st, 1918, caused a maximum deflection of $1 \frac{1}{2}$ in., or an increase in effective loading of 84.5\% above the 1897 test load used by Mr. Buck.

The sidewise deflection of the Suspension Bridge was so excessive as to require the use of stay cables to the cliffs, and although under the proportionately light loads of 1897 the arch was comparatively stiff sidewise, the loads had increased so greatly by 1918, with speeds allowed by sufferance up to 25 or 30 miles per hour, that the side sway had become somewhat alarming in amount. The writer, therefore, reduced the maximum speed to 10 miles per hour in July, 1918, and new sway bracing was introduced, as will be described later, that has practically removed all sidewise deflection. 


\section{IMPAOT.}

When the inspection of 1918 was undertaken the impact on the structure was apparently very excessive, and was composed of various factors, such as direct impact from the excessive speeds, hammering on open rail joints, bad track alignment, flat wheels, and various kinds of vibration. The impact readings made with strain gauges therefore covered all elements of train load outside the merely static effect. The readings were made with the Berry strain gauge and the curves of increase due to speeds of $5,10,15,20$, and 25 miles per hour are shown by solid lines in Fig. 5. These readings indicated that probably the critical speed for the structure was in the neighborhood of 25 miles per hour, at which speed the impact practically agreed with that derived from the old Schneider formula:

$$
I=\frac{300}{l+300} .
$$

- However, as no readings were made at higher speeds, it can only be stated that at 25 miles per hour the impact agreed with that derived from the Schneider formula; but it is by no means certain that at some point of higher speed values as great as those given by the Lindenthal formula. would not be reached.

The values of impact are given in Table 5, which is the stress sheet for the structure as rebuilt. The impact stresses have been computed by three different formulas-the Schneider formula, the Lindenthal formula, and the proposed new American Railway Engineering Association formula; and also for the values adopted for the structure (column headed Niagara in Table 5), as based on the strain-gauge readings, which are for 17 miles per hour, or practically $50 \%$ of the Schneider values. The formulas referred to are as follows:

$$
\begin{array}{ll}
\text { Schneider, } & I_{1}=\frac{300}{l+300} \\
\text { Lindenthal, } \quad I_{2} & =\frac{L^{2}}{D+L} \times \frac{8 Q+q a}{4 Q+4 q a} \\
\text { New A. R. E. A., } I_{3} & =\frac{300}{300+\frac{l^{2}}{100}} \\
\text { Fowler, } & I_{4}=\frac{\left(\frac{I^{2}}{s^{2}}\right) S^{2}}{I_{1}}
\end{array}
$$




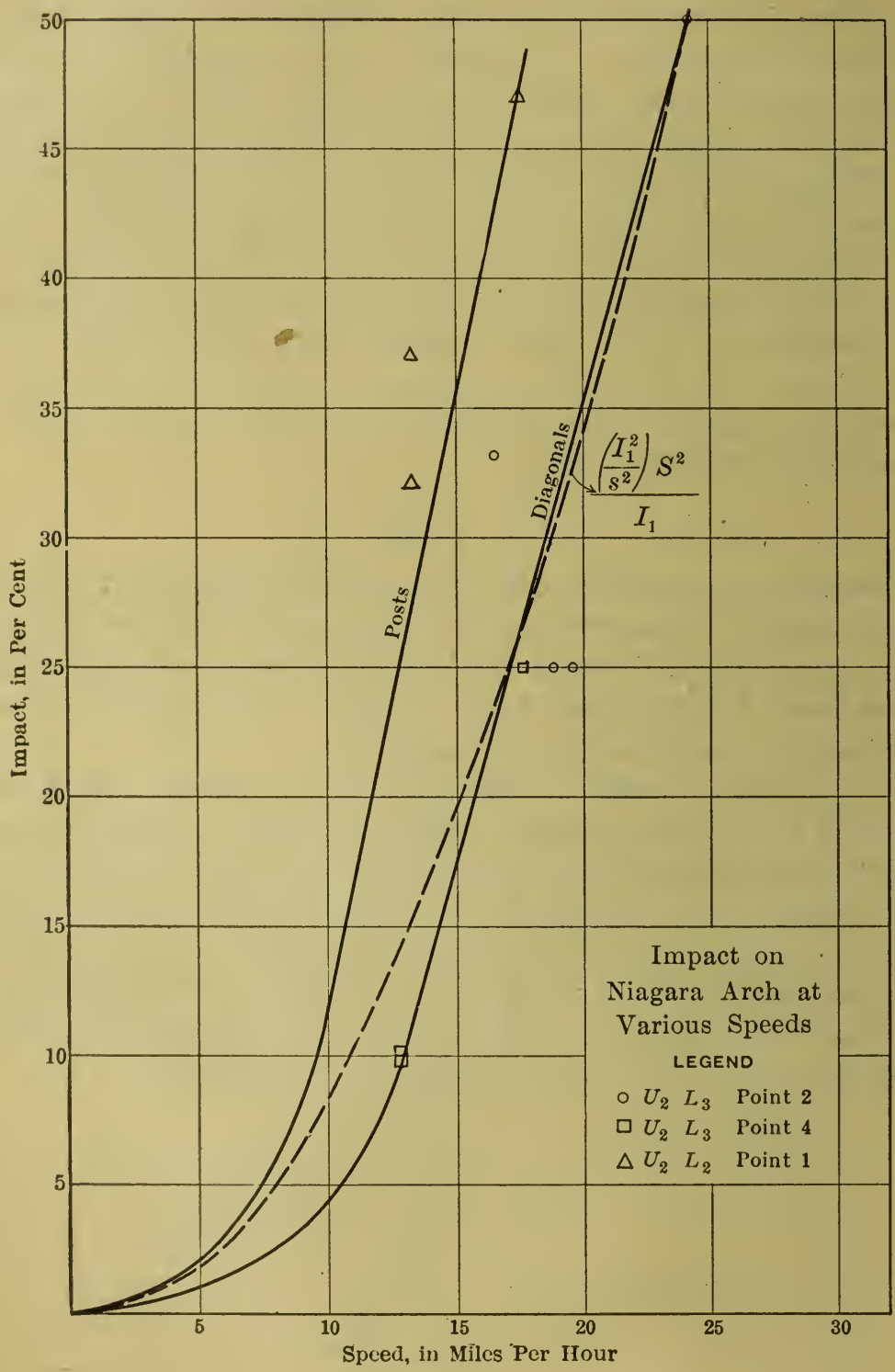

FIG. 5. 
in which,

$I_{4}=$ percentage of impact for any speed below that read;

$L=$ live load stress;

$D=$ dead load stress;

$l=$ loaded length;

$S=$ speed, in miles per hour, for reduction;

$s=$ speed, in miles per hour, for strain-gauge reading;

$Q=$ locomotive weight;

$q=$ train load per linear foot;

$a=$ length of train behind tender.

Although the readings made by the writer were not great in number, they were so harmonious as to make it possible to establish a safe curve for the variation of impact due to variations in speed below the critical point or that speed giving maximum impact. This curve is shown in the dotted line in Fig. 5 and the formula is that given as $I_{4}$ with the denominator $I_{1}$, and for which may be substituted the values derived from either $I_{2}$ or $I_{3}$ if it is desired to use another than the Schneider formula for obtaining maximum impact.

When used for some other structure, check readings should be made for the particular case at several speeds, and the coefficient of $S$ definitely fixed. The actual running speed over the structure should be established of course at some maximum limit, somewhat below the speed used for fixing impact values for the stress sheet.

Whatever impact formula is used, it should certainly be one which gives values high enough to cover as well all the factors of ignorance as to stresses, and thus permit confidence in the logical use of proper maximum unit stresses. With such an idea in view, the impact values given by the Lindenthal formula for the arch do not seem to be very excessive for high speed.

The question of impact from the highway live load was carefully considered, and owing to the fact that the highway deck carries no street cars, and that the maximum highway live load is small in proportion to the train load adopted, no impact allowance was made for this part of the moving load. When still further additions are made to the structure and street cars provided for, then an impact allowance will be made on the street car live load, and also for any additional future loading that may be of a highly dynamic character. 


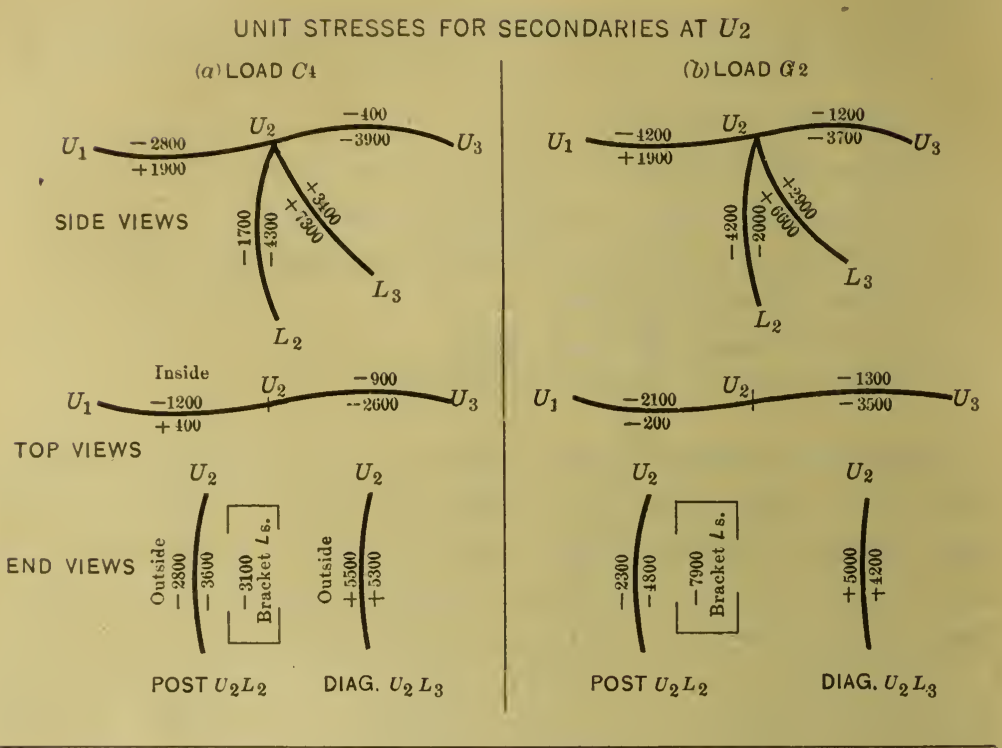

UNIT STRESSES FOR SECONDARIES AT U6

(c) LOAD D1
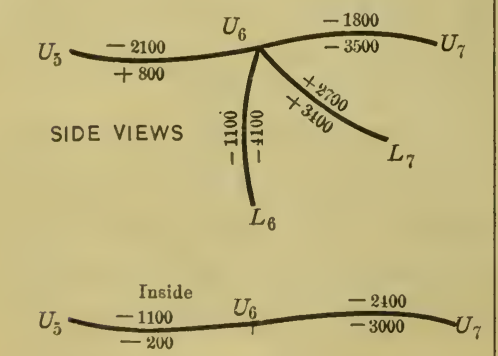

TOP VIEWS

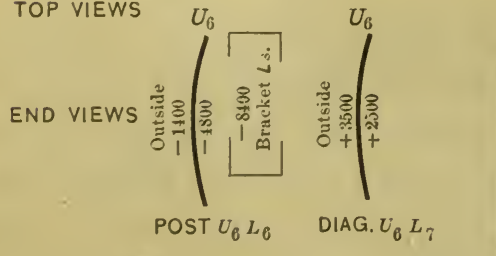

(d)LOAD $K$
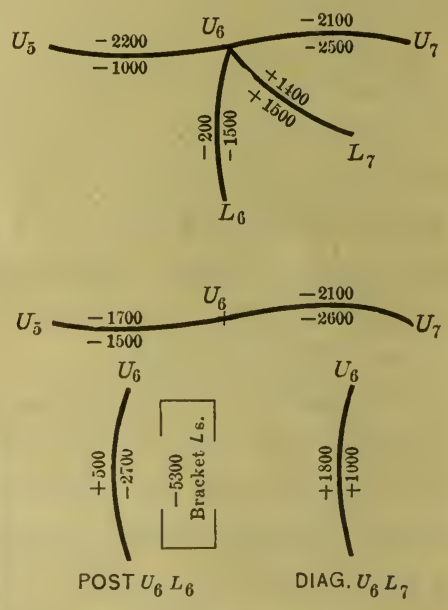

Fig. 6.-Diagrams of Secondary Stresses, Niagara Arch. 
To insure that the railway speeds over the bridge shall not exceed the maximum of 17 miles per hour, a Bristol speed recorder, similar to that installed for the Pennsylvania Tunnels at New York City, has been provided.

\section{Secondary Stress.}

The general inspection of the Niagara Arch indicated that there were comparatively large secondary stresses. The smallest increment of stress of this kind was due to the weights of the members themselves, and another comparatively small amount was caused by the main hinge rollers being locked against proper action. The largest increments were from the distortion of the arch span under moving trains and partial live loads, from the curved sway brackets between the upper and lower floor-beams connecting to the main posts, and from the curved knee-braces connecting the girders and posts of the approach viaducts.

Strain-gauge measurements were made for secondary stresses, with 8-in. Berry instruments, and on points placed near the main gussets and also at other points where judgment indicated maximum values. The character and extent of the secondary stresses in the main posts and curved brackets of the arch span, are shown in Fig. $6(a)$ to $(d)$. One of the greatest variations in unit stress is shown in Fig. 6 (b), where it was $2300 \mathrm{lb}$. on the outside of Post $U_{2} L_{2}, 4800 \mathrm{lb}$. on the inside of the post, and $7900 \mathrm{lb}$. on the flange of the curved bracket.

The fact will also be noted from these diagrams that all the top chords have secondary stresses in both vertical and horizontal planes. Secondary stress in the horizontal planes was always of the same character, and on analysis this was found by the writer to be due to the force acting at the extreme end of the heavy main gussets, and induced by the bending from the curved brackets. The great secondary stresses induced by these curved brackets, however, was only one of the reasons calling for their reinforcement.

The secondary stresses in the posts of the 115-ft. spans and the viaduct posts were provided for by the reinforcing angles which were added to these members to increase the sectional area for the direct compression stress due to the new live load capacity of the structure. These angles were required for giving as large a radius of gyration as possible to the members; but, as providing for the secondary stresses, the angles required as short outstanding legs as possible in order 
to keep down the fiber stress. The method of adding these angles is described under the head of practical strain-gauge applications.

The secondary stresses were not calculated for the main arch members, but were compared with the plotted curves of the secondary stresses as calculated for the Hell Gate Arch, a similar type of structure. Diagrams, four in number, similar to Fig. 7, were prepared for the top chords, the bottom chords, the vertical posts, and the diagonals. On each of these four sheets, the secondary stresses read by the strain gauges upon the Niagara Arch were plotted, and a curve was established similar to the combined dead and live load curve for the Hell Gate Arch. The panel lengths of the Niagara Arch were laid off to the same scale as that used for the Hell Gate Arch, at the bottom of the diagram, thus making it possible to compare directly the percentage of secondary stress for each member in each panel of the Niagara Arch. The probable error in any case is indicated as being on the safe side, and for all practical purposes the resulting secondary stresses as entered in the stress sheet may be considered within the possible error of the Niagara strain-gauge readings, or within 4 to 6 per cent. One feature must be carefully considered.in applying secondary stresses such as these, that is, that they usually reach a maximum near the panel points, and are not necessarily co-existent with a maximum compressive stress due to the flexure of a long column.

The general results of the strain-gauge readings seem to indicate that the stress in built tension members is greatest toward the center and the stress in built compression members is least toward the center of the section, which emphasizes the method used on the compression members of the Hell Gate Arch to make them take stress at the center first, and distribute it to the outsides or flanges.

The fact is also demonstrated that there is a better distribution under heavy stress, than for light stresses, and this was emphasized in many of the readings on the Niagara Cantilever.

The distribution of stress in the eye-bar chords of the Niagara Cantilever was determined by reading with the Berry strain gauge and was found to be better under heavy total stress than with light total stress. Table 2 illustrates this for the light loads $A$ and $B$, and the heavy load $G$, in the top chord $U_{8} U_{9}$, composed of fourteen eyebars. The load $A$ consisted of one 188-ton locomotive followed by twenty cars weighing $2740 \mathrm{lb}$. per lin. ft., with only the train load 


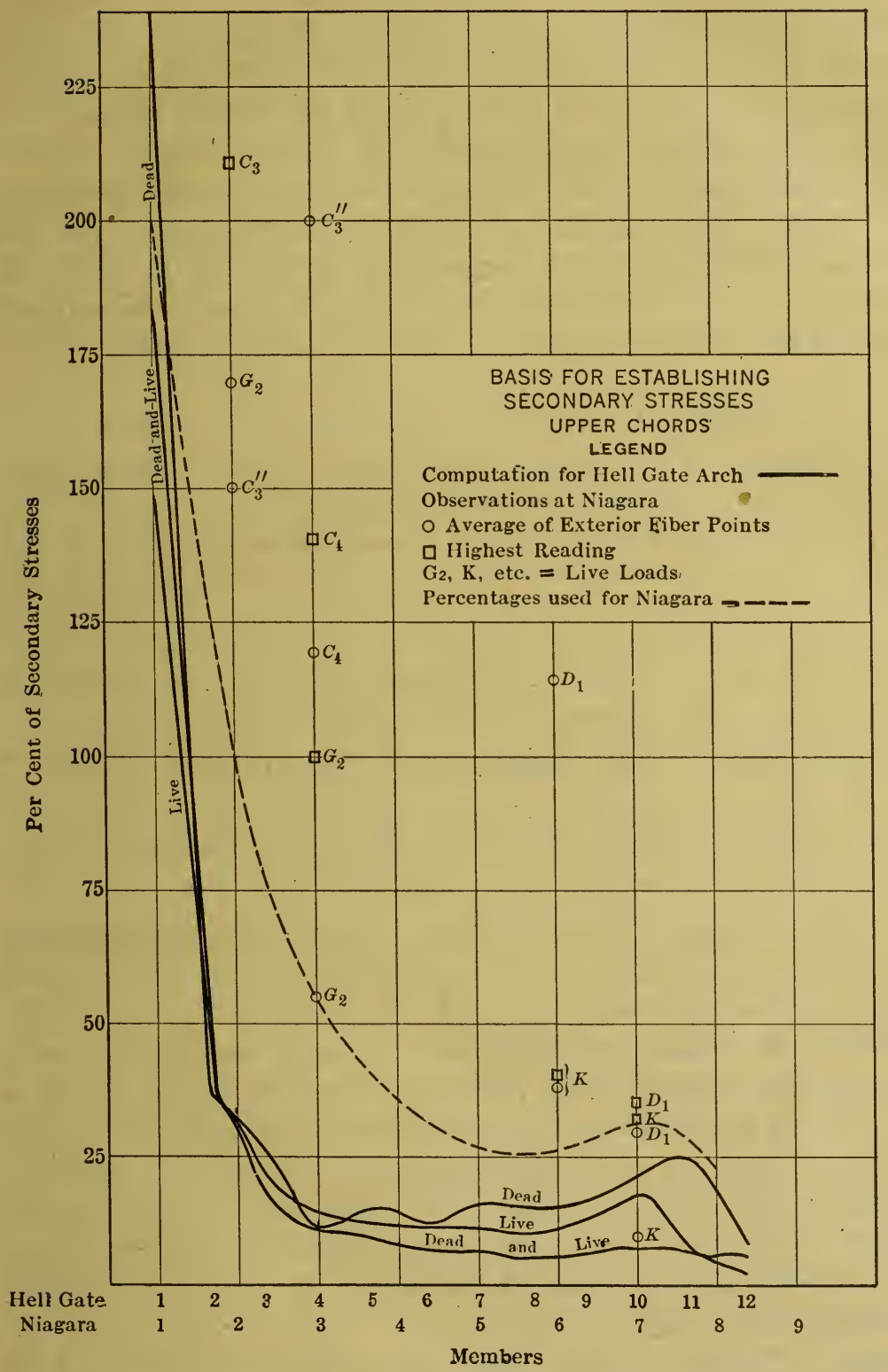

Fig. 7.-Secondary Stresses in NLagara ArCH and Hell Gate ARCH Compared. 
on the bridge; while Load $B$ was the same train, with the locomotive on the suspended span and the train covering the cantilever and anchor arms. Load $G$ was a 167 -ton locomotive and six loaded cars weighing practically the same as for Loads $A$ and $B$, but with the locomotive on the suspended span and the train load on the cantilever arm and suspended span, so located as to give maximum stresses in the bars of $U_{8} U_{8}$, which was the tower panel of the top chord. The unit stresses for Loads $A$ and $B$ ranged from 300 to $1300 \mathrm{lb}$. per sq. in., with an average of 700 . The unit stresses for Load $G$ ranged only from 2300 to $3300 \mathrm{lb}$. per sq. in., with an average of 2800 .

Table 2.-Niagara Cantilever Bridge, North Truss.

Unit Stresses in Top Chord $U_{8} U_{9}$, Read with Berry Strain Gauge.

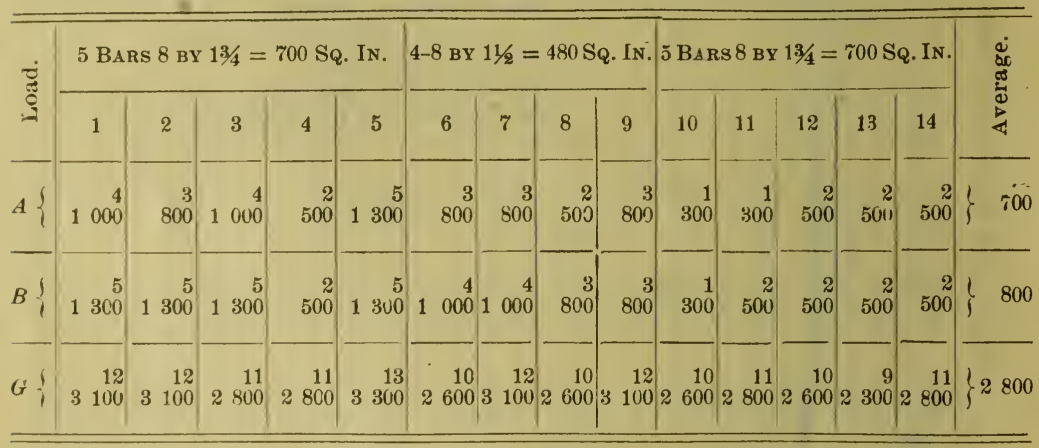

A careful study of the distribution of stress over the cross-section of either compression or tension members shows how little the supposed perfection of designs is realized in practice, both as to correctness of stresses and distribution. The stress measurements made at the same time on another structure, where the stringers rested on top of the floor-beams and were supposed to slide, disclosed the fact that one angle of a floor-beam flange was undergoing compression, while the other was in tension. The results obtained on the Niagara Arch were utilized only to the extent necessary for the re-designing of the structure, but it seems to be certain that comprised within the readings made there are the germs for many rectifications of the methods of calculation and design of large structures, and it is to be hoped that the results of this work will form the basis for future extensive readings on this arch. 


\section{Test Loads.}

The test loads used by Mr. Roebling on the Suspension Bridge in 1855 have already been described, and from this 326 -ton total load to the 1670 -ton load used by Mr. L. L. Buck on the arch span a great advance was marked. The 90-ton locomotives and 52.5-ton cars used to make up the test load, however, indicated that the assumed live load used in designing the new arch bridge was not taken heavy enough, and nothing less than Cooper's E-40 should have been adopted as it was presumably being used by some roads at about this time.

When trains were assembled for the 1918 strain-gauge readings, no . difficulty was found in getting locomotives and cars nearly as heavy as E-50 loading, and no particular trouble would have been experienced in assembling trains fully equal to or heavier than E-50. The test trains, used over a period of nearly two months, were twenty-five in number and varied in average weight from 4250 to $4880 \mathrm{lb}$. per lin. $\mathrm{ft}$. The weight of the cars alone varied from 3840 to $4320 \mathrm{lb}$. per lin. $\mathrm{ft}$. Many cars passing over the bridge indicated also that a train load of $5000 \mathrm{lb}$. per lin. ft. could easily be assembled, and would be considerably exceeded by actual trains before many years.

The test trains were located on the bridge during the strain-gauge readings, as indicated in the typical diagram, Fig. 8. The locations corresponded closely to positions for maximum stress in various members, as determined from a study of the influence diagrams. The length of the trains was also determined for giving maximum stresses for various members, in the locations fixed for the trains. The shorter trains consisted of one locomotive and four cars; the second of one locomotive and seven cars; the third of two locomotives and seven cars; the fourth of one locomotive and sixteen cars; and the longest of two locomotives with fourteen cars. The locomotives ranged in weight from 177 tons and $61 \mathrm{ft} .5 \mathrm{in}$. long, to 220.9 tons and $72 \mathrm{ft}$. 3 in. long. The heaviest locomotive likely to cross the arch is shown in Fig. 9. The cars were mainly steel hopper-bottom gondolas, $33 \mathrm{ft}$. 6 in. long, weighing empty about 18 tons, and loaded about 70 tons. There were a few larger cars, $42 \mathrm{ft}$. 6 in. long, weighing empty about 26 tons, and loaded about 100 tons. The trains used during the entire two months, however, were of an extremely uniform character, thus tending to great uniformity in the strain-gauge readings and increased accuracy. Practically no change was found in the strain-gauge read- 


\begin{tabular}{|c|c|c|c|c|c|c|c|c|c|c|c|c|c|c|c|c|}
\hline is & $\therefore=$ & S. & 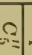 & $f$ & ? & & $\Omega$ & |x & $\vec{A}$ & $\pi_{10}$ & $\equiv$ & ${ }_{10}$ & $\Omega$ & $\Rightarrow$ & $\infty$ & 氮 \\
\hline$\frac{5}{6}$ & $\begin{array}{l}0 \\
\vdots \\
\end{array}$ & & & & & & 㝘 & $\mid \begin{array}{c}\infty \\
\ddot{0}\end{array}$ & $\begin{array}{l}\infty \\
\dot{\leftrightarrow} \\
\dot{\leftrightarrow}\end{array}$ & 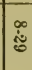 & 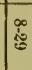 & $\begin{array}{l}\infty \\
\text { i tiv }\end{array}$ & 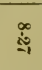 & \begin{tabular}{l}
$\infty$ \\
\multirow{i}{*}{}
\end{tabular} & $\begin{array}{l}\infty \\
\dot{j}\end{array}$ & $\mid \begin{array}{l}\forall \\
\frac{\mathscr{m}}{\omega}\end{array}$ \\
\hline$\pi$ & 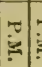 & & 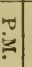 & 8 & 5 & & 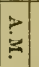 & & & & & $\not$ & $\stackrel{p}{:}$ & $\stackrel{p}{g}$ & $\vec{s}$ & 媦 \\
\hline 䜌 & \begin{tabular}{|l|}
$z$ \\
0 \\
$\frac{1}{b}$
\end{tabular} & $\begin{array}{l}z \\
0 \\
z \\
\bar{c}\end{array}$ & $\begin{array}{l}7 \\
\vdots \\
\vdots \\
\vdots \\
\vdots \\
\end{array}$ & $\begin{array}{l}7 \\
\vdots \\
\frac{1}{5}\end{array}$ & $\begin{array}{l}2 \\
\vdots \\
\vdots \\
\frac{1}{2}\end{array}$ & 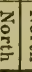 & $\begin{array}{l}z \\
0 \\
\frac{2}{\sigma} \\
\end{array}$ & $\mid \begin{array}{l}z \\
0 \\
\vdots \\
\vdots \\
y\end{array}$ & 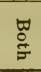 & $\mid \begin{array}{l}\frac{\pi}{2} \\
0 \\
\frac{3}{5}\end{array}$ & $\mid \begin{array}{l}z \\
0 \\
\vdots \\
z\end{array}$ & 范 & 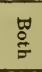 & 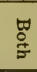 & 曽 & 品 \\
\hline
\end{tabular}

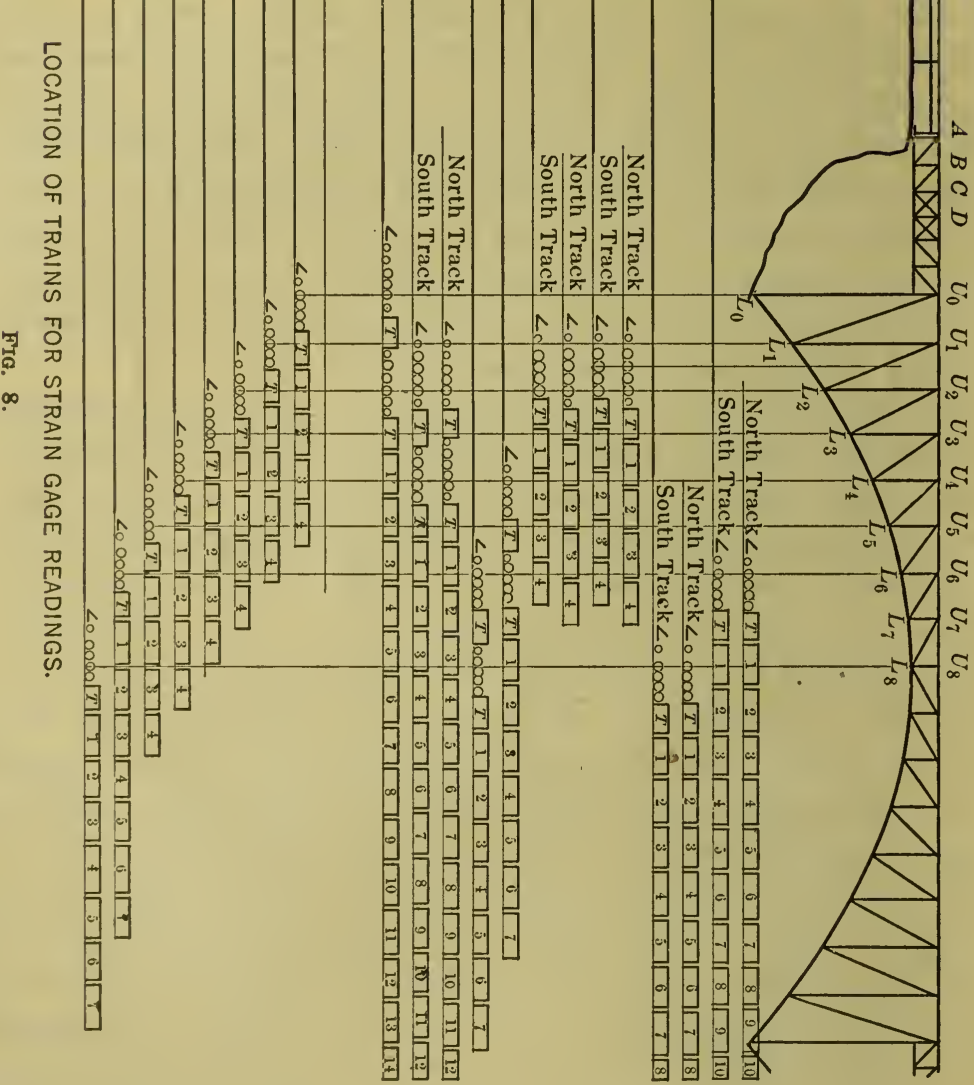


ings on the arch members whether the first, second, or third driver was located at a panel point.

\section{Strain Gauges.}

The greater part of the work of measuring stresses was done by the use of the well-known Berry strain gauge, using the 8-in. gauge for secondary stress work, and the 20-in. gauge for primary stresses. These instruments (Fig. 10) have the side strips made of "Invar" metal, the coefficient of expansion of which is only about one-twenty-eighth that of carbon steel, and the handling during use does not seriously affect the accuracy of the readings. One end has a fixed conical steel point, and the other end a movable conical steel point attached to a bell-crank lever. The long arm of this is attached to the spindle of an Ames gauge dial, and the lever has a multiplication of five times, so that while readings are made directly to 0.0002 in., they may be estimated to 0.00002 in.

All the instruments were carefully calibrated to determine their error, by the use of a standard micrometer screw, and all three Berry instruments were found to read slightly high, one $3 \%$, one $3 \frac{1}{2} \%$, and the greatest error was $4 \%$ on the third gauge. These errors were of course constant, and as they were far within the degree of accuracy desired, no correction for this has been made in the results as given in the tables.

The Howard gauge (Fig. 10) used on the Hell Gate Bridge was kindly

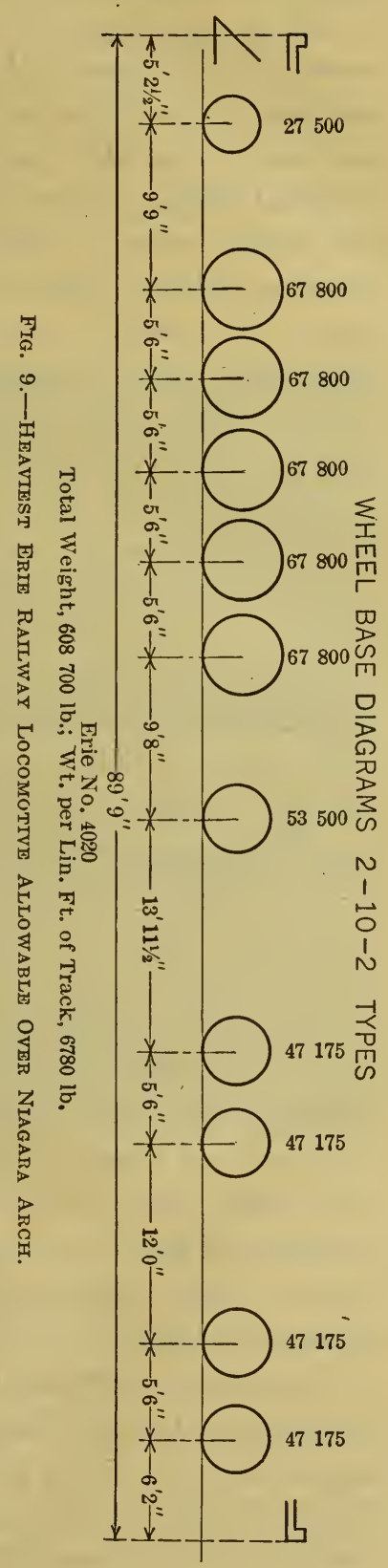


loaned by Gustav Lindenthal, M. Am. Soc. C. E., for the purpose of making some comparative readings to determine the respective accuracy of the Berry, the Howard, and the Fuller-West instrument described in the following paragraph. The Howard gauge has one fixed and one movable conical steel point, the movable one having a horizontal sliding movement and being attached to a rod sliding in the tube which carries the fixed point. The distance between the two points is read by a micrometer contact screw at the end of the tube next to the movable point, and reads to 0.0001 in. There are two milled heads with a spring ratchet between them, which slips where contact is made. The inside milled head may be used, the operator depending on the sense of touch for the contact, or the ratchet outside head may be used. This instrument, not being of Invar metal is covered with leather for protection from heat in handling.

The Howard gauge obviously cannot be used except for static load readings, and while the Berry instrument was used with moving loads and for impact readings, the excessive vibration of the needle of the Ames dial made it difficult for the observer to get accurate readings of the maximum stress at all times, and, therefore, many check readings were required. This led A. H. Fuller, M. Am. Soc. C. E., to an investigation of the "Last Word" dial, made in Cleveland, Ohio, and to the construction of a much more reliable instrument, using this dial, by Mechanician West, of Lafayette College, embodying Professor Fuller's ideas and some suggestions from the writer. This instrument, called the "Fuller-West", is shown in Fig. 10 (the two lower figures), and is provided with fibroid handles to obviate trouble from change of temperature in handling. The joint of the movable point lever is a double cone pivot and much more accurate readings of moving load stresses can be made, and for static stresses it has been found to be more accurate than the Berry, or, in other words, where from eight to ten readings were made on a point with the Berry, a less number and one check reading with the Fuller-West instrument gave just as reliable results.

The accessory instruments are practically the same in all cases, so only those used in the Niagara Arch readings and for the stress readings made by the writer and his assistants on the Michigan Central Niagara Cantilever, will be briefly described, those for the Howard instrument having been fully described in the paper by D. B. Stein- 


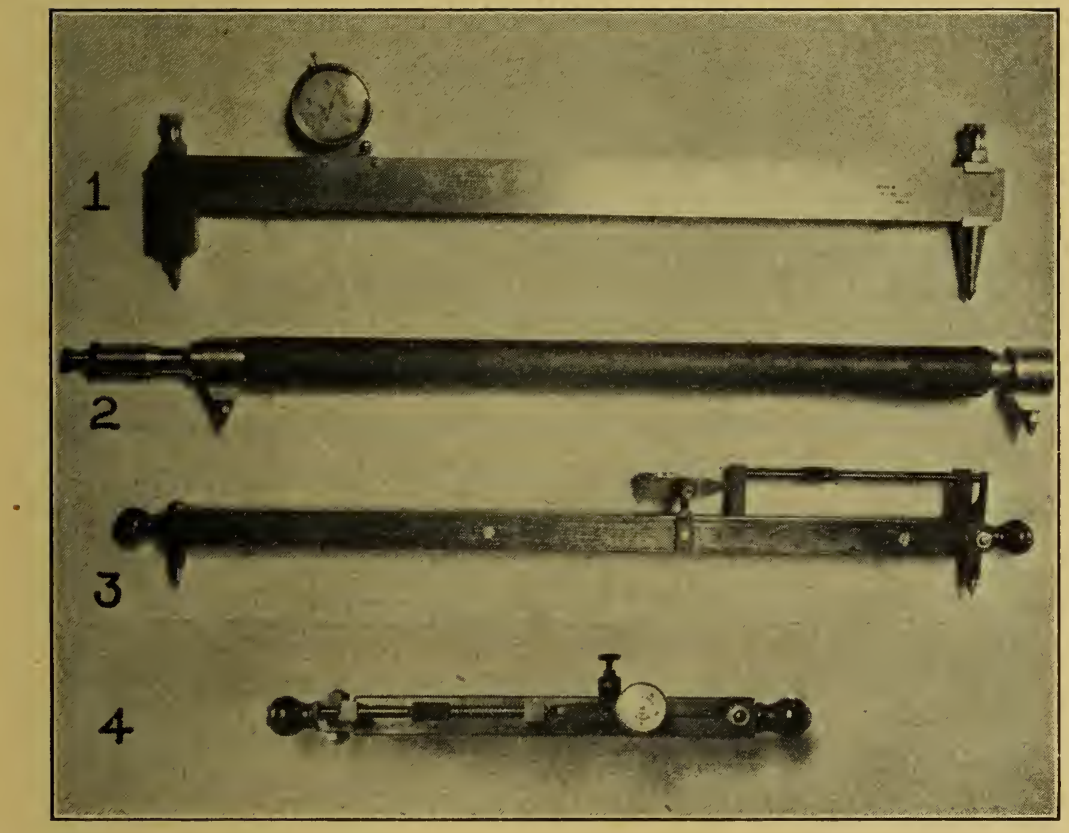

Fig. 10.-Strain GaUges.

1.-Berry 20-In. Gauge.

2.-Howard 20-IN. GaUge.

3.-Fuller-West 20-In. Gauge.

- 4.-Fuller-West 8-In. Gauge, top View. 

man, M. Am. Soc. C. E., entitled "Stress Measurements on the Hell Gate Arch Bridge"**

Standard Bars.-Two bars were made from pieces of $\frac{3}{4}$-in. gas pipe, long enough to allow caps to be screwed on to the ends and not interfere with the gauge points 20 in. apart. The caps were screwed on tight and were then ground down flat on one side to give a flat base to rest upon. In the center of each a slot was cut on the opposite side and a thermometer placed inside where it could easily be read. These standard bars were marked $A$ and $B$.

In making observations a reading with the gauge was made on the standard bar, a group of points on members read, and then a check reading was made on the standard bar. The thermometer was read and recorded each time the standard bar was read.

Corrections for Temperature.-These were made from readings of special Fahrenheit thermometers which had been calibrated by comparison with a standard laboratory thermometer. The thermometers, twelve in number, were fastened in close contact to members of the bridge and the bulbs bedded in putty to protect them from the air. The locations were changed as the work progressed. It was not considered necessary to have a thermometer on each bar or member when it was being read for stress, but the temperatures were read at the same hour for members similarly located. Very large differences, up to $27^{\circ}$, were found on opposite sides of a member-in the sun or away from it. The corrections for temperature were made by taking the coefficient of expansion of the steel in the bridge as 0.0000065 . All the thermometers were kept in the shade.

\section{Members Read for Stress.}

The members read for stress are shown by the heavy lines in Fig. 11. The members of the northeast quarter of the arch, down stream on the American end, were read most extensively, as that was more shaded from the sun. Members in the other quarters of the arch were read in sufficient number to give a check on this northeast quarter.

Gauge Points.-These were located on the upper part of the arch so as to be easily reached from the highway deck, and by means of low staging or ladders. The points for secondary stress were located near the main top gussets and in large enough numbers to obtain results

* Transactions, Am. Soc. C. E., Vol. LXXXII (1918), p. 1040. 
for both longitudinal and transverse secondary stresses. Points were located on Post $U_{2} L_{2}$ at two elevations below the highway deck, and, for the arched chord, they were located inside the chord members. The location of the temporary and permanent gauge points was recorded in tabular form.

Spots about $1 \frac{1}{2}$ in. in diameter were cleaned of paint and rust and placed either 8 in. or $20^{\circ} \mathrm{in}$. apart as needed. The holes for the "points" were drilled with a Yankee drill about $\frac{1}{10} \mathrm{in.}$ deep, and with a No. 56 drill. The burr was removed by a flat-angle countersink and finished by rubbing with a center punch. One hole of each pair was finished before the other was marked, by using a bar with center punches spaced $8 \mathrm{in}$. apart. The holes were protected when not in use by filling them with vaseline.

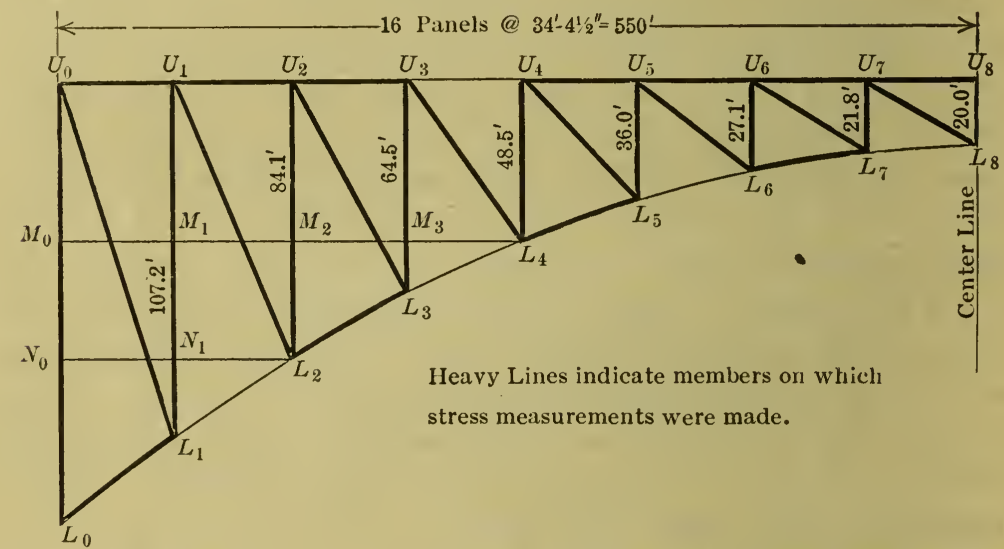

Fig. 11.-Members of Niagara Arch to Which Strain Gauges Were Applied.

Permanent Gauge Points.-These were placed on members, as indicated in a list in the Company files, so that readings on such members could be checked up for different loadings at any future time. These points were set in the bottom of $\frac{1}{2}$-in. holes $\frac{1}{4} \mathrm{in}$. deep, which were tapped and provided with cap-screws having a lead washer under the heads. The holes were filled with vaseline before the cap-screws were put in place.

Modulus of Elasticity.-The modulus of the steel in the bridge is the basis on which the strain-gauge readings have been reduced, and this is undoubtedly $29000000 \mathrm{lb}$. per sq. in. The character of the ruaterial was specified to be steel having a strength of from 60000 to 
$68000 \mathrm{lb}$. per sq. in. and an elastic limit of at least $33000 \mathrm{lb}$. per sq. in. It should be noted, however, that the steel was really only of $30000 \mathrm{lb}$. elastic limit, as the value determined by the drop of the beam of the testing machine was what is now termed the yield point, and $30000 \mathrm{lb}$. has been used as the real value of the elastic limit.

The original tests of the material were obtained by the writer from R. W. Hunt and Company, of Pittsburgh, Pa., successors to G. W. G. Ferris and Company, the original inspectors of the steel in 1896 and 1897. These tests show the yield point to be as specified for the elastic limit, and, therefore, the elastic limit used in determining the proper load to put on the arch and approaches, has been taken at $30000 \mathrm{lb}$.

The stress measurements or readings were recorded after the manner shown on the typical sheet, Table 3. In the first column, headed "Load", $D L$ represents the static train load, and the letters refer to the standard

TABLE 3.-Typical Strain-Gauge Record.

Dead and Live Load Averages, in Dial Units.

\begin{tabular}{|c|c|c|c|c|c|c|c|c|c|c|c|c|}
\hline \multirow{2}{*}{ 苛 } & \multirow{2}{*}{ ه্ّ } & \multirow{2}{*}{ 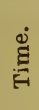 } & \multicolumn{3}{|c|}{ Temperature. } & \multirow{2}{*}{$\begin{array}{l}\text { Stand- } \\
\text { ard. }\end{array}$} & \multicolumn{6}{|c|}{ Points. } \\
\hline & & & $\begin{array}{l}\text { Stand- } \\
\text { ard. }\end{array}$ & Arch. & $\begin{array}{l}\text { Mem } \\
\text { ber. }\end{array}$ & & 1 & ; & & 4 & 5 & 6 \\
\hline
\end{tabular}

Vertical $U_{0} L_{0}$, Bottom.-Gauge Length 20 In.

\begin{tabular}{|c|c|c|c|c|c|c|c|c|c|c|c|c|}
\hline D.L. & $10-14$ & 11.00 & 49 & 49 & 49 & B & $\left\{\begin{array}{l}-41 \\
-41\end{array}\right.$ & $\begin{array}{l}-22 \\
-22\end{array}$ & $\begin{array}{l}-35 \\
-35\end{array}$ & $\begin{array}{l}-42 \\
-42\end{array}$ & & \\
\hline$C_{1}^{\prime \prime}$ & $10-16$ & 8.40 & 53 & 53 & 53 & B & $\left\{\begin{array}{l}-26 \\
-26\end{array}\right.$ & $\begin{array}{l}-8 \\
-8\end{array}$ & $\begin{array}{l}-22 \\
-22\end{array}$ & $\begin{array}{r}-29 \\
-\quad 29\end{array}$ & $\begin{array}{c}\cdots \cdots \\
\cdots \cdots\end{array}$ & $\ldots$ \\
\hline
\end{tabular}

Vertical $U_{0} L_{0}$, Top.-Gauge Length 20 In.

\begin{tabular}{|c|c|c|c|c|c|c|c|c|c|c|c|}
\hline D.L. & $8-13$ & 11.30 & 84 & 85 & 83 & A & $\left\{\begin{array}{l}-56 \\
-57\end{array}\right.$ & $\begin{array}{l}-43 \\
-43\end{array}$ & $\begin{array}{r}-49 \\
-49\end{array}$ & $\begin{array}{l}-39 \\
-39\end{array}$ & $-66+18$ \\
\hline D.L. & $\begin{array}{r}8-20 \\
\text { ad los }\end{array}$ & $\begin{array}{r}7.40 \\
\mathrm{dea}\end{array}$ & 61 & 70 & 60 & $\begin{array}{c}\mathrm{A} \\
\ldots \ldots\end{array}$ & $\left\{\begin{array}{l}-52 \\
=53 \\
-55\end{array}\right.$ & $\begin{array}{l}-41 \\
-42 \\
-42\end{array}$ & $\left|\begin{array}{l}-46 \\
-47 \\
-48\end{array}\right|$ & $\begin{array}{l}-37 \\
-38 \\
-38\end{array}$ & $\begin{array}{l}-64+22 \\
=65+21 \\
-66+20\end{array}$ \\
\hline$A_{1}$ & $8-15$ & 9.20 & 65 & 66 & 65 & A & $\left\{\begin{array}{l}-42 \\
-42\end{array}\right.$ & $\begin{array}{r}-27 \\
-27\end{array}$ & $\begin{array}{l}-40 \\
-40\end{array} \mid$ & $\begin{array}{r}-30 \\
-30\end{array}$ & $\begin{array}{r}-53+26 \\
-53+26\end{array}$ \\
\hline$C_{1}$ & $8-20$ & $8.3 \check{5}$ & 64 & 63 & 62 & A & $\left\{\begin{array}{l}-35 \\
-36\end{array}\right.$ & $\begin{array}{l}-22 \\
-23\end{array}$ & $\begin{array}{l}-36 \\
-37\end{array}$ & $\begin{array}{l}-28 \\
-29\end{array}$ & $\begin{array}{r}-51+29 \\
-52+28\end{array}$ \\
\hline$C_{\mathbf{1}^{\prime}}$ & $8-20$ & 9.00 & 65 & 64 & 63 & A & $\left\{\begin{array}{l}-34 \\
-35\end{array}\right.$ & $\begin{array}{r}-22 \\
-23\end{array}$ & $\begin{array}{l}-36 \\
-37\end{array}$ & $\begin{array}{l}-28 \\
-29\end{array}$ & $\begin{array}{l}-50+29 \\
-51+28\end{array}$ \\
\hline
\end{tabular}

Vertical $U_{1} L_{1}$.-Gauge Length $20 \mathrm{Jn}$.

\begin{tabular}{|c|c|c|c|c|c|c|c|c|c|c|c|}
\hline D.L. & $10-12$ & 11.50 & 60 & $6 \tilde{\varepsilon}$ & 62 & B & $\left\{\begin{array}{l}-79 \\
-78\end{array}\right.$ & $\begin{array}{l}-70 \\
-69\end{array}$ & $\begin{array}{l}-63 \\
-62\end{array}$ & $\begin{array}{l}+96 \\
+97\end{array}$ & $\begin{array}{r}+24-55 \\
+25-54\end{array}$ \\
\hline$C_{2}^{\prime \prime}$ & $10-16$ & 9.10 & 52 & 53 & 53 & B & $\left\{\begin{array}{l}-64 \\
-64\end{array}\right.$ & $\begin{array}{l}-54 \\
-54\end{array}$ & $\begin{array}{l}-58 \\
-58\end{array}$ & $\begin{array}{l}+102 \\
+102\end{array}$ & $\begin{array}{l}+34 \\
+34 \mid-42 \\
+42\end{array}$ \\
\hline
\end{tabular}


trains as indicated on Fig. 8, the details of each train being recorded in a record of "Test Loads". The date of the readings is given in the second column, and the exact hour in the third column. This enabled exact co-ordination of temperatures taken from sheets similar to Fig. 12. The first of the three columns headed "Temperature" gives the reading of the thermometers in the standard bars. Two standard bars were needed, one for each observation crew, and these were standardized one with the other, so that readings could be compared, and with duplicate bars kept in the fireproof vault, so that in case of loss they could be replaced. The second temperature column headed "Arch" contains the temperature as reduced from a large number of thermometers at various places on the structure, and represents the values used in making corrections for temperature stresses. The third temperature column gives that of the member read, and was

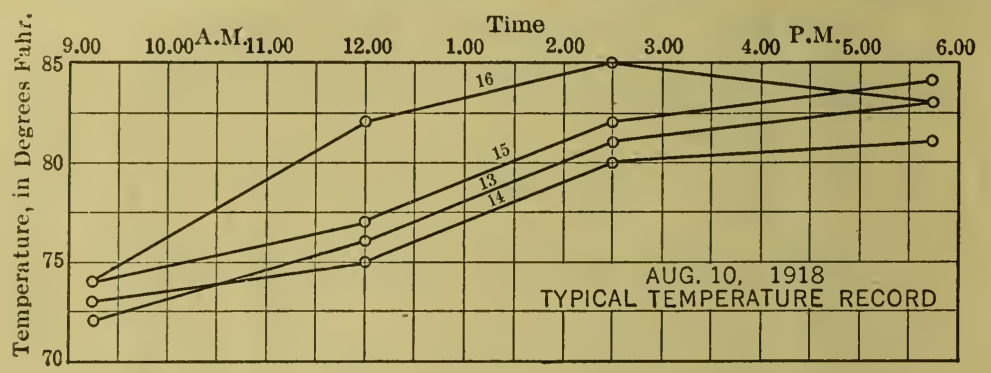

FIG. 12.

determined from thermometers fastened directly to the member or to one adjacent.

The results in the numbered columns are the strain-gauge dial units for the corresponding numbered point on the cross-section of the member in Table 4. The figures given are the averages of all the readings for that point, which were always two or more independent readings. Two temperature corrections were made for some of them, one, where there was a difference between the temperature of the member and the standard bar, and the other due to the temperature stresses in the arch. The large figures are the corrected ones, and the small ones the originals, thus making it possible to check the temperature corrections at any time.

The tables of live load stress measurements, Table 4 being typical, give the deformations in dial units which are direct deductions from 
the dead and live load averages, and the stresses in pounds per square inch which have been computed from the deformations. An average of all the unit stresses in one member has been made and the area is given, thus making it possible readily to determine the total stress in the member.

About 400 gauge points were read on the members shown in heavy lines in Fig. 11, and upward of 5000 individual and check readings made to establish the unit stresses. The readings were made in the cooler hours of each day so far as this was possible, but careful records of the temperatures were made as noted, and kept. on about fifty diagrams similar to Fig. 12.

The comparisons made by calculating the stresses for certain members due to the test train used in the location for maximum stress, indicated that the results obtained by the strain-gauge readings were in error only from 4 to 6 per cent. This, of course, would not be true for members having very low unit stresses, as the unit stress must be of considerable amount to obtain an accurate result with the strain gauge; or, in other words, the error in the strain gauge is largely fixed in amount, and would, therefore, increase as a percentage the smaller the unit stress.

The practical uses for the strain gauge in actual construction or maintenance work on bridges were found to be many. Pending the substitution of stiff sway bracing instead of the rods in the 550-ft. arch span, it was necessary carefully to adjust all of them, some 96 in number, previous to the fall and winter of 1918; the former most careful adjustments by careful judgment were found to have put very little initial tension into some of the rods and too much into others. Some were found with 27000 to $28000 \mathrm{lb}$. per sq. in., or practically up to the elastic limit of the bars, which were of iron. They were all adjusted with the use of the strain gauge for an initial stress of 7000 lb. per sq. in.

The movement of the segmental hinge rollers of the main arch at the skewbacks was so slight as not to be discernible by the eye, but by establishing gauge points, one on the upper steel casting and one on the lower, it was possible to detect movements with the strain gauge, due to moving trains, of from $\frac{1}{2} \frac{1}{50}$ to $\frac{1}{100}$ in., and readings at various temperatures established the total movement for extremes of temperature and loadings at practically: $\frac{1}{10}$ in. This is quite small and extends over an 


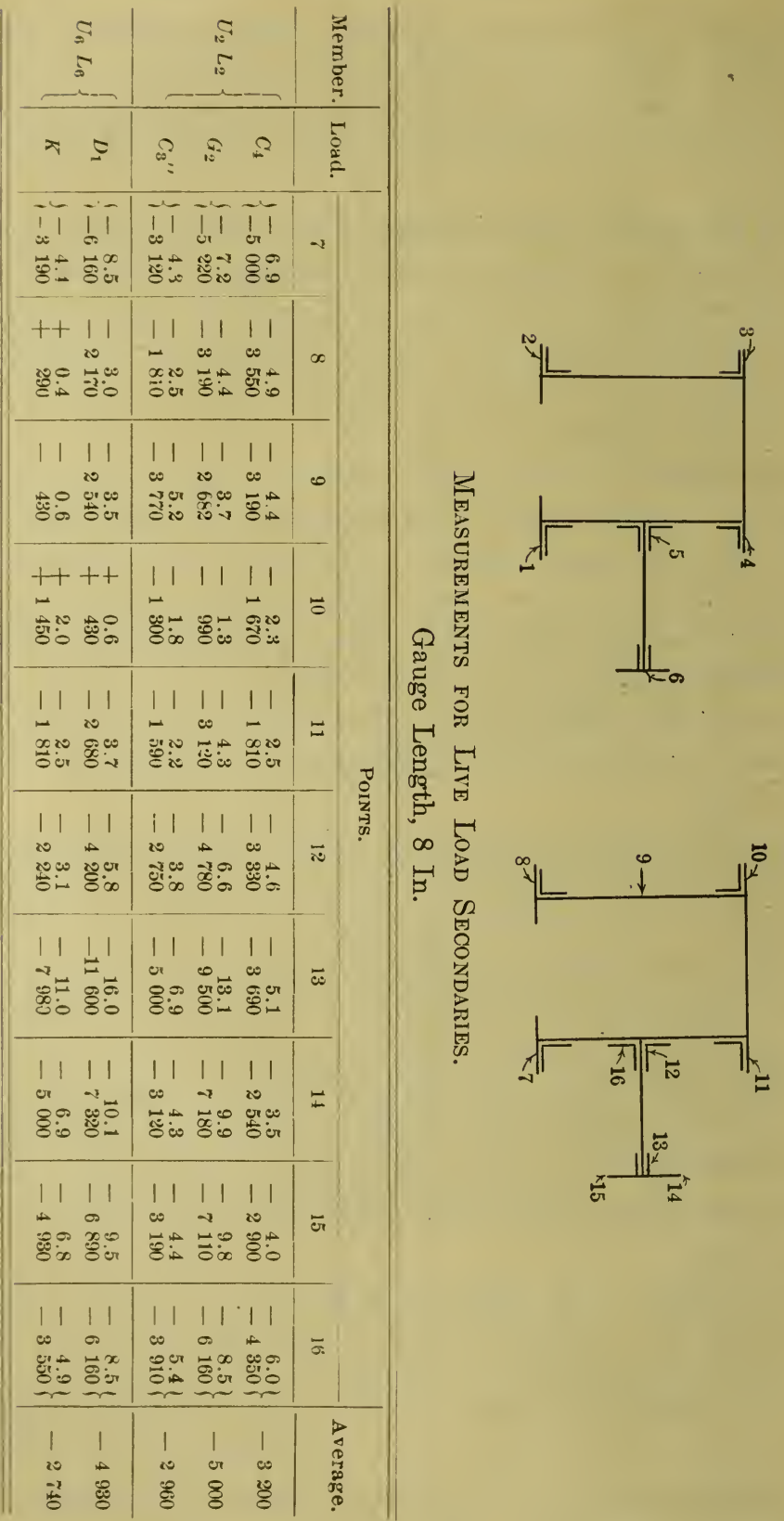




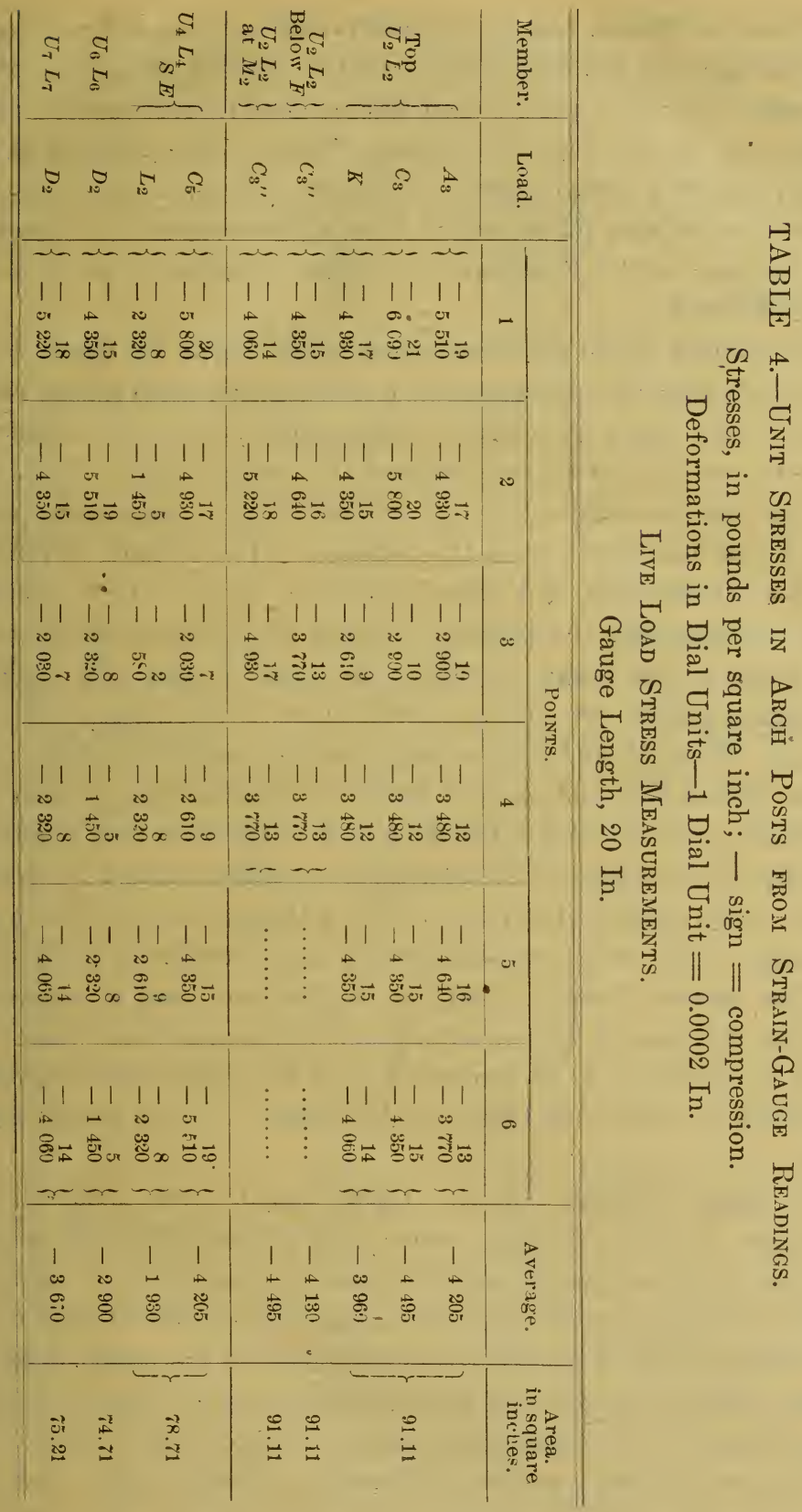


entire year, so that no fear is now entertained as to the rollers creeping, and although this has been corroborated by careful inspection extending over a year and a half, such rollers should have gearing similar to that used on the Ohio River Beaver Bridge. The addition of such gearing was first contemplated at Niagara, but hook indicators were attached to the side plates, which have a clearance of $\frac{1}{8} \mathrm{in}$. from the steel castings at $50^{\circ}$ Fahr., and so if any creeping occurs it can be readily detected.

The reading of the dead load stress in the center top chord, $U_{7} U_{8}$, of the arch span was accomplished in 1918 by the strain gauge, and by using a heavy toggle as described subsequently; and as this toggle was improved and duplicated for changing the center shims in 1919, there was available the toggle slabs and screws for other adjustments necessary in the reinforcement of the members. The method of reinforcing the intermediate and shore end posts of the 115-ft. approach spans, contemplated the placing of expensive falsework down to the lock banks of the Gorge, to relieve the posts of dead load while the reinforcing angles were being riveted to the old members. With an A-toggle (Figs. 13 and 14), abutting on the reinforced shelf at the bottom of each post and on steel blocks to distribute the pressure over the flange of the top chord, the dead load on the posts was relieved by screwing up the toggle until strain-gauge readings showed the posts to be free. This required from four to five dial units on the strain gauge. The toggle, when trains crossed, carried also a portion of the live load from the opposite track, as only two toggles were used at a time and placed on the posts of the trusses adjacent to the abandoned track. The fitting up bolts had to be loosened before the toggles were tightened, and drawn up again just before riveting began, to give proper adjustment.

The eight counters in the $115-\mathrm{ft}$. spans were replaced with $\mathrm{U}$-counters having double the section, and the new rods were set with the strain gauge to have an initial tension of about $3000 \mathrm{lb}$. per sq. in.

The greatest value of the strain gauge in the practical work on the arch revision was, of course, the checking up of the actual dead load stresses, which, on account of the introduction of the adjusting shims, did not agree with the theoretical stresses; an accurate checking of the distribution of stress over the cross-section of built tension and compression members; the checking of secondary stress; and the effect of impact at varying speeds. 


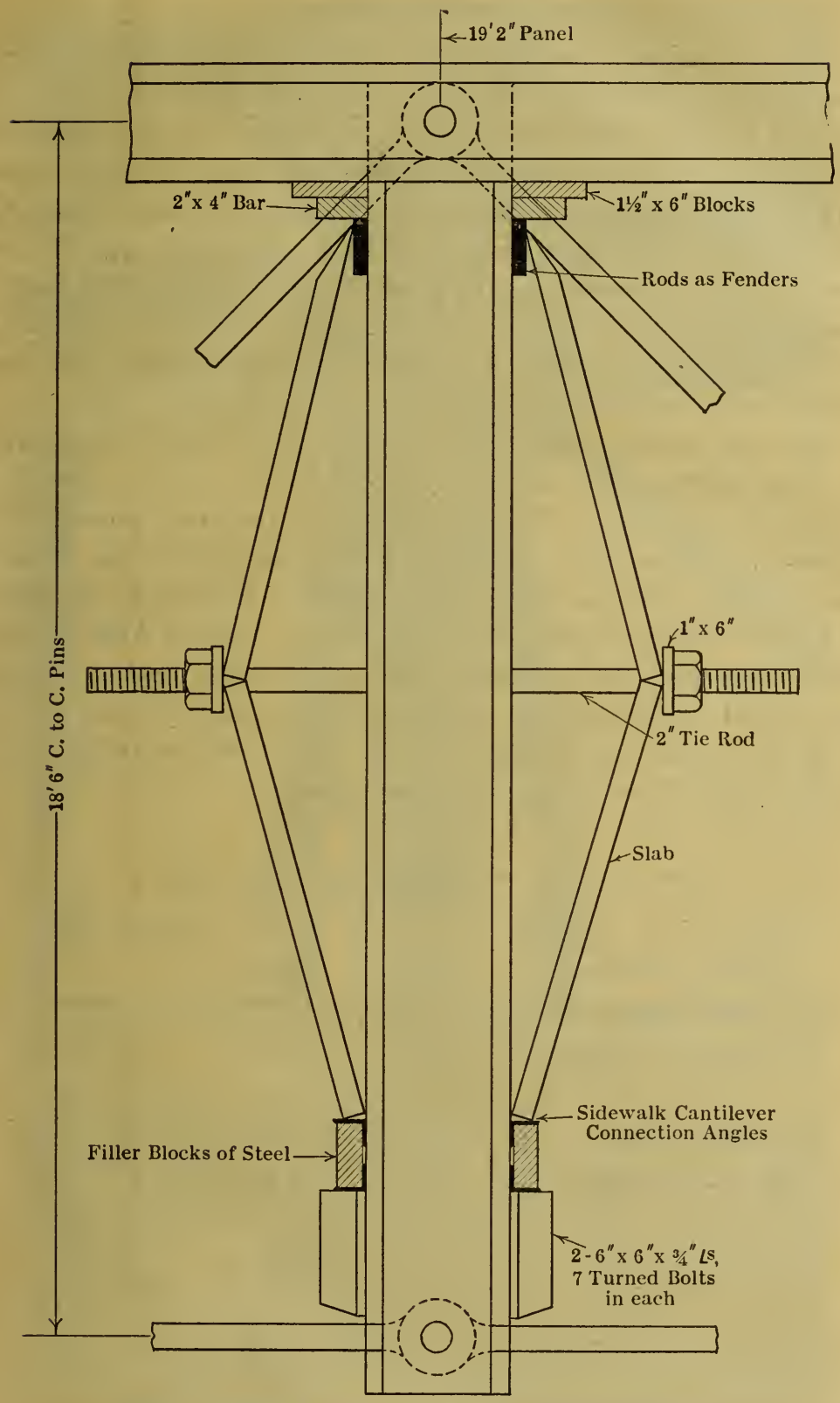

Fig. 13.-Toggle Applied to Post of 115-Ft. Truss. 


\section{Unit Stresses.}

The fact has been recognized for some time that for heavy, special, and long-span bridges, the Profession is no longer warranted in using the low values for unit stresses that are prevalent for less important shorter spans in which the secondary stress and closely accurate impact stresses have not been calculated or determined. Some authorities believe that where all stresses have been taken into account, unit stresses closely approaching the elastic limit should be used, with a loading that is quite sure not to be exceeded during the life of the structure, such as Cooper's E-90 loading or one similar to the composite loading proposed in this paper.

The fact remains, however, that there are still some uncertainties as to the uniformity of the elastic limit and the ultimate strength of materials, be they steel or steel alloys, as to the exact amount to be allowed for impact and vibration and as to the distribution of stress over the cross-section of the members, or stress transmission by means of pin and riveted joints. Therefore, for the Niagara Arch revision, after determining the minimum value of the elastic limit of the steel as shown by the somewhat extensive original tests thereof, it was decided to adopt unit stresses that are practically two-thirds of the elastic limit of $30000 \mathrm{lb}$. per sq. in., as follows:

\section{Tension}

Built truss members.......... 20000 lb. per sq. in.

Eye-bar members.............. 22000 " " " "

Girder flanges, net.......... 18000 " " " " "

Laterals of shapes............ 26000 " " " "

Shearing

Girder webs.................. 15000 " " " "

Pivets and pins............. 15000 " " " "

\section{Bearing}

Rivets and pins............. 30000 " " "

\section{Compression}

Girder flanges.................20 $000-200 \frac{l}{b}$ 


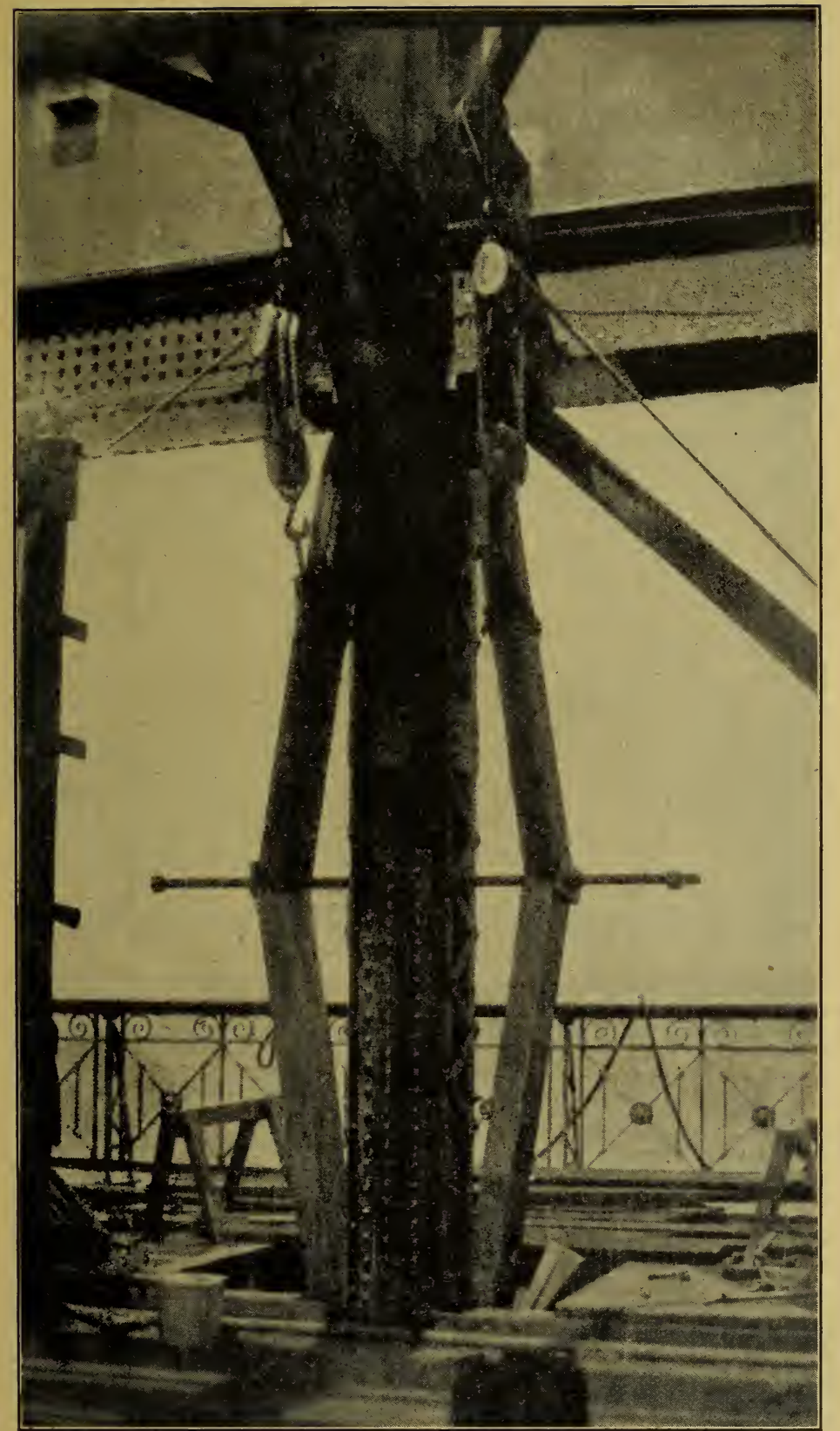

Fig. 14.-Toggla for Relieving Dead LoAd Stress in Posts of $115-\mathrm{F}$. SPANS. 

Compression units for built chords and posts, were taken from diagrams similar to Fig. 15, using in each case the curves for an elastic limit of $30000 \mathrm{lb}$.; while curves for nickel steel were established for use in future extensions of the bridge, where such material might be adopted. All these curves were established by plotting the values for column unit stresses as given by Mr. Lindenthal, in the specifications for the Hell Gate Arch, and then drawing the smooth curve which closely averaged them. The formula:

$$
p=23000-100 \frac{l}{r}
$$

represents closely one of these curves as shown in Fig. 15 and at the top

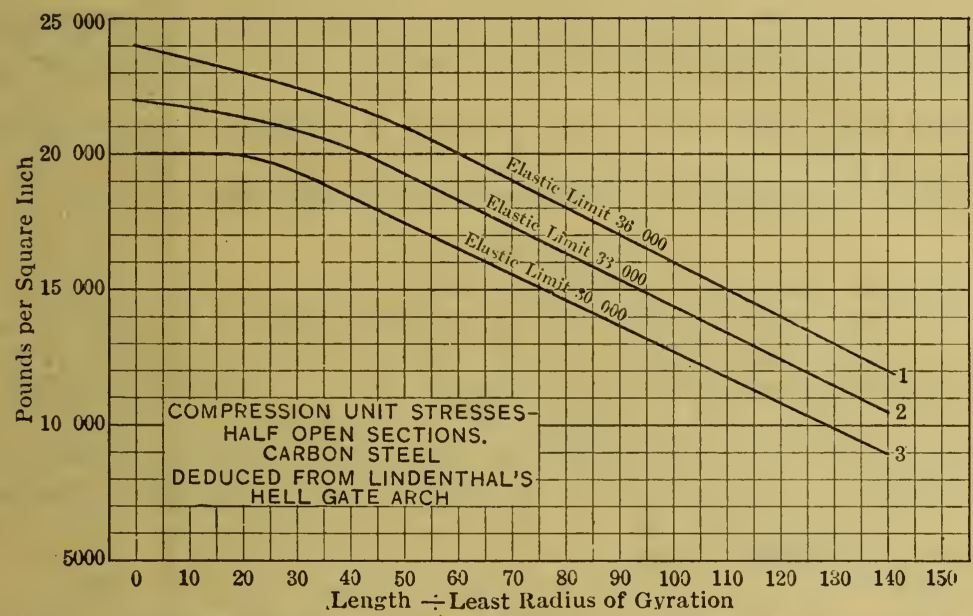

Fig. 15.

of Plate XXXVII, the maximum limit being fixed at $20000 \mathrm{lb}$. per sq. in. and the maximum value of $\frac{l}{r}$ at 135 .

The formula originally proposed for the Quebec Cantilever when all stresses, including secondaries and impact, were included, was:

$$
p=22000-88 \frac{l}{r}
$$

as shown in Plate XXXVII, which also shows the plotting of most of the principal column formulas, and which was made the basis of the adoption of the formula used for the Niagara work. The greatest number of these, in fact all those that are in general use, lie in a zone bounded 
br $p=12000-60 \frac{l}{r}$ and $p=18000-60 \frac{l}{r}$. the arerage being the -traight line formula, $p=1 . ;\left(100-60 \frac{l}{r}\right.$. The study by O. E. Horey, M. Am. Soc. C. E., of the tests of columns made under the direction of the Special Committee on Steel Columns and Struts of the Societs, shows that the ultimate strength of the light and heary sections tested is represented by the respective formulas:

$$
\begin{aligned}
& \text { Light columms. } p=38000-i 0 \frac{l}{r} ; \\
& \text { Heary columns. } p=35000-i \cdot 2 \frac{l}{r} .
\end{aligned}
$$

These are plotted on Plate XXIVIl for a safety factor of 2. and would indicate that all the present column formulas reduce unit stresses too fast for large values of $\frac{l}{r}$ and that for a two-thirds ralue of the arerage of the two Hoves formulas, we hare practicalls:

$$
p=24000-4 i \frac{l}{r}
$$

which gives much higher ralues proportionately than ans of the ordinary formulas. especially for large ralues of $\frac{l}{r}$ or for very slender columns; and also indicates that the unit stresses used for columns in the Niagara rerision were in comparison rery conservative for the ralues of $\frac{l}{r}$ which existed.

The recent discussions before rarious technical societies and in the columns of the engineering journals indicate a strong preference for the retention of the straight line formula whenever a more logical ralue can thus be determined, and a careful study of the question shors that at least we should hare a most careful reriew of all column tests made in the last thirts sears, as the basis for a rational formula; and that it is preferable that more tests of columns of large size and careful design be made in a most painstaking and thorough manner. When such checked data are arailable, then unit stresses for columns can be tabulated once for all for safe end conditions, and no reason logically exists for caring what form the plotted line or curve mas take, except that for conrenience in memorizing and for use when tables are not at hand, some simple equation will still be desirable. 
PLATE XXXVII.
TRANS. AM. SOC. CIV. ENGRS.
VOL. LXXXIII, NO. 1460 .

FOWLER ON

REVISION OF
NIAGARA RAILWAY ARCH BRIDGE,

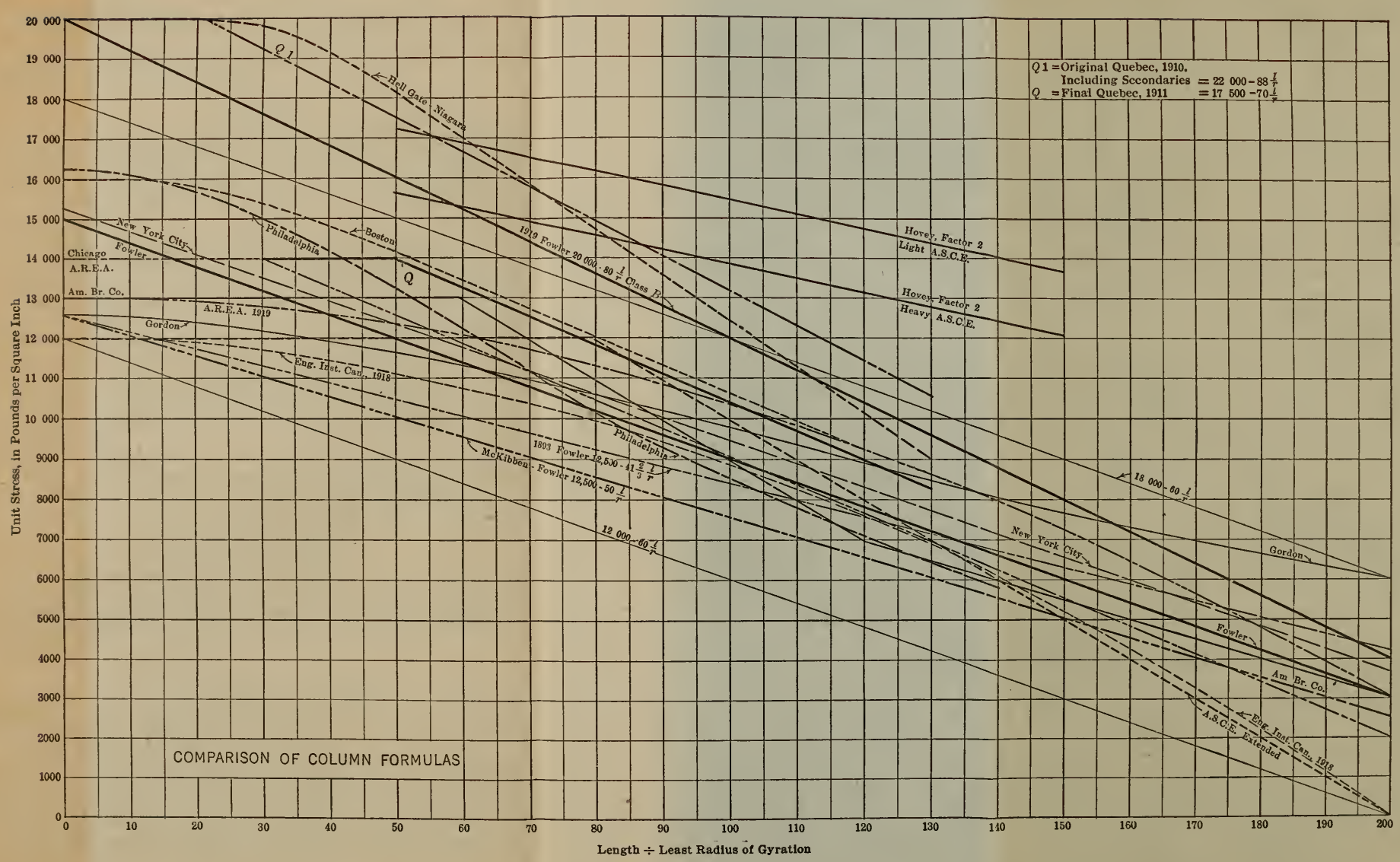




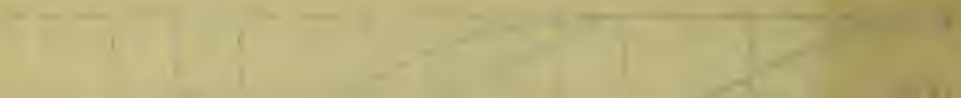

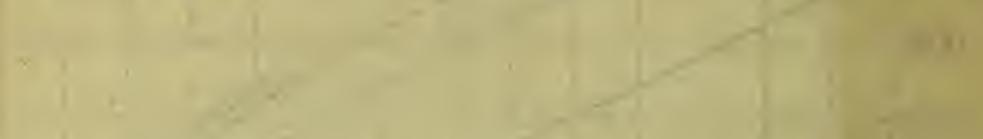

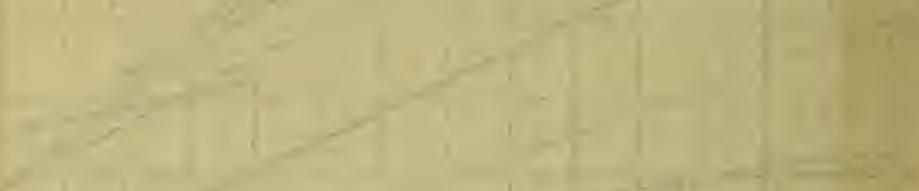

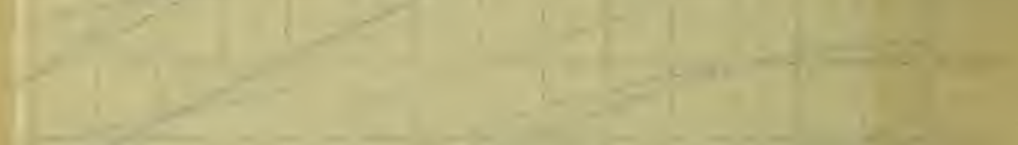

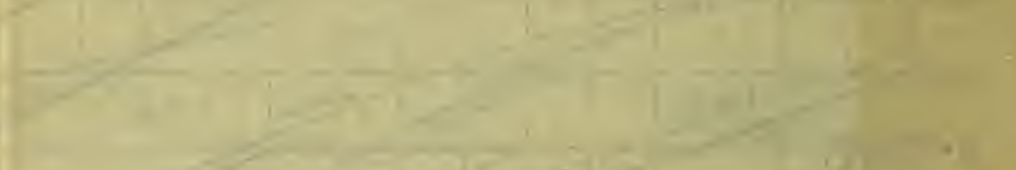

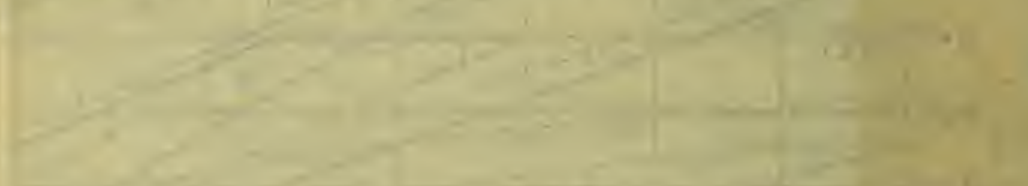

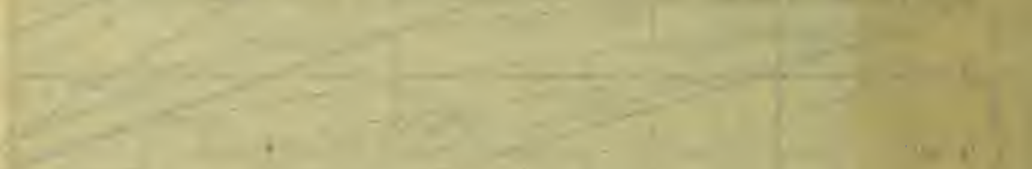
(1)

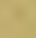
fint 


\section{Preliminary Methods of Calculation for 1918 Revision.}

The following methods were applied in making calculations for the 1918 revision of the Niagara Bridge.

\section{Arch Span.}

Dead Load.-The dead load shall be taken at the value for the center top chord that will best assist the lowering of the stresses in the top chord, posts, and diagonals, and at the same time not overload the arch chord to an unsatisfactory degree. This will presumably be a value between 200000 and $300000 \mathrm{lb}$. for $U_{\tau} U_{8}(300000 \mathrm{lb}$. was finally adopted).

Live Load.-The live load shall be Cooper's E-60 trains on both tracks, and on account of the peculiar terminal nature of the service on this structure, they shall both be considered headed the same way.

Impact.-The impact shall be taken at $50 \%$ of the live load stress impact as determined by the old American Railway Engineering Association formula on the above amount of live load on each truss, based on tests of 1918 (or for a speed of 17 miles per hour).

The stresses shall be computed for the maximum position with both tracks loaded, and $90 \%$ of this value shall be used for the total stresses in both trusses, one-half of this to be taken for the stress on the members of one truss.

Wind and Lateral Stresses.-The wind and lateral stresses shall be shown separately, but shall be considered as combined and shall not be used in determining the final unit stresses unless the combined amount of such stress on any member exceeds $25 \%$ of the total of all the other stresses on the member; and then only the amount in excess of such $25 \%$ shall be used in determining the unit stress.

Floor-Beams and Stringers.-The stresses in the floor-beams and stringers shall be determined by using the full value of the impact as determined by the old A. R. E. A. formula (for E-60), on account of the very severe service wear of this part of the structure and excessive corrosion (50\% used for E-70).

\section{5-Ft. Approach Truss Spans.}

The live load on the trusses of these spans shall be taken as $100 \%$ on both tracks, but the impact shall be taken at $50 \%$ of the old A. R. E. A. formula, as for the arch span.

The wind and lateral stresses shall be considered, as provided for the arch span, except in the case of the reinforcing for the intermediate posts, in which case the whole of the bending stress may be taken account of, if so elected or considered necessary on final analysis.

The impact on the floor-beams and stringers shall be considered in the same manner as for the same members of the arch $(50 \%$ used for . E-70). 


\section{Approach Girders and Columns.}

The impact on the approach girders and columns shall be considered in the same manner as for the floor-beams and stringers of the arch span and of the approach truss spans (50\% used for E-70).

\section{Reinforcement of Floor System.}

The railway floor-beams on the arch rest on the top chords and are riveted to them; but additional rivets, seven in number, were added at each end. Large curved brackets for sway bracing are riveted to the beams and to the vertical posts, extending down to the bottom of the highway floor-beams which are riveted between the brackets. This entire construction was figured as a rectangular frame, and it was found that it was unnecessary to reinforce the flanges of the beams for the E-70 loading, but it was found necessary to add 10 by $\frac{1}{2}$-in. plates to the flanges of the brackets. The plates on the inside of the brackets were extended along the bottom flanges of the beams to provide enough rivets to take up the stress carried by the plate, and attached to the beam flange by an I-section of plates and angles.

The values of the horizontal thrust, $H$, were determined by the Greene method, applying the formula originally used in figuring the arch stresses. This is a very sensitive formula and great care was used in calculating the value for each panel load, and all the calculations were thoroughly checked, so that it is certain that no sensible error was made in this basic matter. This was regarded as particularly important, due to the fact that much doubt was expressed by those discussing the paper describing Mr. Buck's methods as used in 1896, as to the correctness of the value of $H$ originally used.

\section{Aroh Stress Readjustment.}

The very extensive investigation made by the writer, in preparing a discussion* of the paper on "Economics of Steel Arch Bridges", indicated that for such a structure as the $550-\mathrm{ft}$. Niagara Arch it would have been economical to have designed it as a three-hinged arch for dead load, but also to act as a two-hinged arch under live load. The fact that Mr. L. L. Buck had added a section to the curved chord equal to one-half the difference between the section required in a two-hinged and that for three-hinged arch, showed the advisability of determining in some manner the actual dead load stresses existing in the arch ribs after the introduction of the 1-in. shim for closure of the arch when the erection of the span was completed. This operation was partly described in the paper published in 1897 , but, briefly, it may be stated that the 
ribs did not close at the center top chord joints by about $\frac{1}{2}$ in. The arch was opened still further by the large shore toggles and a small adjusting toggle on each chord, so that a 1-in. shim was placed in each opening, which it was calculated would give the final $572000-1 \mathrm{~b}$. stress in each chord as required for a true two-hinged arch. No way was provided at that time to measure the stress, and while it was at once evident that the small adjusting toggle would not have produced so much stress, it was later learned by the writer that the large shore toggle aided in producing a stress of $689000 \mathrm{lb}$. in each chord, as measured on October 13th, 1918, for the north center chord, $U_{7} U_{8}$, in the following manner:

The plates riveted on the center top chord webs for skewbacks in $\mathbf{1 8 9 6}$ were reinforced for the load to be picked up by the new toggle by driving additional rivets in the front edge, and by bolting with 1 -in. turned bolts, near the end a 4 by 1 -in. bar at each point, to prevent the buckling up of the plate under pressure (Fig. 17). The adoption of a kingpost toggle, such as was originally used, was out of the question owing to interference with the beams and bracing on the inside of the chords, and a heavy queen-post toggle was designed, as shown in Figs. 16 and 17, of sufficient strength to pick up a 400 -ton load. This was supplemented by placing house-jacks inside the chords to counteract the transverse thrust at the skewback contact. The toggle, as modified slightly for actually changing the shim, is shown in Fig. 16.

Gauge points were placed on the chords between the center joint and the skewback points, so that when the toggle was screwed up, after cutting out all splice rivets on one side of the joint, this portion of the chord was free, even from its dead load stress, and the difference between the strain-gauge readings before and after the joint was opened gave the actual unit stress. Traffic was suspended during the time of operating the toggle but a light passenger train was allowed to use the opposite track before the toggle had been entirely slacked away.

The use of the toggle in 1918 for stress measurement indicated, from the bending of the heaviest wrenches at hand, that screws with more threads per inch should be substituted the next year for actually changing the shims. The use of wood blocking for keeping the toggle in line at the "hips" proved very unsatisfactory, and spacer bars with check nuts were used against the chords in 1919. Then, for safety, 

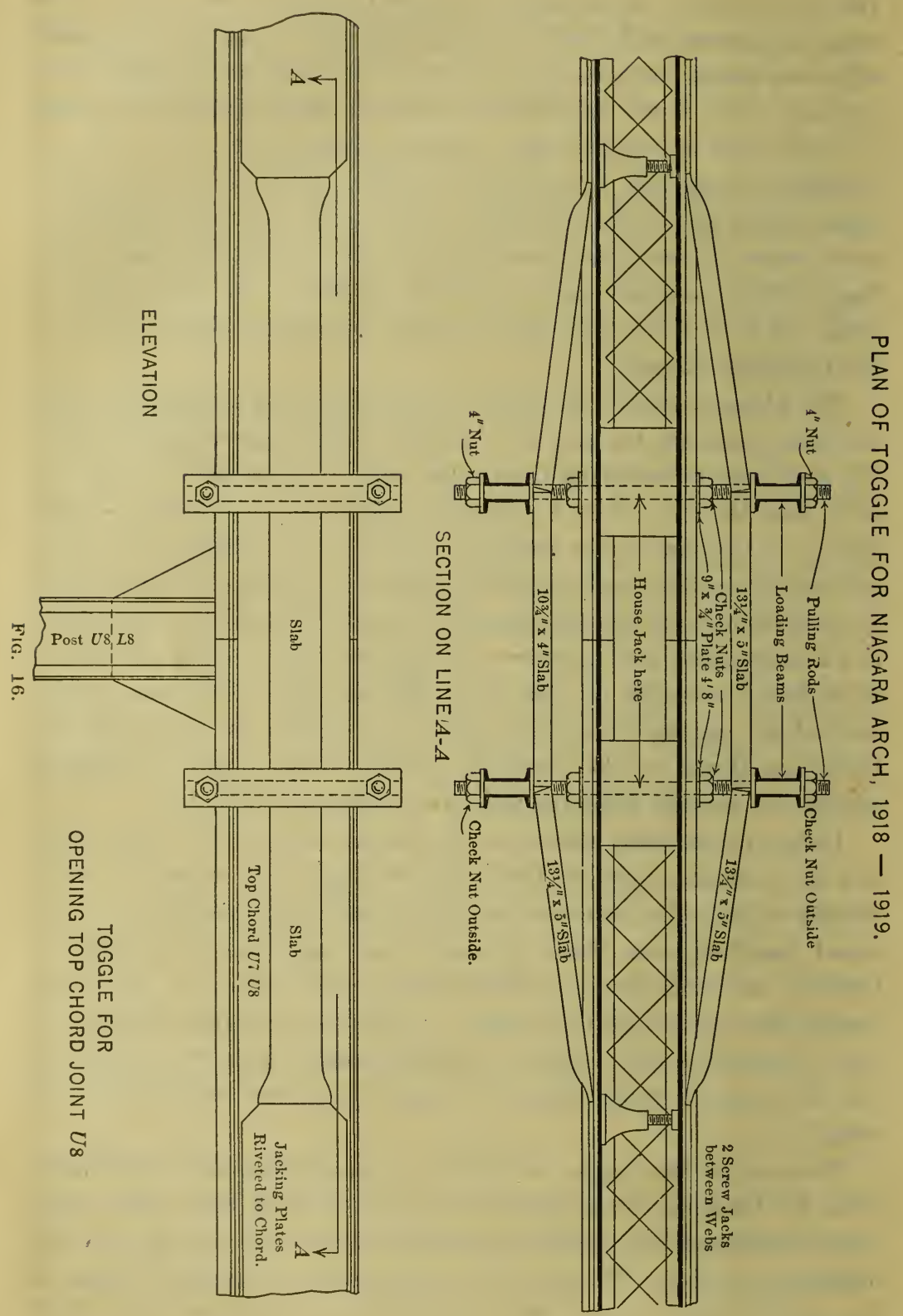


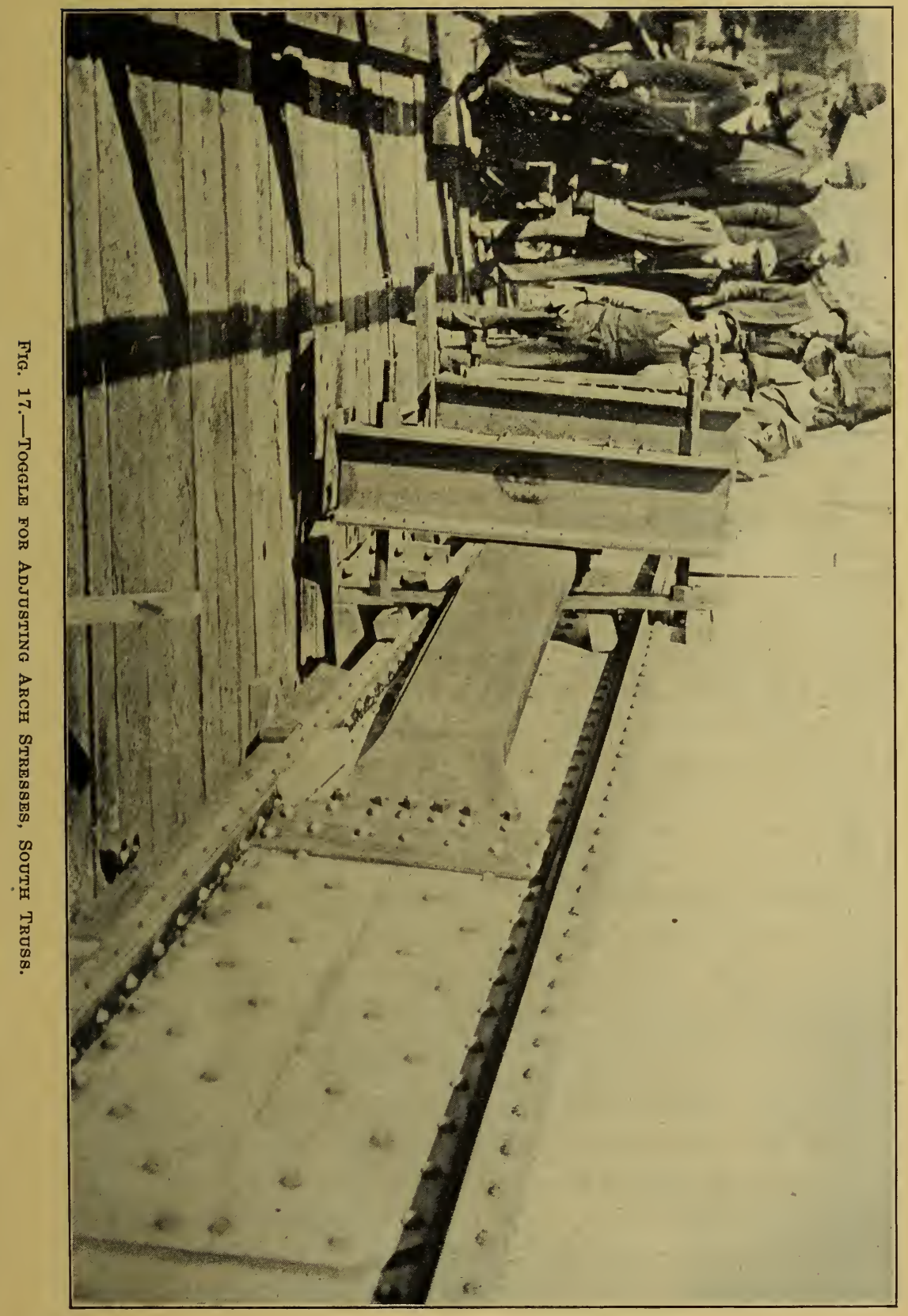



lock nuts were provided outside the main adjusting nuts on one pair of rods in each of the two toggles, and special long nuts were provided for the other sets of rods for making the final turns. Screw-jacks were also placed opposite the hips inside the chord, to account for the thrust from the spacing bars.

When the stress had been read for $U_{7} U_{8}$ in 1918, a dead load stress sheet (Table 5) was prepared showing the stresses from dead load only in each member of the arch ribs, for zero stress in the center top chord, and for other values advancing by steps of $200000 \mathrm{lb}$. for each column in the table. From this it was possible to determine that it would be out of the question to change the center shim to make the arch truly threehinged under dead load, and it was decided to prepare the new stress sheet for a center top chord dead load stress of $300000 \mathrm{lb}$., and on the completion of all stress computations, this proved to be the value adopted for final use.

The old toggle was remodeled, a second one was made for the other chord, and after careful preparation the shims were changed on October 1st, 1919. Operating platforms were built outside and inside both chords (Fig. 17), about $2 \mathrm{ft}$. below the bottom flanges, so as to facilitate the erection and operation of the toggles. The rivets were cut out of all splices on both chords, on all beams and bracing in any way tying the two halves of the ribs together, and $50 \%$ of the $\frac{15}{16}$-in. holes were filled with $\frac{5}{8}$-in. bolts with washers on both sides, and these were only loosely tightened so as to allow the joints to slide the necessary distance on the gussets, the outside splice plates being entirely removed to permit changing the shims. The stringer connections were cut loose at the eight points at the $U_{7}$ floor-beams, thinner filler plates placed, and the connections bolted, 1 -in. turned bolts being used in the connections under the north track carrying trains.

During the changing of the shims highway traffic was not stopped, but at $8.00 \mathrm{~A}$. M. railroad traffic was entirely suspended. Two hours were consumed in completing bolting operations and adjusting the toggles, but at $10.00 \mathrm{~A}$. M. the tightening of the screws began. The superintendent blew a whistle and each of the sixteen nuts, one on each end of each rod, was given four turns, and when all were abreast this operation was repeated. Some delays occurred, but on the completion of twenty-six turns in less than two hours, the old shims were loosened and could be withdrawn with the fingers. After lunch they 
TABLE 5.-Dead Load Stresses in Arch for Various Values of Stress in $U_{7} U_{8}$.

All Stresses in Thousands of Pounds; $-=$ Compression.

\begin{tabular}{|c|c|c|c|c|c|c|c|}
\hline \multirow{2}{*}{ Member. } & \multicolumn{7}{|c|}{ VALUE of Stress iN $U_{7} U_{8}$. } \\
\hline & 0 & 200 & 400 & 600 & 800 & 1000 & 1200 \\
\hline
\end{tabular}

\section{UPPER CHORDS}

\begin{tabular}{|c|c|c|c|c|c|c|c|c|c|}
\hline 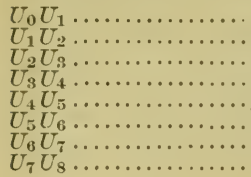 & $\begin{array}{l}- \\
- \\
- \\
-\end{array}$ & $\begin{array}{r}38 \\
55 \\
63 \\
60 \\
50 \\
35 \\
12 \\
0\end{array}$ & $\begin{array}{r}45 \\
72 \\
100 \\
121 \\
143 \\
169 \\
192 \\
200\end{array}$ & $\begin{array}{r}53 \\
96 \\
140 \\
132 \\
239 \\
316 \\
372 \\
400\end{array}$ & $\begin{array}{r}62 \\
116 \\
176 \\
242 \\
331 \\
442 \\
552 \\
600\end{array}$ & $\begin{array}{l}71 \\
138 \\
211 \\
307 \\
451 \\
580 \\
731 \\
800\end{array}$ & $\begin{aligned} 78 \\
156 \\
251 \\
368 \\
525 \\
718 \\
910 \\
1090\end{aligned}$ & $\begin{array}{l}- \\
- \\
- \\
- \\
-1\end{array}$ & $\begin{array}{r}91 \\
179 \\
202 \\
432 \\
622 \\
855 \\
1091 \\
1200\end{array}$ \\
\hline
\end{tabular}

\section{LOWER CHORDS}

\begin{tabular}{|c|c|c|c|c|c|c|c|}
\hline 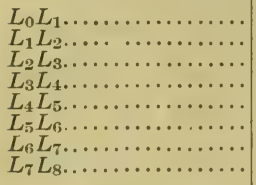 & 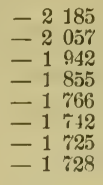 & $\begin{array}{ll}2 & 141 \\
2 & 008 \\
1 & 880 \\
1 & 775 \\
1 & 684 \\
1 & 611 \\
1 & 553 \\
1 & 512\end{array}$ & $\begin{array}{ll}2 & 100 \\
1 & 953 \\
1 & 816 \\
1 & 696 \\
1 & 582 \\
1 & 479 \\
1 & 380 \\
1 & 298\end{array}$ & $\begin{array}{ll}2 & 055 \\
1 & 900 \\
1 & 751 \\
1 & 616 \\
1 & 480 \\
1 & 344 \\
1 & 215 \\
1 & 084\end{array}$ & $\begin{array}{ll}2 & 010 \\
1 & 846 \\
1 & 6 \times 6 \\
1 & 532 \\
1 & 373 \\
1 & 207 \\
1 & 031 \\
& 867\end{array}$ & $\begin{array}{ll}1 & 966 \\
1 & 793 \\
1 & 622 \\
1 & 453 \\
1 & 271 \\
1 & 075 \\
& 860 \\
& 654\end{array}$ & 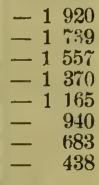 \\
\hline
\end{tabular}

\section{Diagonals}

\begin{tabular}{|c|c|c|c|c|c|c|c|c|}
\hline$U_{0} L_{1} \ldots \ldots \ldots \ldots \ldots$ & & 12.3 & 149 & 127 & 205 & 235 & 263 & $29: 3$ \\
\hline$U_{1} L_{2} \ldots \ldots \ldots \ldots \ldots$ & & $4 x$ & 79 & 110 & 143 & 175 & 207 & 241 \\
\hline$U_{2} L_{3} \ldots \ldots \ldots \ldots \ldots \ldots \ldots \ldots$ & & 22 & 56 & 94 & 130 & 168 & 203 & $24 \%$ \\
\hline$U_{3} L_{4} \ldots \ldots \ldots \ldots \ldots \ldots$ & & 0 & 41 & 82 & 125 & 166 & 209 & 251 \\
\hline$U_{4} L_{5} \ldots \ldots \ldots \ldots \ldots \ldots$ & - & 15 & 34 & 81 & 130 & 180 & 227 & 278 \\
\hline$U_{5} L_{f} \ldots \ldots \ldots \ldots \ldots$ & - & 23 & 8!) & 8 & 142 & 19.5 & 250 & 305 \\
\hline$U_{6} L_{7} \ldots \ldots \ldots \ldots \ldots \ldots$ & - & 25 & 28 & 79 & 129 & 180 & 232 & 283 \\
\hline $\boldsymbol{L}_{7} L_{8} \ldots \ldots \ldots \ldots \ldots$ & 一 & 15 & 10 & 33 & 56 & SO & 103 & 127 \\
\hline
\end{tabular}

\section{VERTICALS}

\begin{tabular}{|c|c|c|c|c|c|c|c|c|c|}
\hline $\begin{array}{l}U_{0} L_{0} \ldots \ldots \ldots \ldots \ldots \ldots \ldots \ldots \\
U_{1} L_{1} \ldots \ldots \ldots \ldots \ldots \ldots \ldots \ldots \\
U_{2} L_{2} \ldots \ldots \ldots \ldots \ldots \ldots \ldots \ldots \\
U_{3} L_{8} \ldots \ldots \ldots \ldots \ldots \ldots \ldots \ldots \\
U_{4} L_{4} \ldots \ldots \ldots \ldots \ldots \ldots \ldots \ldots \ldots \\
U_{5} L_{5} \ldots \ldots \ldots \ldots \ldots \ldots \ldots \ldots \\
U_{B} L_{6} \ldots \ldots \ldots \ldots \ldots \ldots \ldots \ldots \\
U_{7} L_{7} \ldots \ldots \ldots \ldots \ldots \ldots \ldots \ldots \\
U_{8} L_{8} \ldots \ldots \ldots \ldots \ldots \ldots \ldots \ldots\end{array}$ & $\begin{array}{l}- \\
- \\
- \\
- \\
-\end{array}$ & $\begin{array}{l}460 \\
289 \\
230 \\
200 \\
175 \\
160 \\
158 \\
162 \\
284\end{array}$ & $\begin{array}{l}486 \\
315 \\
261 \\
231 \\
210 \\
194 \\
186 \\
174 \\
\cdots\end{array}$ & $\begin{array}{l}512 \\
346 \\
293 \\
266 \\
241 \\
228 \\
213 \\
187 \\
\ldots\end{array}$ & $\begin{array}{l}539 \\
376 \\
325 \\
300 \\
279 \\
262 \\
240 \\
198 \\
\ldots\end{array}$ & $\begin{array}{l}567 \\
406 \\
358 \\
336 \\
314 \\
296 \\
268 \\
210 \\
\cdots \cdots\end{array}$ & $\begin{array}{l}593 \\
435 \\
390 \\
370 \\
350 \\
331 \\
295 \\
233 \\
\ldots\end{array}$ & $\begin{array}{l}- \\
- \\
- \\
- \\
- \\
-\end{array}$ & $\begin{array}{l}620 \\
467 \\
423 \\
404 \\
385 \\
365 \\
324 \\
334 \\
284\end{array}$ \\
\hline $\begin{array}{l}\text { Thrust, } H \ldots \ldots \ldots \\
\text { Reaction, } \ddot{V} \ldots \ldots .\end{array}$ & & $\begin{array}{l}1710 \\
1782\end{array}$ & $\begin{array}{l}1705 \\
1782\end{array}$ & $\begin{array}{l}16 \% 0 \\
1 \% 82\end{array}$ & $\begin{array}{ll}1 & 635 \\
1 & 782\end{array}$ & $\begin{array}{ll}1 & 599 \\
1 & 782\end{array}$ & $\begin{array}{ll}1 & 564 \\
1 & 782\end{array}$ & & $\begin{array}{ll}1 & 528 \\
1 & 782\end{array}$ \\
\hline
\end{tabular}


were all removed and the new shims, about $\frac{3}{8}$ in. less in thickness, were placed, and on all adjustments being made, the nuts were slacked off five turns at a time, and by $4.00 \mathrm{P}$. M. the joints had all been bolted sufficiently to allow resumption of railway traffic. Not a mishap had occurred in completely jacking apart the top chords of the 550-ft. arch span, and in picking up with both toggles practically 700 tons. The adjustment of the center diagonals and the center sections of the bottom chord to the new stress conditions had been provided for by curving out the gussets between the diagonals and the center posts by means of a oxy-acetylene burning torch and by cutting out all the rivets in the connection at $L_{8}$ as far as possible with the south track out of commission; the number of rivets that were cut out was roughly 50 per cent.

The measurement of stresses in the toggles showed that at one time, near the maximum load, the small center slab was undergoing bending, due to the eccentric application of the load on the end. This slab was blocked and no trouble resulted.

The stresses, as read on October 1st, were calculated that evening and showed a wide variation from the $300000 \mathrm{lb}$. total desired in each chord, as follows:

North chord.................... $98000 \mathrm{lb}$.

South chord.................... $200000 \mathrm{lb}$.

The check made of the old stress of $689000 \mathrm{lb}$., as measured in 1918, showed for the north chord $715000 \mathrm{lb}$. and for the south chord 688900 lb., being only $3.8 \%$ larger for the north chord, presumably due to stress carried in 1918 by the four lines of stringers which were tightly fitted, and a practically identical reading for the south chord.

The large number of heavy freight trains that had been held up while the work was in progress, were run over the north track during the ensuing 16 hours, until final readings could be made the next morning, October $2 \mathrm{~d}$. Then the resulting total stress after full readjustment was as follows, adding for the stress that would be caused by the placing of the ties and rails of the south track which was just ready for laying:

North chord.............................. 288000 lb.

Stress from south track.............. $14000 \mathrm{lb}$.

Total stress................. $302100 \mathrm{lb}$. 
South chord...................... $255000 \mathrm{lb.}$

Stress from south track............ $38900 \mathrm{lb}$.

Total stress.................... $293900 \mathrm{lb}$.

These stresses may be considered as practically exact, that for the north chord being within $1 \%$ of the desired value, and that for the south chord within 2 per cent. This close agreement resulted from the reading of the dead load stress in 1918, the very careful calipering of the old shims, and the many check strain-gauge readings. Owing to the fact that the thickness of the new shims was reduced in exact proportion from that of the old shims, the distribution over the crosssection of the four chord sections, $U_{7} U_{8}$, remains practically the same as before the change.

\section{Stress SheEt.}

The recorded data on the former stress computations were very meager, consisting of the stress sheet* of the paper by Mr. L. L. Buck, a blue-print diagram of lateral and sway stresses, together with a record of the calculation for $\Sigma H$ for the arch ribs.

The original total stresses included simply live load, dead load, and temperature stresses, no account being taken of secondary stresses or impact. The unit stresses assumed were, for the diagonals in tension, dead load 20000 lb. per sq. in., and live load 10000 lb. per sq. in.; for compression in the top chords, dead load $18000 \mathrm{lb}$. per sq. in., and live load

$$
\frac{9000}{1+\frac{l^{2}}{30000 r^{2}}} ;
$$

for posts and diagonals in compression, dead load $16500 \mathrm{lb}$. per sq. in., and live load

$$
\frac{9000}{1+\frac{l^{2}}{30000 r^{2}}} .
$$

The resulting unit stresses on the sectional areas adopted were as follows:

Top chords................ 3650 to $12700 \mathrm{lb}$.

Bottom chords............... 11500 to $12800 \mathrm{lb}$.

Diagonals (tension)............ 10600 to $12600 \mathrm{lb}$.

Vertical posts................ 5350 to $11100 \mathrm{lb}$.

- Transactions, Am. Soc. C. E., Vol. XL (1898), p. 149, Plate XII. 
The new stress sheet, Table 6, consists of a column for each class of stress, and by every method for each class which it was desired to have, either for comparison or final combination. The result was a sheet of thirty columns, affording much data in the way of valuable comparison and enlightenment for obtaining final maximum and minimum stresses. The first eight columns are all dead load or non-dynamic stresses, including dead load, temperature, snow and wind load stresses; the next nine columns are for train live load stresses both direct and reverse, together with impact by the Schneider formula, the Lindenthal formula, the proposed new American Railway Engineering Association formula added later, and from the Niagara impact readings with the strain gauge. Attention is called to the low values given by the proposed new A. R. E. A. formula, and their comparison with the Niagara readings, which are not necessarily a corroboration of the correctness of the proposed new A. R. E. A. formula. The comparison of the Schneider and Lindenthal values shows that there is not a wide divergence on the average for the compression members, but indicates much higher values by the Lindenthal formula for the tension diagonals, as would seem logical from the viewpoint of safety, although not corroborated by the Niagara strain-gauge results. The careful study of all the values would indicate that the results obtained by the proposed new A. R. E. A. formula are very low for the usual average speeds over main-line bridges. The fixing of the critical speed would therefore seem to be the first necessity of a perfect formula, and, secondly, the coefficient or function herein developed to be introduced for variation in speed-these two factors being intimately correlated.

The next seven columns of the stress sheet cover the highway live. load, direct and reverse; the lateral live load; and the secondary stress percentage, with the equivalent in thousands of pounds, the percentages being $10 \%$ flat for the bottom chords, from 20 to $200 \%$ for the top chords, from 15 to $45 \%$ for diagonals, and from 30 to $60 \%$ for the vertical posts.

The last six columns comprise the total stresses as combined from the various stresses, giving both minimum and maximum stresses, and $50 \%$ of the reverse minimum. The last two columns give the allowable unit stresses as fixed for the revision of the structure and the maximum resulting from the combination of the co-existing actual stresses. 


\section{TABLE 6.-Stress SheET.}

All Stresses in Thousands of Pounds; $-=$ Compression. Dead Load, Temperature, Snow, and Wind Stresses.

\begin{tabular}{|c|c|c|c|c|c|c|c|c|}
\hline \multirow{2}{*}{ Member. } & \multicolumn{3}{|c|}{ DEAD Load. } & \multirow{2}{*}{$\begin{array}{l}\text { Tempera- } \\
\text { ture } \\
\pm\end{array}$} & \multirow{2}{*}{ Snow. } & \multicolumn{3}{|c|}{ WIND. } \\
\hline & $\begin{array}{c}\text { True } \\
\text { two- } \\
\text { hinge. }\end{array}$ & $\begin{array}{l}\text { Existing } \\
\text { shims. }\end{array}$ & $\begin{array}{l}\text { Modified } \\
\text { shims. }\end{array}$ & & & $\begin{array}{l}\text { Piane of } \\
\text { truss. }\end{array}$ & $\begin{array}{l}\text { Lateral } \\
\text { and } \\
\text { sway. }\end{array}$ & Total. \\
\hline
\end{tabular}

\section{UPPER CHORDS}

\begin{tabular}{|c|c|c|c|c|c|c|c|c|c|c|}
\hline$U_{0} U_{1} \ldots \ldots$ & - & 59 & 65 & 49 & 20 & -1 & -89 & 0 & - & 89 \\
\hline$U_{1} U_{2} \ldots \ldots$ & 一 & 111 & 121 & 84 & 50 & -2 & -160 & 81 & - & 79 \\
\hline$U_{2} U_{3} \ldots \ldots$ & 一 & 169 & 189 & 120 & 90 & - & -210 & 148 & - & 62 \\
\hline$I_{8} U_{4} \ldots \ldots$ & 一 & 23:3 & 264 & 151 & 148 & $T$ & -223 & 201 & - & 22 \\
\hline$U_{4} U_{5} \ldots \ldots$ & - & 318 & 367 & 191 & 229 & -8 & -193 & 243 & & 50 \\
\hline$U_{5} U_{6} \ldots \ldots$ & 一 & $42 \%$ & 490 & $233^{\circ}$ & 33. & -12 & -110 & 273 & & 163 \\
\hline$U_{6} U_{7} \ldots \ldots$ & - & 527 & 614 & 282 & 434 & -15 & -2 & 294 & & 292 \\
\hline$U_{7} U_{8} \ldots \ldots$ & - & 572 & 689 & 300 & 480 & $-1 i$ & 56 & 305 & & 361 \\
\hline
\end{tabular}

\section{LOWER CHORDS}

\begin{tabular}{|c|c|c|c|c|c|c|c|c|}
\hline$L_{n}, L_{1} \ldots \ldots \ldots$ & -2063 & 2040 & 2 120 & 107 & 一 59 & -898 & 151 & -747 \\
\hline$L_{1} L_{2}, \ldots \ldots$ & -1910 & 1881 & 1980 & $12 \tau$ & -54 & -744 & $14 \pi$ & -297 \\
\hline$L_{2} L_{3} \ldots \ldots$ & -1764 & 1729 & 1848 & 155 & -51 & -628 & 731 & 103 \\
\hline$L_{3} L_{4} \ldots \ldots$ & -1628 & 1587 & 1735 & 193 & -48 & -550 & $9 ! 5$ & 445 \\
\hline$L_{4} L_{5} \ldots \ldots \ldots$ & -1497 & 1442 & 1633 & 248 & -44 & -517 & 1229 & 712 \\
\hline$L_{5} L_{6} \ldots \ldots \ldots$ & -1367 & 1297 & 1545 & 324 & -39 & -532 & 1421 & 892 \\
\hline$L_{8} L_{7} \ldots \ldots \ldots$ & -1230 & 1145 & 1467 & 421 & -34 & -608 & 1565 & 957 \\
\hline$L_{7} L_{8} \ldots \ldots$ & -1113 & 1009 & 1405 & 519 & -29 & -707 & 1635 & 928 \\
\hline
\end{tabular}

\section{Diagonals}

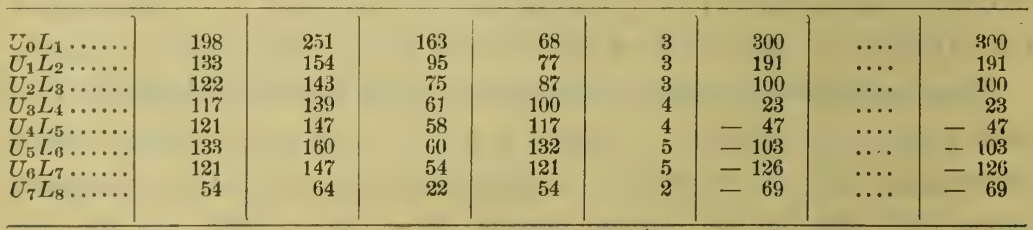

\section{VERTICALS}

\begin{tabular}{|c|c|c|c|c|c|c|c|c|}
\hline $\begin{array}{l}U_{0} L_{0} \ldots \ldots \\
U_{1} L_{1} \ldots \ldots \\
U_{2} L_{2} \ldots \ldots \\
U_{8} L_{8} \ldots \ldots \\
U_{4} L_{4} \ldots \ldots \\
U_{5} L_{5} \ldots \ldots \\
U_{8} L_{8} \ldots \ldots \\
U_{7} L_{7} \ldots \ldots \\
U_{8} L_{8} \ldots \ldots \\
\ldots\end{array}$ & $\begin{array}{l}-532 \\
-370 \\
-318 \\
-294 \\
-273 \\
-256 \\
-236 \\
-197 \\
-100\end{array}$ & $\begin{array}{r}549 \\
386 \\
336 \\
312 \\
291 \\
274 \\
249 \\
212 \\
-100\end{array}$ & $\begin{array}{r}499 \\
330 \\
277 \\
248 \\
227 \\
211 \\
200 \\
180 \\
-100\end{array}$ & $\begin{array}{l}65 \\
71 \\
77 \\
82 \\
85 \\
82 \\
65 \\
27 \\
\ldots\end{array}$ & $\begin{array}{l}-9 \\
-8 \\
-8 \\
-9 \\
-8 \\
-8 \\
-8 \\
-6 \\
-4\end{array}$ & $\begin{array}{r}284 \\
-177 \\
-\quad 88 \\
-\quad 19 \\
32 \\
67 \\
68 \\
37 \\
\ldots . . .\end{array}$ & $\begin{array}{l}-382 \\
-\quad 77 \\
-\quad 63 \\
-\quad 48 \\
=\quad 35 \\
-\quad 25 \\
=\quad 18 \\
-\quad 14 \\
-\quad 11\end{array}$ & $\begin{array}{r}-672 \\
-\quad 254 \\
-\quad 151 \\
-\quad 6 \% \\
-\quad 3 \\
42 \\
50 \\
-\quad 23 \\
-\quad 11\end{array}$ \\
\hline
\end{tabular}


TABLE 6.-STREss Sheet (Continued).

Live Load Stresses.

\begin{tabular}{|c|c|c|c|c|c|c|c|c|c|}
\hline \multirow[b]{2}{*}{ Member. } & \multicolumn{2}{|c|}{ RAILWAY. } & \multicolumn{2}{|c|}{ HIGHWAY. } & \multicolumn{3}{|c|}{ Lateral Live Load. } & \multicolumn{2}{|c|}{ SECONDARY. } \\
\hline & Direct. & Reverse. & Direct. & Reverse. & $\begin{array}{c}\text { Plane } \\
\text { of } \\
\text { truss. }\end{array}$ & $\begin{array}{l}\text { Lateral } \\
\text { and } \\
\text { sway. }\end{array}$ & Total. & $\begin{array}{l}\text { Percent- } \\
\text { age of } \\
\text { railway } \\
\text { direct. }\end{array}$ & $\begin{array}{l}\text { Equiv- } \\
\text { alent } \\
\text { stresis. }\end{array}$ \\
\hline
\end{tabular}

\section{UPPER CiIORDS}

\begin{tabular}{|c|c|c|c|c|c|c|c|c|c|c|}
\hline $\begin{array}{c}U_{0} U_{1} \ldots \\
U_{1} U_{2} \ldots \\
U_{2} U_{8} \ldots \\
U_{3} U_{4} \ldots \\
U_{4} U_{5} \ldots \\
U_{5} U_{6} \ldots \\
U_{6} U_{7} \ldots \\
U_{7} U_{8} \ldots\end{array}$ & $\begin{array}{ll}- & 1 \\
- & 3 \\
- & 6 \\
- & 8 \\
-1 & 0 \\
-1 & 2 \\
-1 & 1 \\
-\quad 9\end{array}$ & $\begin{array}{l}185 \\
383 \\
610 \\
835 \\
025 \\
205 \\
120 \\
915\end{array}$ & $\begin{array}{l}117 \\
251 \\
380 \\
522 \\
580 \\
585 \\
387 \\
160\end{array}$ & $\begin{array}{rr}- & 19 \\
-\quad 41 \\
-\quad 66 \\
-\quad 93 \\
-\quad 114 \\
-134 \\
-\quad 129 \\
-\quad 105\end{array}$ & $\begin{array}{l}14 \\
29 \\
44 \\
59 \\
66 \\
66 \\
42 \\
18\end{array}$ & $\begin{array}{r}7.1 \\
-13.2 \\
-17.5 \\
-19.5 \\
-18.4 \\
-14.8 \\
-\quad 9.6 \\
-\quad 6.2\end{array}$ & $\begin{array}{c}0 \\
11.1 \\
20.7 \\
28.8 \\
35.5 \\
40.6 \\
44.3 \\
46.6\end{array}$ & $\begin{array}{r}7.1 \\
-\quad 2.1 \\
3.2 \\
9.3 \\
17.1 \\
25.8 \\
34.7 \\
40.4\end{array}$ & $\begin{array}{r}200 \\
100 \\
55 \\
35 \\
25 \\
25 \\
30 \\
20\end{array}$ & $\begin{array}{l}370 \\
380 \\
330 \\
290 \\
250 \\
300 \\
340 \\
180\end{array}$ \\
\hline
\end{tabular}

\section{Lower Chords}

\begin{tabular}{|c|c|c|c|c|c|c|c|c|c|}
\hline $\begin{array}{l}L_{0} L_{1} \ldots \\
L_{1} L_{2} \ldots \\
L_{2} L_{3} \ldots \\
L_{3} L_{4} \ldots \\
L_{4} L_{5} \ldots \\
L_{5} L_{4} \ldots \\
L_{6} L_{7} \ldots \\
L_{7} L_{8} \ldots\end{array}$ & $\begin{array}{rl}-2 & 505 \\
-2 & 310 \\
-2 & 270 \\
-2 & 220 \\
-2 & 150 \\
-2 & 110 \\
-1 & 175 \\
-1 & 490\end{array}$ & $\begin{array}{r}\cdots 32 \\
31 \\
176 \\
278 \\
354 \\
336 \\
228\end{array}$ & $\begin{array}{r}-292 \\
-273 \\
-260 \\
-251 \\
-240 \\
-223 \\
-194 \\
-158\end{array}$ & $\begin{array}{r}\cdots \\
3 \\
9 \\
17 \\
28 \\
36 \\
35 \\
24\end{array}$ & $\begin{array}{r}-91.3 \\
-78.0 \\
-68.0 \\
-60.2 \\
-56.1 \\
-55.4 \\
-58.1 \\
-62.8\end{array}$ & $\begin{array}{r}12.4 \\
37.2 \\
61.7 \\
85.3 \\
106.7 \\
124.4 \\
137.1 \\
144.2\end{array}$ & $\begin{array}{r}-78.9 \\
-40.8 \\
-\quad 6.3 \\
25.1 \\
50.6 \\
19.0 \\
79.0 \\
81.4\end{array}$ & $\begin{array}{l}10 \\
10 \\
10 \\
10 \\
10 \\
10 \\
10 \\
10\end{array}$ & $\begin{array}{l}250 \\
240 \\
230 \\
220 \\
210 \\
200 \\
180 \\
150\end{array}$ \\
\hline
\end{tabular}

\section{Diagonals}

\begin{tabular}{|c|c|c|c|c|c|c|c|c|c|}
\hline $\begin{array}{l}U_{0} L_{1} \ldots \\
U_{1} L_{2} \ldots \\
U_{2} L_{3} \ldots \\
U_{3} L_{4} \ldots \\
U_{4} L_{5} \ldots \\
U_{5} L_{6} \ldots \ldots \\
U_{6} L_{7} \ldots \\
U_{7} L_{8} \ldots\end{array}$ & $\begin{array}{l}618 \\
573 \\
535 \\
514 \\
518 \\
565 \\
736 \\
940\end{array}$ & $\begin{array}{l}-398 \\
-358 \\
-391 \\
-248 \\
-220 \\
-268 \\
-537 \\
-\quad 850\end{array}$ & $\begin{array}{r}63 \\
58 \\
53 \\
52 \\
5.2 \\
58 \\
81 \\
102\end{array}$ & $\begin{array}{l}-46 \\
-42 \\
-36 \\
-30 \\
-26 \\
-30 \\
-55 \\
-90\end{array}$ & $\begin{array}{r}23.7 \\
16.6 \\
8.9 \\
3.2 \\
-\quad 1.3 \\
-\quad 5.0 \\
-\quad 6.0 \\
-\quad 4.0\end{array}$ & 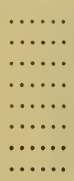 & $\begin{array}{r}23.7 \\
16.6 \\
8.9 \\
3.2 \\
-\quad 1.3 \\
-\quad 5.0 \\
-\quad 6.0 \\
-\quad 4.0\end{array}$ & $\begin{array}{l}35 \\
45 \\
35 \\
20 \\
.15 \\
15 \\
20 \\
15\end{array}$ & $\begin{array}{r}220 \\
260 \\
190 \\
100 \\
80 \\
80 \\
150 \\
140\end{array}$ \\
\hline
\end{tabular}

\section{Verticals}

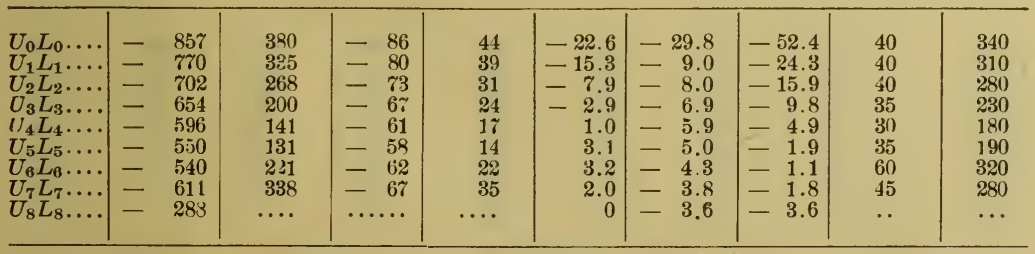


TABLE 6.-Stress Sheet (Continued).

Impact Stresses.

\begin{tabular}{|c|c|c|c|c|c|c|c|c|}
\hline \multirow{2}{*}{ Nember. } & \multicolumn{4}{|c|}{ RaILWAy IMPACT, DIRECT. } & \multicolumn{4}{|c|}{ RAILWAy ImpaCt, ReVerse. } \\
\hline & Niagara. & $\begin{array}{l}\text { Schnei- } \\
\text { der. }\end{array}$ & $\begin{array}{c}\text { Linden- } \\
\text { thal. }\end{array}$ & $\begin{array}{l}\text { New } \\
\text { A.R. E.A }\end{array}$ & Niagara. & A.R. E.A. & $\begin{array}{c}\text { Linden. } \\
\text { thal. }\end{array}$ & $\begin{array}{l}\text { New } \\
\text { A. R. E.A }\end{array}$ \\
\hline
\end{tabular}

\section{UPPER CHORDS}

\begin{tabular}{|c|c|c|c|c|c|c|c|c|}
\hline $\begin{array}{l}U_{0} U_{1} \ldots \ldots \\
U_{1} U_{2} \ldots \ldots \\
U_{2} U_{8} \ldots \ldots \\
U_{8} U_{4} \ldots \ldots \\
U_{4} U_{5} \ldots \ldots \\
U_{5} U_{6} \ldots \ldots \\
U_{6} U_{7} \ldots \ldots \\
U_{7} U_{8} \ldots \ldots\end{array}$ & $\begin{array}{l}55 \\
-\quad 111 \\
-174 \\
-229 \\
-272 \\
-302 \\
-269 \\
-238\end{array}$ & $\begin{array}{l}-109 \\
-222 \\
-348 \\
-458 \\
-544 \\
-603 \\
-538 \\
-476\end{array}$ & $\begin{array}{l}-150 \\
-306 \\
-473 \\
-622 \\
-715 \\
-760 \\
-601 \\
-504\end{array}$ & $\begin{array}{l}76 \\
-119 \\
-220 \\
-275 \\
-298 \\
-\quad 301 \\
-236 \\
-258\end{array}$ & $\begin{array}{r}28 \\
60 \\
93 \\
131 \\
151 \\
161 \\
112 \\
43\end{array}$ & $\begin{array}{r}55 \\
120 \\
186 \\
261 \\
302 \\
322 \\
224 \\
85\end{array}$ & $\begin{array}{r}61 \\
139 \\
217 \\
308 \\
334 \\
323 \\
170 \\
32\end{array}$ & $\begin{array}{r}23 \\
53 \\
87 \\
130 \\
162 \\
193 \\
151 \\
45\end{array}$ \\
\hline
\end{tabular}

\section{LOWER CHORDS}

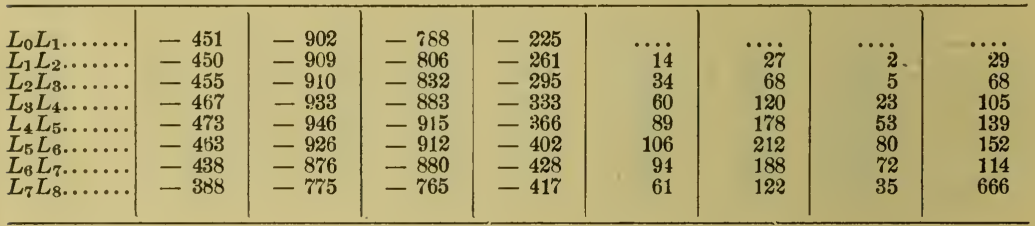

\section{Diagonals}

\begin{tabular}{|c|c|c|c|c|c|c|c|c|}
\hline $\begin{array}{l}U_{0} L_{1} \ldots \ldots \\
U_{1} L_{2} \ldots \ldots \\
U_{2} L_{3} \ldots \ldots \\
U_{8} L_{4} \ldots \ldots \\
U_{4} L_{5} \ldots \ldots \ldots \\
U_{5} L_{6} \ldots \ldots \ldots \\
U_{6} L_{7} \ldots \ldots \ldots \\
U_{7} L_{8} \ldots \ldots \ldots\end{array}$ & $\begin{array}{l}185 \\
175 \\
169 \\
165 \\
169 \\
170 \\
177 \\
240\end{array}$ & $\begin{array}{l}370 \\
350 \\
337 \\
329 \\
337 \\
339 \\
353 \\
480\end{array}$ & $\begin{array}{l}512 \\
521 \\
522 \\
502 \\
525 \\
500 \\
500 \\
760\end{array}$ & $\begin{array}{l}266 \\
258 \\
268 \\
257 \\
285 \\
243 \\
155 \\
244\end{array}$ & $\begin{array}{lr}- & 92 \\
- & 81 \\
- & 66 \\
- & 55 \\
-\quad 48 \\
-\quad 62 \\
-\quad 156 \\
-\quad 230\end{array}$ & $\begin{array}{l}-184 \\
-161 \\
-132 \\
-109 \\
-\quad 95 \\
-123 \\
-\quad 312 \\
-459\end{array}$ & $\begin{array}{l}-205 \\
-196 \\
-155 \\
-122 \\
-102 \\
-138 \\
-453 \\
-745\end{array}$ & $\begin{array}{l}-\quad 80 \\
-\quad 68 \\
-\quad 51 \\
-\quad 42 \\
-\quad 35 \\
-\quad 51 \\
-210 \\
-\quad 264\end{array}$ \\
\hline
\end{tabular}

\section{Verticals}

\begin{tabular}{|c|c|c|c|c|c|c|c|c|}
\hline $\begin{array}{l}U_{0} L_{0} \ldots \ldots \\
U_{1} L_{1} \ldots \ldots \\
U_{2} L_{2} \ldots \ldots \\
U_{8} L_{8} \ldots \ldots \\
U_{4} L_{4} \ldots \ldots \\
U_{5} L_{5} \ldots \ldots \\
U_{6} L_{8} \ldots \ldots \\
U_{7} L_{7} \ldots \ldots \\
U_{8} L_{8} \ldots \ldots\end{array}$ & $\begin{array}{l}-257 \\
-223 \\
-207 \\
-196 \\
-179 \\
-154 \\
-124 \\
-147 \\
-120\end{array}$ & $\begin{array}{l}-514 \\
-416 \\
-414 \\
-392 \\
-358 \\
-308 \\
-248 \\
-294 \\
-240\end{array}$ & $\begin{array}{l}-575 \\
-537 \\
-513 \\
-493 \\
-447 \\
-\quad 370 \\
-281 \\
-371 \\
-412\end{array}$ & $\begin{array}{l}-368 \\
-300 \\
-288 \\
-281 \\
-256 \\
-187 \\
-103 \\
-135 \\
-250\end{array}$ & $\begin{array}{r}88 \\
81 \\
63 \\
46 \\
33 \\
32 \\
68 \\
97 \\
\ldots\end{array}$ & $\begin{array}{r}175 \\
161 \\
126 \\
92 \\
65 \\
63 \\
135 \\
193 \\
\ldots\end{array}$ & $\begin{array}{r}123 \\
128 \\
96 \\
63 \\
37 \\
37 \\
120 \\
217 \\
\ldots .\end{array}$ & $\begin{array}{r}76 \\
70 \\
54 \\
49 \\
28 \\
32 \\
100 \\
128 \\
\ldots .\end{array}$ \\
\hline
\end{tabular}


TABLE 6.-Stress SheEt (Continued).

Maximum, Minimum, and Unit Stresses.

\begin{tabular}{l|l|l|l|l|l|}
\hline Iember. & Maximum. Minimum. & $\begin{array}{c}50 \% \text { of } \\
\text { reverse } \\
\text { minimum. }\end{array}$ & $\begin{array}{c}\text { Area, in } \\
\text { square } \\
\text { inches. }\end{array}$ & Maximum. & Allowed. \\
\hline
\end{tabular}

\section{UPPER CHORDS}

\begin{tabular}{|c|c|c|c|c|c|c|}
\hline $\begin{array}{l}U_{0} U_{1} \ldots \ldots \ldots \ldots \ldots \ldots \ldots \\
U_{1} U_{2} \ldots \ldots \ldots \ldots \ldots \ldots \ldots \\
U_{2} U_{3} \ldots \ldots \ldots \ldots \ldots \ldots \ldots \\
I_{3} U_{4} \ldots \ldots \ldots \ldots \ldots \ldots \ldots \ldots \\
U_{4} U_{5} \ldots \ldots \ldots \ldots \ldots \ldots \ldots \\
U_{5} U_{6} \ldots \ldots \ldots \ldots \ldots \ldots \ldots \\
U_{6} U_{7} \ldots \ldots \ldots \ldots \ldots \ldots \ldots \\
U_{7} U_{8} \ldots \ldots \ldots \ldots \ldots \ldots \ldots\end{array}$ & 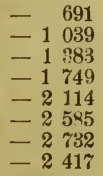 & $\begin{array}{l}120 \\
2 \% 9 \\
438 \\
627 \\
709 \\
722 \\
448 \\
129\end{array}$ & $\begin{array}{r}60 \\
140 \\
219 \\
314 \\
354 \\
361 \\
224 \\
65\end{array}$ & $\begin{array}{r}69.5 \\
69.5 \\
79.6 \\
103.5 \\
138.4 \\
167.1 \\
176.5 \\
175.9\end{array}$ & $\begin{array}{r}9.9 \\
14.9 \\
17.3 \\
16.1 \\
15.3 \\
15.5 \\
15.5 \\
13.7\end{array}$ & $\begin{array}{l}18.2 \\
18.2 \\
18.2 \\
18.2 \\
18.2 \\
18.3 \\
18.3 \\
18.3\end{array}$ \\
\hline
\end{tabular}

\section{LOWER CHORDS}

\begin{tabular}{|c|c|c|c|c|c|c|}
\hline 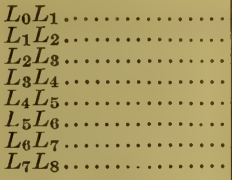 & $\begin{array}{l}5477 \\
-5194 \\
-4955 \\
-4817 \\
-4642 \\
-4426 \\
-4107 \\
-3697\end{array}$ & 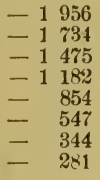 & $\begin{array}{l}\cdots \cdots \\
\cdots \cdots \\
\cdots \cdots \\
\cdots \cdots \\
\cdots \cdots \\
\cdots \cdots \\
\cdots \cdots \\
\cdots \cdots\end{array}$ & $\begin{array}{l}316.7 \\
289.5 \\
282.0 \\
270.0 \\
262.4 \\
249.3 \\
225.8 \\
191.1\end{array}$ & $\begin{array}{l}17.3 \\
17.9 \\
17.6 \\
17.6 \\
17.7 \\
17.8 \\
17.9 \\
19.3\end{array}$ & $\begin{array}{l}19.6 \\
19.7 \\
19.7 \\
19.8 \\
19.8 \\
19.9 \\
19.9 \\
19.9\end{array}$ \\
\hline
\end{tabular}

\section{Diagonals}

\begin{tabular}{|c|c|c|c|c|c|c|c|c|}
\hline $\begin{array}{l}U_{0} L_{1} \ldots \ldots \ldots \ldots \ldots \ldots \ldots \\
U_{1} L_{2} \ldots \ldots \ldots \ldots \ldots \ldots \ldots \ldots \\
U_{2} L_{3} \ldots \ldots \ldots \ldots \ldots \ldots \ldots \ldots \\
U_{3} L_{4} \ldots \ldots \ldots \ldots \ldots \ldots \ldots \ldots \\
U_{4} L_{5} \ldots \ldots \ldots \ldots \ldots \ldots \ldots \\
U_{5} L_{6} \ldots \ldots \ldots \ldots \ldots \ldots \ldots \ldots \\
U_{6} L_{7} \ldots \ldots \ldots \ldots \ldots \ldots \ldots \ldots \\
U_{7} L_{8} \ldots \ldots \ldots \ldots \ldots \ldots \ldots \ldots\end{array}$ & $\begin{array}{ll}1 & 293 \\
1 & 221 \\
1 & 106 \\
1 & 001 \\
1 & 009 \\
1 & 087 \\
1 & 691 \\
2 & 023\end{array}$ & $\begin{array}{l}- \\
- \\
- \\
- \\
-\end{array}$ & $\begin{array}{l}406 \\
425 \\
368 \\
316 \\
380 \\
359 \\
748 \\
170\end{array}$ & $\begin{array}{l}- \\
- \\
- \\
- \\
-\end{array}$ & $\begin{array}{l}203 \\
213 \\
184 \\
158 \\
145 \\
180 \\
374 \\
585\end{array}$ & $\begin{array}{r}72.3 \\
67.3 \\
61.1 \\
56.8 \\
56.8 \\
61.9 \\
94.1 \\
126.4\end{array}$ & $\begin{array}{l}17.8 \\
18.2 \\
18.1 \\
17.6 \\
17.8 \\
16.8 \\
18.0 \\
16.0\end{array}$ & $\begin{array}{l}20.0 \\
20.0 \\
20.0 \\
20.0 \\
20.0 \\
20.0 \\
20.0 \\
20.0\end{array}$ \\
\hline
\end{tabular}

\section{Verticals}

\begin{tabular}{|c|c|c|c|c|c|c|}
\hline $\begin{array}{l}U_{0} L_{0} \ldots \ldots \ldots \ldots \ldots \ldots \ldots \\
U_{1} L_{1} \ldots \ldots \ldots \ldots \ldots \ldots \\
U_{2} L_{2} \ldots \ldots \ldots \ldots \ldots \ldots \ldots \\
U_{3} L_{3} \ldots \ldots \ldots \ldots \ldots \ldots \ldots \\
U_{4} L_{4} \ldots \ldots \ldots \ldots \ldots \ldots \ldots \\
U_{5} L_{5} \ldots \ldots \ldots \ldots \ldots \ldots \ldots \\
U_{6} L_{6} \ldots \ldots \ldots \ldots \ldots \ldots \ldots \\
U_{7} L_{7} \ldots \ldots \ldots \ldots \ldots \ldots \ldots \\
U_{8} L_{8} \ldots \ldots \ldots \ldots \ldots \ldots \ldots\end{array}$ & $\begin{array}{l}2.060 \\
-1755 \\
-1595 \\
-1466 \\
-1322 \\
-1243 \\
-1301 \\
-1274 \\
-\quad 484\end{array}$ & $\begin{array}{r}45 \\
156 \\
121 \\
58 \\
3 \\
3 \\
140 \\
300 \\
100\end{array}$ & $\begin{array}{r}23 \\
78 \\
61 \\
29 \\
2 \\
2 \\
70 \\
150 \\
\ldots\end{array}$ & $\begin{array}{r}123.4 \\
97.1 \\
91.1 \\
84.6 \\
78.7 \\
74.7 \\
74.7 \\
75.2 \\
41.9\end{array}$ & $\begin{array}{l}16.7 \\
18.1 \\
17.5 \\
17.3 \\
16.8 \\
16.6 \\
17.4 \\
17.0 \\
11.5\end{array}$ & $\begin{array}{l}16.8 \\
16.5 \\
16.5 \\
16.5 \\
16.5 \\
18.0 \\
19.0 \\
19.7 \\
19.4\end{array}$ \\
\hline
\end{tabular}


Although the posts from $U_{1} L_{1}$ to $U_{4} L_{4}$ show an excess, a consideration of the secondary stress strain-gauge readings shows them to be within the limits set for direct compressive stress; furthermore, the effective length is much reduced by the highway floor-beams and stringers connecting at the highway level.

\section{Methods of Reinforcing.}

The reinforcement of the posts of the 115-ft. span, and of the viaduct, consisted of two angles back to back on each web, but in some cases a filler plate was used. The holes in these plates and angles matched the old rivet spacing in the webs as far as it extended, and when the new material had been bolted in place by a few bolts, the additional holes were drilled through the webs with high-speed air drills. Every other hole was bolted before riveting, and the bolts tightened before riveting but after the dead load had been relieved, either by the toggle on the 115-ft. span posts as already described, or by shores and jacks to carry the dead and live load for the approach columns.

The old cover-plates on the approach girders, the stringers, and the floor-beams of the spans were cut loose by cutting out the rivets by hand, except for the old rusted top plates which were to be thrown away and could stand the heat from a cutting torch. These rivet heads were burned off at the rate of 600 to 700 per day, or equal to the number removed by four hand gangs, and the rivets were then backed out by hand. The new top cover-plates were countersunk so as to leave a smooth surface to receive the 14-in. maple risers, but experience indicates the desirability of countersinking top flange rivets in all railway bridge stringers or deck girders, so that ties need not be bored or notched for rivet heads. All new plates were riveted up after removing the dead load stress by shoring up from below with 8 by 8-in. shores and wedges for the stringers on the spans, one for each stringer; but two 12 by 12 -in. shores were used under each of the approach girders, which were from 40 to $52 \mathrm{ft}$. in length.

The reinforcing plates on the curved brackets were clamped in place, the holes drilled through the old flange and the riveting done without any shoring, as there was practically no dead load stress to be considered. The new counters in the 115 -ft. spans were $1 \frac{13}{16}$-in. square U-bars, or two bars replacing one of the same size, which would 
have been stressed to more than $40000 \mathrm{lb}$. under E-60 loading. The old loop eyes were burned off on each side of the pin by using a torch, so that the old counters were easily removed, after previously putting in four strands of wire rope, tightened by turnbuckles to carry the counter stress until the new rods were in place. The short U-bars were then slipped around the top and bottom pins, the straight sections connected up, and tightened with the four turnbuckles to an initial stress of $3000 \mathrm{lb}$. per sq. in., as shown by strain-gauge readings.

The viaduct posts had originally been built with bases 40 by 43 in., resting on pedestal blocks of stone 5 by 5 by $2 \mathrm{ft}$., entirely above the pavement. This had become an obstruction to traffic of a very serious nature, and as two of the stone pedestals had become cracked, it was decided to replace the two nearest each entrance to the highway floor with extensions of the steel post section to below pavement level, with a flaring base to distribute the pressure over the concrete footing. These bases were built up of channels and plates, as it was impossible to obtain steel castings within any reasonable time. They were fully spliced to the columns after the old base plates and connections had been burned off, the pockets having been filled with water-proof concrete directly against the metal. The space between the bases and the pavement was filled with concrete in concave curves to ward off the wheels of vehicles. The additional gain in roadway width was about $4 \mathrm{ft}$. The post reinforcing was increased to provide for the increased value of $\frac{l}{r}$.

\section{Sway Bracing.}

The new diagonal sway bracing (Fig. 18), in the bents, $U_{0} L_{0}$, $U_{2} L_{2}, U_{4} L_{4}$, is composed of two 12-in. channels for each member, laced with 3 by 3 by $\frac{3}{8}$-in. angles double-riveted, and having a stiffening angle on each tie-plate. The old rods were not removed until four wire ropes with turnbuckles had been placed to take the stress, one vertical panel being replaced at a time, and it was required that a panel be finished the day it was begun, as a measure of safety. The connections to the arch ribs was made by means of the large gussets connecting generally to old holes with very few new ones to drill. The posts were also diaphragmed opposite the bottom gussets. The center gussets were made large enough and holes were provided for connecting struts that will be necessary when two more ribs are 
added to the arch, and then the end connections can be increased in strength by placing the rivets in double shear. When new ribs are added, stiff bracing will be placed in the alternate bents as well. The bracing of the end bents, $U_{0} L_{0}$, has connected to it steel stairways as shown by Fig. 18, the outside stringer being a single channel, and the steps formed of two rods with pipe separators. The rise makes the stairways very easy to climb and they are a distinct advantage in ease of access for making repairs to the bridge.

The two vibration struts in each bent, $U_{1} L_{1}$, and one in each bent, $U_{3} L_{3}$, as shown in Fig. 18, are $10 \mathrm{ft}$. deep, with two 5 by 3 by $\frac{3}{8}$-in. angle flanges, and $4 \frac{1}{2}$ by 3 by $\frac{3}{8}$-in. angle web members. They are purely for counteracting vibration, and are connected or steadied by angle lugs at the middle pin of the sway rods. They, as well as the diagonals, serve the purpose perfectly, and the side sway and swing of the bridge which was so objectionable has been practically eliminated, besides making the arch perfectly safe against vibration from heary trains.

\section{New Grade Line.}

The grade line of the arch was originally made to conform to the large camber of the old suspension bridge, as a means of erecting the arch around the stiffening trusses of the latter without stopping traffic. This made a sag in the grade of practically $18 \mathrm{in}$. between the center of the arch span and the New York Central Railroad crossing on the American shore, or practically at the shore end of the 115-ft. span. The heavy grade incidental to this made it necessary for the heavier freight trains to cross the bridge at speeds of from 20 to 30 miles per hour, which were considered unsafe for a bridge of this character-so high and directly above the Rapids. Therefore, it was decided to remove this sag by means of steel risers on top of the stringers, which also were made to serve as the new top flange of these stringers on the American half of the arch and on the 115-ft. span. The rise in the first panel next to the center of the arch was made entirely in the 14-in. maple risers of the new floor.

The risers in the next two panels consist of four angles telescoped, and, for the remainder of the arch, of four angles and a web-plate, with stiffeners every $4 \mathrm{ft}$., all risers being tapered to conform to the new grade. The risers on the 115 - $\mathrm{ft}$. span are of Bethlehem $\mathrm{H}$-beams, 10 and $12 \mathrm{in.}$ deep, with end stiffeners only. 


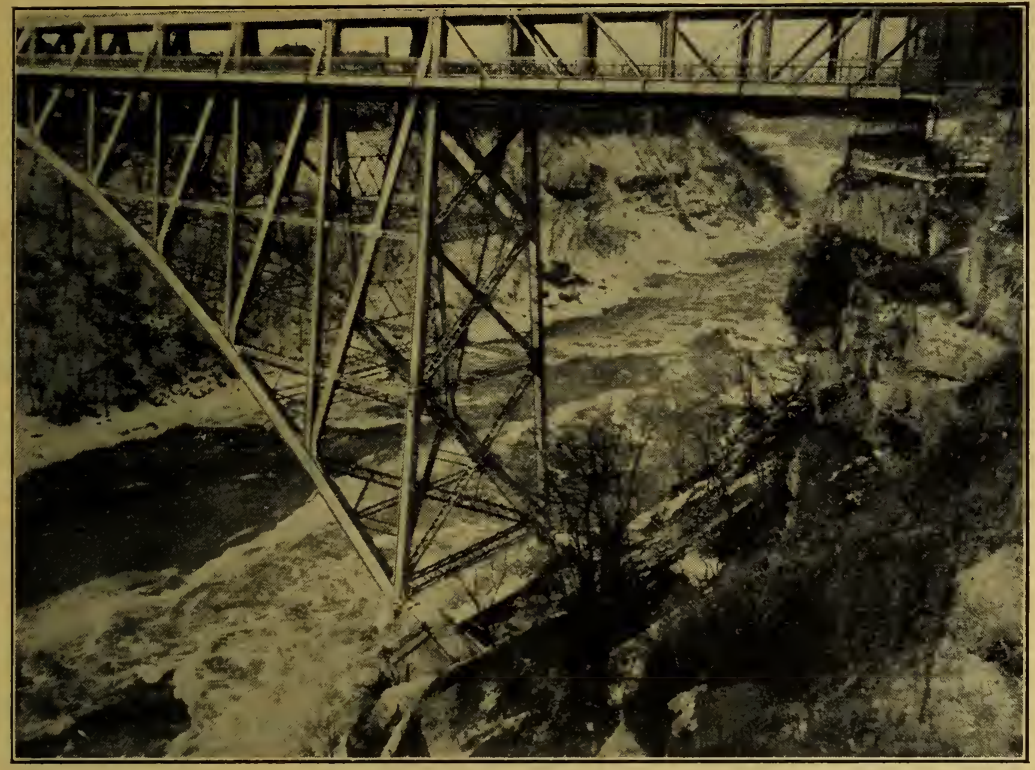

Fig. 18.-New Sway and Vibration Bracing.

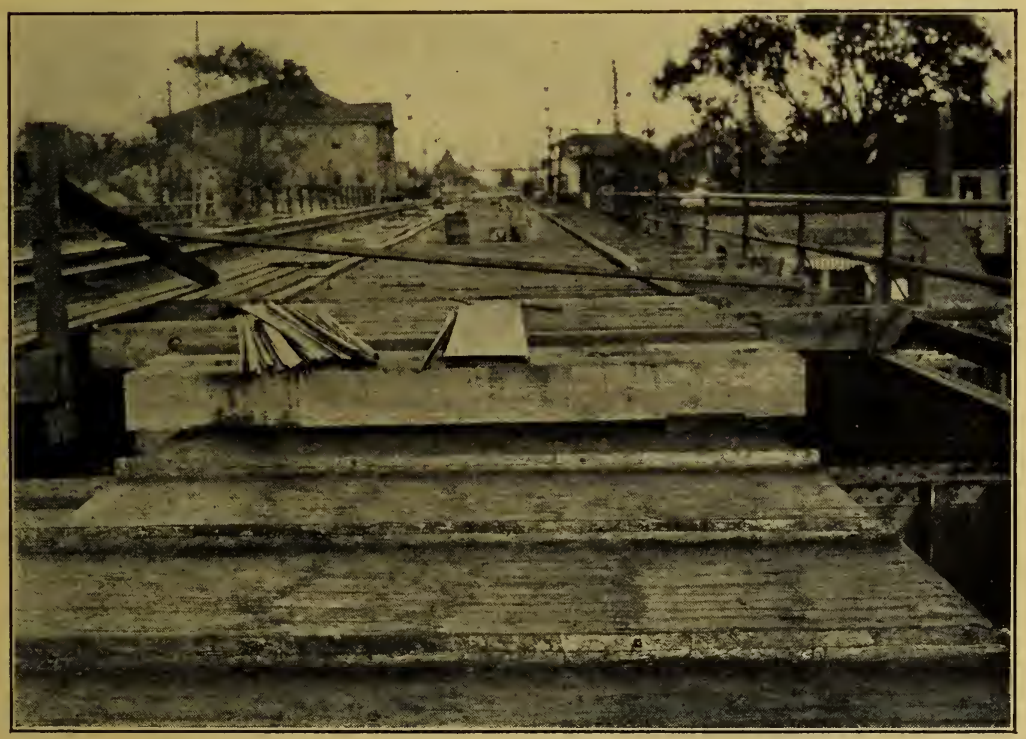

Fig. 19.-Copper-Steel Ratlway Protection Floor, Showing TIE RISERS AND COVER STRIPS. 

The American approach was jacked up bodily 12 in., and cast-steel bases were inserted between the steel bases of the columns and the masonry. This jacking was done for all three of the American $48 \mathrm{ft}$. 6-in. double-track spans, during the two hours when the trains were stopped. Bents of 12 by 12 -in. timbers had been previously placed, and eight 60 -ton jacks on shores, two at each point, were used to raise the 300 tons. The jacking began on a whistle signal, and all points were raised and blocked $1 \mathrm{in}$. When all were abreast, a second signal was given for raising the second inch. Marks had been made to watch for creeping, but none occurred. With the new castings and sheet lead in place, the anchor-bolts were temporarily placed, the new north track was connected, and trains were allowed to cross.

\section{New Railway Floor.}

The old railway deck had been placed originally with galvanized strips between the ties, small wooden side gutters, and $2 \frac{1}{2}$-in. galvanized downspouts to protect the steelwork from salt water drip and the highway traffic from water coming through from above. This proved unsatisfactory, and, later, wooden strips with a groove for a gutter were used between the ties. This was apparently a passable protection, but in the dry weather period a great deal of leakage made it unpleasant for the highway traffic. While making the 1918 inspection, the condition of the top flanges and angle laterals between them, of the stringers, floor-beams, and girders was investigated to ascertain the extent of the salt-water corrosion from refrigerator car drippings. The-only places that could be reached were the small spaces between the ties, and below the small, wooden gutter strips. It was found that the corroded metal could easily be pried off in flakes from $\frac{1}{8}$ to $\frac{3}{8}$ in. thick. Later, by using a rolling staging, spots were scraped on each top flange at frequent intervals and it was found that plates and angles originally from $\frac{3}{8}$ to $\frac{1}{2} \mathrm{in}$. thick, were wasted away on an average of $50 \%$, or in extreme cases only $\frac{1}{16}$ to $\frac{1}{8}$ in. thickness remained.

Studies were at once begun to find some type of floor that would be a practically perfect protection against this salt water and also the blow-off water from locomotive boilers. There was found to have been no real attempt by any one to solve the problem, except the endeavor of the American Railway Engineering Association to have 
efficient drip tanks placed in refrigerator cars, and the use in some cases of heavy concrete troughs to carry ballast and tracks.

The latter solution is represented by the heavy reinforced concrete floor as designed and used by Charles F. Loweth, M. Am. Soc. C. E., Chief Engineer of the Chicago, Milwaukee and St. Paul Railway. This is a splendid type of construction, but as it weighs $3400 \mathrm{lb}$. per lin. ft. of track, could not be considered for use on the Arch Bridge. One of the lightest floors of this type is in use by the Buffalo, Rochester and Pittsburgh Railway, and was only slightly too heavy to be considered, weighing $2200 \mathrm{lb}$. per lin. ft. of single track. The design shown in cross-section in Fig. 20 was within the weight limit desired, and a test section was made with the cement gun. Tested with its own

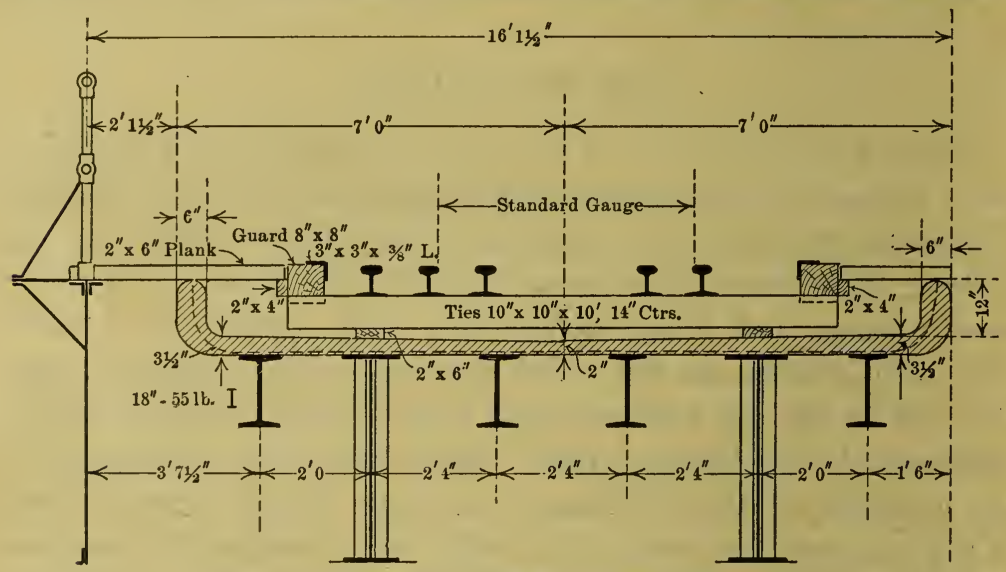

Fig. 20.-Light Concrete Floor as Tested.

weight over a span of $13 \mathrm{ft}$. on 12-in. blocking, it sagged about 6 in. and developed hair cracks. It could be tetered up and down 6 in. with one's foot and return to its original sagged elevation, and so far as tests indicated would be satisfactory for the short spans between stringers and new jack stringers. It was discarded mainly on account of the certainty that it would shatter under traffic. The idea, with certain evident modifications, is worthy of a trial on some new bridge.

The design, which was finally approved from an engineering standpoint, was a $\frac{3}{8}$-in. flat steel plate protection with proper protective coating. Furthermore, this made it possible to carry the water away by side downspouts, but when the cost was considered, and the cost of maintenance as well, some lighter plate floor was found desirable. 
The suggestion of the use of $\frac{1}{8}$-in. special iron was at once rejected, and a plan for $\frac{3}{16}$-in. special iron floor was prepared for bids. The labor and shop conditions were finally responsible for the use of this $\frac{3}{16}$-in. floor, shown in detail in Fig. 21, which could be largely fabri-
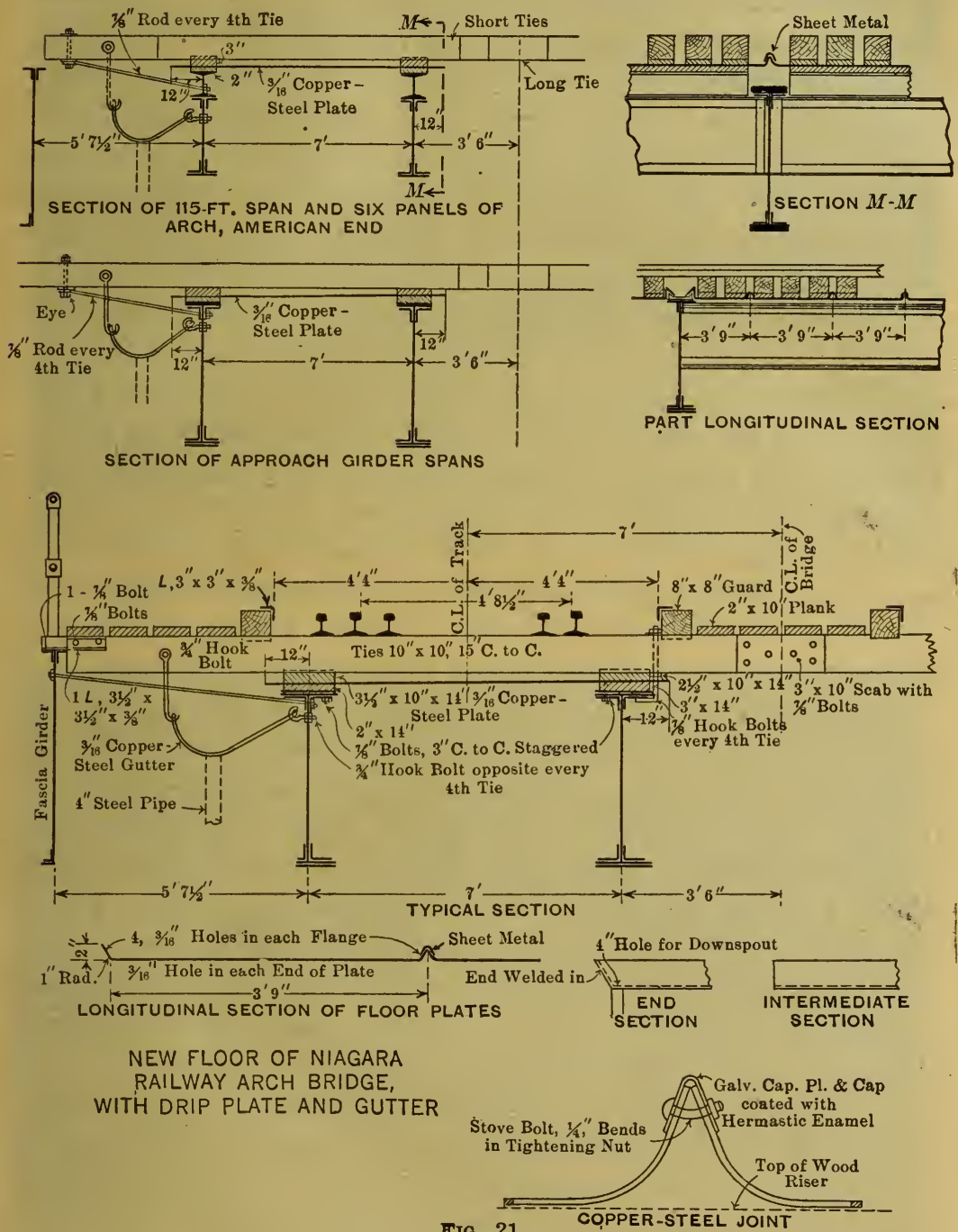

FIG. 21.

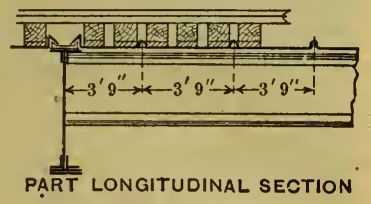


idea was entertained, however, that any metal as usually painted would last long when undergoing the corrosive action of the salt-water brine; therefore, the copper steel was coated, after fabrication and laying, with Hermastic enamel of a grade such as is used for the double bottoms of ships. The metal was first carefully cleaned by wire brushing and rubbing with burlap and coarse rags, coated with the special primer, and then the Hermastic enamel applied "piping" hot. Even then it could only be given one spread of from 12 to 18 in. with the special daubers used, and on account of the thin metal being kept constantly cool by the current of air up and down the Gorge, about $50 \%$ more enamel was used than was expected, giving a coating more than $\frac{1}{4}$ in. in average thickness.

The design is quite plainly shown in Figs. 19 and 21, but attention is called to a few vital points. The 9 -ft. floor-plates have a fall of 1 in 84 , arranged by the inside and outside 14-in. maple stringer risers, thus draining the water to the large gutters on each side of the bridge. This side slope is taken out of the track by making the outside 10 by 14-in. hardwood tie block 1 in. thicker than the inside one. These blocks are dapped into the 10 by 10 -in. ties about $\frac{1}{2}$ in., the ties being dapped to a uniform thickness of $9 \frac{1}{2} \mathrm{in}$. The blocks are spiked edgewise to prevent splitting, are fastened to the ties with two 6 -in. spikes, and are treated with hot carbolineum, as are also the stringer risers.

The copper-steel floor sections are flanged, as shown, to a width of $3 \mathrm{ft} .9 \mathrm{in}$, so that'a section can be pulled out sidewise for re-coating or repair, by slightly jacking up the track. The flanges are protected on the edges by a cap of No. 16 galvanized steel, coated with enamel and held in place by $\frac{5}{16}-i n$. stove bolts so as to be easily renewed. When the plates were laid in place on the 14-in. maple risers, with a clear span of $5 \mathrm{ft} .10 \mathrm{in}$., they were perfectly stiff for carrying the workmen, and the writer, who weighs $200 \mathrm{lb}$., was unable to sag them by jumping up and down in the middle of a sheet. Some few of the plates were dished in flanging and required jacking up to level.

No injury was done the coating by walking over it, and it is not expected that it will be affected by the $120^{\circ}$ variation in temperature from summer to winter. Cleaning it with a scraper would be injurious, and brushes are used, ordinarily, with frequent flushing by a hose.

The flanging of the plates was done at the bridge by the home-made bending machine shown in Fig. 22. This was constructed from old 12 by 12 -in. timbers drift-bolted together with the edges of the jaw 


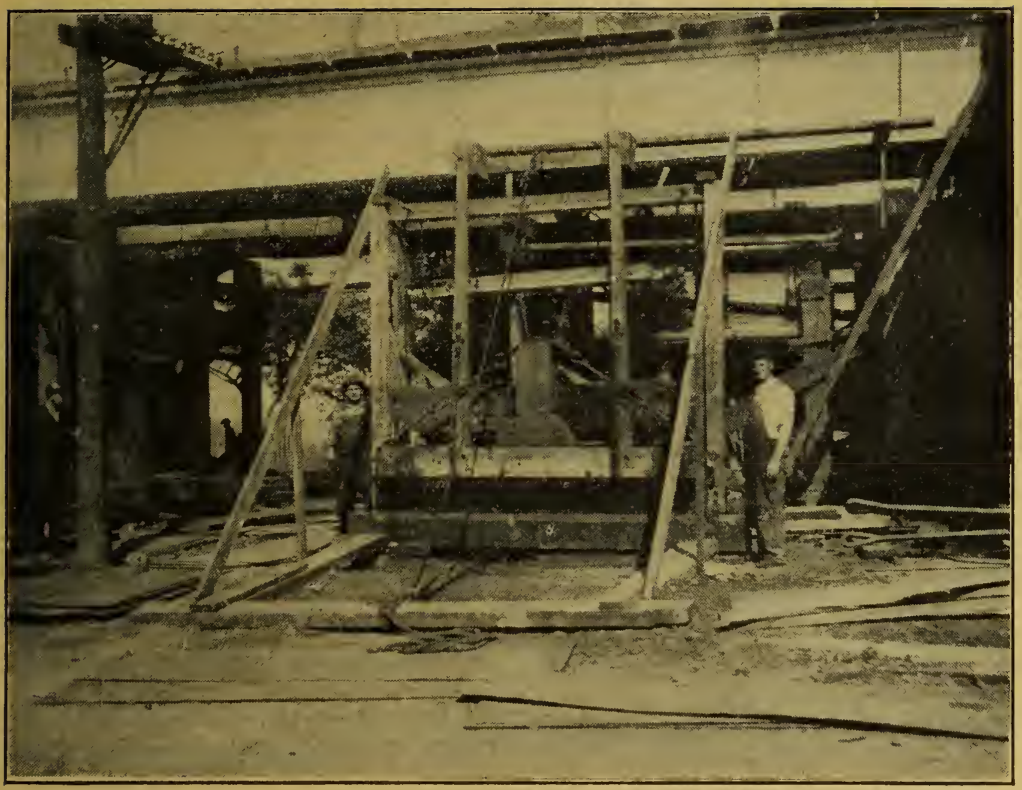

Fig. 22.-Bending Machine for Copper-Steel Floor Plates.

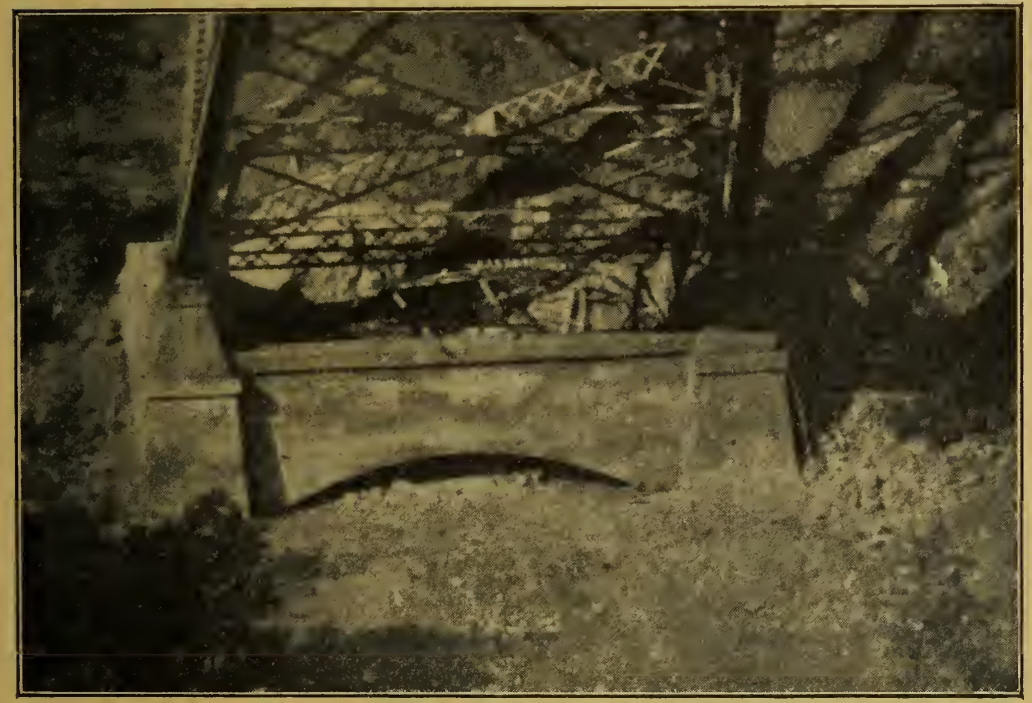

Fig. 23.-Skewback Thrust Wall and Armored Casing, Canadian Side. 

timbers protected by old angles and plates. The copper-steel plates were extraordinarily stiff, and the flanging timber was trussed by a hog rod as shown. This timber was operated by two oak levers about $10 \mathrm{ft}$. long and by lines running over snatch blocks to the nigger-heads of a hoist engine. The plates were clamped in the machine by the counterweighted timber, which in turn was clamped down by the two levers bound on the edges with strap iron, which turned down on to plates spiked to the timbers. The exact width of the plates was obtained by using gauge angles on the bed of the machine, and the exact angle of the bend was first found by trial, allowing for the spring of the plates. The machine was operated without trouble to bend about 600 plates, five men bending an average of about 50 to 60 plates per day of 8 hours. These plates under the tracks have wooden stop-waters of 3 by 3 -in. carbolineum-coated timber, spiked to the under side of the ties so as to bear tightly against the inner ends of the floor-plates.

The gutters (Fig. 21) were formed into the desired cross-section by bending rolls at the shop, after being punched on the interior ends for lap splicing with $\frac{3}{8}$-in. rivets, which were driven by air guns in the field. The ends were welded in the field with a welding torch, and the holes for the 4-in. downspouts were burned in the field with a torch.

The gutters have a fall of 6 in. for the girder spans, varying from $40 \mathrm{ft}$. to $52 \mathrm{ft} .3 \mathrm{in}$. for the $19 \mathrm{ft}$. 2 -in. panels, and $4 \mathrm{in}$. for the arch panels of $34 \mathrm{ft} .4 \frac{1}{2} \mathrm{in}$. length. This is a slope of from 1 in 100 to 1 in 80 , and gives quick drainage. The large size of the gutters was adopted in order to protect the highway deck near the sidewalks from splash and drip beyond the floor-plates.

The downspouts are of 4-in. steel pipe with screw joints, but attached to the gutter with flanges having oak filler gaskets soaked in linseed oil, and band-sawed to fit the curve of the gutter. All the downspouts are long enough to discharge below the bottom chords of the three spans, and are supported below by band clamps on the pipe and fastened to convenient lateral gussets.

The track is fastened down by hook-bolts to the inside stringers at every fourth tie, and anchored sidewise by the eye-bolt rods on the approach girders, and in the same manner on the spans, where the raised track is above the fascia girders. On the remainder of the spans the fascia girders have tie-rods to the stringers, as shown, with angle clips connecting every fourth tie to the top flange of the fascia girder. 
The cost of repairs to make good the damages caused by salt water was over $\$ 30000$ and the cost of the copper-steel salt-water protection was about the same. These two items indicate how serious a problem is confronted in the matter of having refrigerator cars equipped with salt-water drip-tanks. These might be made very easily and economically by using large wooden boxes of matched flooring and lining them with thin sheet copper, well nailed in place to prevent its being stolen. These tanks cannot be emptied automatically, since they would be about as likely to discharge on a bridge as elsewhere; so they must be arranged for quick discharging, and yardmen must be trușted to keep them emptied.

The track as finished has a practically smooth surface and only about $0.1 \%$ grade. It belongs to and was laid by the railway company, lessees of the railway deck, and is of the best type of construction throughout, as was mutually agreed upon. The rails are $100 \mathrm{lb}$. per yd., of the A. R. E. A. section, with continuous bridge joints. The tie-plates, 7 by $10 \frac{1}{2}$ in., are of the Lundie type, especially large and heavy. The rails are laid with tight joints to prevent hammering and are provided with large expansion joints in each track of the Quebec Bridge type, at both of the ends of the bridge, to allow for approximately 5 in. of expansion, which is concentrated at the shore ends of the 115-ft. spans. Inside guard-rails of 100-lb. section are used, and an outside steel guard-rail of the same size spaced $5 \mathrm{ft}$. from the inside of the inside track rail to the inside of the guard. Borden tie-spacers are used between the ties, two lines to each track. The walkways are of 3 by 3 -in. timbers laid $\frac{1}{2}$ in. apart.

The old floor was very noisy during the passing of trains, but the new one, due to the maple risers and the Hermastic enamel, is very quiet and as nearly noiseless as is possible to build. Certainly, it is a demonstration that elevated railways of practically noiseless construction can be built. The cost of the high-class tracks alone was about $\$ 12.90$ per lin. ft. of one track, and including the copper-steel floor complete about $\$ 27.50$ per lin. $\mathrm{ft}$. of one track. This would indicate that no bridge on account of extra cost need be constructed, leaving the upper metal work exposed to corrosion, and the floor system and bridge subject to destructive local impact increments, due to the desire for the possible financial saving that would result from the use of a less perfect track, and the lightest possible protection. 


\section{HighWAY FLOOR.}

The new highway floor was built for a capacity of $2130 \mathrm{lb}$. per lin. $\mathrm{ft}$., on the trusses of the 115-ft. spans, and of $1500 \mathrm{lb}$. per lin. $\mathrm{ft}$. of bridge on the trusses of the arch span. The joists on the roadway are 9-in. 18-lb. I-beams, spaced about $2 \mathrm{ft}$. $4 \frac{1}{2}$ in. on centers, and calculated for a live load of $100 \mathrm{lb}$. per sq. ft. of roadway and for the concentrated load from a 15-ton motor truck. The sidewalk joists are 6-in. 15-lb. I-beams, calculated for a live load of $80 \mathrm{lb}$. per sq. ft. of sidewalk.

The live load capacities were assumed after a careful consideration of the data gathered by the late C. C. Schneider, Past-President, Am. Soc. C. E., and in the investigation of the Blackwell's Island Bridge in New York City.

The joists were fastened to the bridge stringers by 3 by 3 by $\frac{3}{8}$-in. clips, bolted through the joist flange only. The $2 \frac{1}{2}$-in. hard pine sidewalk floor and the $3 \frac{1}{2}$-in. white oak roadway plank are fully spiked to pine spiking strips, which had been treated with hot carbolineum, and which are bolted to the top flanges of the steel joist. The curb was set back $4 \frac{1}{2}$ in. on each side of the road to give more roadway room, making the clear width $28 \mathrm{ft} .9$ in. The plank was spiked with full $\frac{1}{4}$-in. openings to give proper drainage, and the spiking strip for carrying the ends of the sidewalk plank was spiked to a raising block 3 in. thick every $3 \mathrm{ft}$. to give plenty of opening for the dirt to be blown and scraped into the river. A protection of 3 by $\frac{1}{4}$-in. strap iron was spiked at the curb to the ends of the sidewalk plank, which had been previously treated against decay.

\section{Highway Entrances.}

The bridge when rebuilt in 1896 had a comparatively light highway traffic, and no need was found to give the greatest room possible for pedestrians and vehicles. The change made in the viaduct column bases to give about $4 \mathrm{ft}$. more roadway directly at the highway entrance has been described, and the fact noted that all the stone pedestals that were allowed to remain were cut to a batter to allow more hub room in the roadway, and they were curved out at the sidewalks to give more room for pedestrians. The width of the walks was further increased by cutting off the toll windows about 15 in., also the corner of the American toll-house to give about 20 in. more width. The 
corner of the building was supported as an eccentric load on a special steel column and the space on each side turned into windows to give better light in the Customs Office.

The sidewalk to Whirlpool Street on the American side, about one and one-half blocks, was changed and landscaped with a curved walk to the north side of Mill Street, so as to avoid crossing the vehicle traffic twice. This change and a similar one across Mill Street made it possible very materially to add to the width of this street and to carry it practically full width to the bridge entrance. The railings to the small parks on both shores were improved, and reinforced concrete fence posts of a simple but neat design were used at the Canadian park. The same high standard as applied to the bridge itself was used in putting all the accessories in first-class condition to care for the present extensive highway traffic and to provide for future reasonable increase.

\section{Sand-Blasting and Painting.}

The paint on the structure was in very good condition, except as already detailed in regard to the upper work of the railway deck. It had been completely renewed three times in the preceding 22 years, with a $75 \%$ home-mixed white lead, zinc, and linseed oil paint. While no comprehensive method had been adopted in removing rust spots before applying the new coats of paint, the deterioration from rusting was practically nothing (except on the railway floor) on starting to clean the structure thoroughly with Mott sand-blast machines, and it was found that the original coats of red lead and white lead and zinc were intact over about $80 \%$ of the $480000 \mathrm{sq}$. ft. of surface. Therefore, the sand-blasting was only used to clean off all dirt, loose and dead paint, and thoroughly to burrow out the small rust spots. As soon as possible after cleaning, these rust spots were coated with Tockolith to kill any small amount of rust missed, or the starting of incipient rust. The machines used for the sand-blasting were two No. 1 Mott sandblasting machines and one No. 2.

When it was found that silica sand would cost more than $\$ 6$ per ton delivered at the bridge from Illinois, several local sands were tried, and the dried locomotive sand procured from the Grand Trunk Railway roundhouse was found to be sharp enough to give the results desired. The maximum speed in cleaning reached as high as 25 to 30 sq. ft. of surface per min. and the entire cost of the work, including 
labor, sand, and power, was close to 1 cent per sq. ft., so that the average reached was only about one-tenth of the maximum possible, due to lost time in charging sand, changing nozzles, building and changing scaffolds, and all the usual delays in work of this character. The interference from other classes of work under way was also a big factor in reducing the efficiency of the cleaning, and it would seem easily possible on an ordinary bridge with no other work in progress to reach an average of 6 to $8 \mathrm{sq}$. $\mathrm{ft}$. per min. In any event, it proved to be the one best way properly and thoroughly to clean an old bridge. Improvements in the apparatus were made by reaming out a tapering entry for the sand in the inner ends of the loose nozzle tips, and by using bent nozzles for reaching surfaces that were difficult for the operator to get at, and for the inside of latticed members.

The carburetor on the machine should also be improved so as not to clog up with damp sand, as it was nearly impossible to keep the sand dry in only damp and foggy weather, while in wet weather work soon had to be practically suspended.

The great variety of conditions on various parts of the structure required the use of twelve different kinds of coatings, each one for a specific purpose, as will be briefly described. They were red lead, white lead and zinc, Tockolith, graphite, Galvanum, cement paint, fireproof paint, turpentine asphaltum, Hermastic enamel, enamel primer, carbolineum, and cement gun coating.

The red lead was $60 \%$ ready mixed, with asbestine and other suspension pigments. This was used for the shop assembling and first coat, but for the field $3 \mathrm{lb}$. of lamp black per bbl. was added to insure further the keeping of the red lead in suspension, to increase the spreading, and to darken it so the silver-gray lead paint would cover more easily. It was intended to use this for all metal fully exposed by the sand-blast as a first or spotting coat, but a study of conditions caused a change to Tockolith, as stated.

The white lead silver-gray color paint was for the finish coat. It was $60 \%$ white lead, $20 \%$ zinc, and $20 \%$ barytes and other pigments. The white lead and the zinc were each increased from 5 to $10 \%$ in the field, so as thoroughly to cover the darker paints.

The Tockolith was substituted for the red lead to cover rust spots after cleaning, as the writer's experience for several years in painting badly rusted metals has shown that this paint absorbs the oxygen from 
rust and stops further rusting. The cutting apart of girders for reinforcing disclosed that where the surfaces had been painted with red lead between cover-plates and angles before shop assembling, all the paint had been practically burned out during riveting. Therefore, Tockolith was used for much of the assembling paint in the field.

The use of Superior graphite was deemed necessary on the bottom of the copper-steel floor to resist drippings from salt water, acids, and gases. One coat was used for this purpose and the second coat was the white lead finish paint. Graphite is undoubtedly one of the few paints that should be used for assembling, so as not to be burnt out in rivet driving. Possibly better results would be had by substituting something, at least in part, for the linseed oil.

The Galvanum was used for painting a few hundred square feet of galvanized corrugated-steel roofing between the girders at the Toll Offices. Ordinary paint could have been used by first washing the galvanizing with a weak muriatic acid solution, or by adding cut shellac to ordinary paint.

The cast-steel bases and boxed-in bases of the viaduct columns were filled with water-proofed concrete, formed with the addition of Medusa compound. To exclude the water further and to match up with the silver-gray coat on the bridge, Acme cement paint was used for painting the exposed surfaces of this concrete.

The use of Acme fireproof paint for the timber floor was investigated by painting some boxes and attempting to burn them. The results were so satisfactory that it has been recommended that the cracks in the roadway and sidewalk floors be sprayed with this paint as soon as the lumber dries out in the spring, in order to prevent fires starting from cigarette and cigar butts.

The elbows and inclined sections of the 4-in. steel-pipe downspouts were painted with turpentine asphaltum as a partial protection from salt water, since it was not possible under the conditions existing to use Hermastic enamel in this location.

The Hermastic enamel was used for coating the copper-steel drainage floor as a protection against the rusting or corrosion of the steel of the railway floor system due to salt water and other drippings. The coppersteel plates were also coated with this where they had a bearing on the maple risers, and in addition the maple was given a coat. The metal was first cleaned, then coated with the enamel primer, and the 
Hermastic enamel applied with special daubers, while the enamel was very hot. Even then it would only spread a distance of 12 to 18 in. Owing principally to the thickness of the plates and the constant breeze or wind down the Gorge, about $50 \%$ excess of the enamel was used and the average thickness was more than $\frac{1}{4}$ in.

Carbolineum was used for all timber treating, and it was generally applied hot with a brush, but the blocks were dipped in the kettles where it was heated. From one-fourth to one-half of coal oil was added to increase the spreading and penetration of the carbolineum. The timbers treated were the spiking strips for the highway floor, the maple risers and blocks for the tie-risers, as well as the stop-waters and other minor timber details.

The coating with cement mortar by the cement gun has been spoken of under the discussion of the skewbacks and only mention of it need be made here. The concrete abutments and walls were simply painted with a cement mortar cream.

\section{Steel Repair Plant.}

The steel construction plant used by the Terry and Tench Company, which did the construction work, was exceptionally complete. The three compressors of about $230 \mathrm{cu}$. ft. per min. capacity of free air, were of the motor-driven type such as has been used on elevated railway work in New York City. The motors are 50 h. p., 250 volts, and the whole equipment for both motor and compressor is mounted on steel wagon trucks. The electric current was obtained from the feed lines of the electric railways on either shore, and so no shut-down of the work was necessary when power was off at one end. They all fed into the same $2 \frac{1}{2}$-in. pipe extending the length of the bridge, and connecting to two air tank reservoirs. Frequent branches and valves were provided for connecting the hose for air drills, riveters, sand-blast machines, and cement gun. The long gun riveters were of the usual type, and the air drills and reamers were of the high-speed type running at 700 rev. per min., with drills and reamers to correspond, so that no diffculty was found in keeping work abreast. There were twelve riveters in use, and fifteen air drills and reamers.

The sand-blast machines were made by the Mott Sand Blast Company, of Brooklyn, N. Y., and as stated were three in number; the No. 1 size consuming $94 \mathrm{ft}$. of free air per min., and holding $500 \mathrm{lb}$. of sand; 
while the No. 2 size consumed $94 \mathrm{ft}$. of free air per min. and held $1000 \mathrm{lb}$. of sand. They consisted of a sand tank filled through a sieve at the top, and discharging through a conical bottom to the carburetor where the compressed air is introduced, all regulated by suitable valves. The discharge hose is of special heavy reinforced rubber, and carries a nozzle which has small hardened cast replaceable tips. These tips were those reamed out conically to allow freer discharge, and special bent nozzles were made to facilitate work which was often somewhat out of reach and partly inaccessible for the ordinary nozzle.

The oxy-acetylene torches for cutting were of the ordinary type, the burners or tips having three holes one above the other. They were used for cutting off old column bases, curving out gussets, cutting up old flange plates, and many other cuts which if made by hand would have taken hours instead of minutes. For cutting off rivet heads, the tips used for ordinary burning were slow and a special tip was used with three holes in line, which cut off an average of about 80 heads per hour and did not weld the shank of the rivets into the holes. No more valuable tool can be found for field repair work, and it can be used for any work where the danger of overheating the steel does not need to be considered.

The material was unloaded by a small "jiniwink" or shear-leg type of boom derrick, operated by an engine using compressed air, and was distributed over the highway deck as far as possible by means of a hook buggy and by several large lumber-yard buggies. Owing to the great height of the work above the Rapids and the necessity for keeping up traffic, double hitches and double slings were used, so that with constant watchfulness not one accident from this source occurred.

\section{Rocis Cliffs.}

The cliffs at each end of the bridge were found to be quite solid when the arch was built to replace the Suspension Bridge in 1896, and therefore they were left with an overhang above a vertical cliff wall of 50 or $60 \mathrm{ft}$. in height. Some rock falls had occurred during the years following, one of which did some damage to the end shoe strut, really a tie, on the Canadian end of the arch. There had been some bad falls up and down the Gorge from the bridge, and as the cliffs were badly weathered, it was decided to remove all the loose rock and overhang which might, in falling, damage the arch span. This removal con- 
sisted in taking off a 12 -ft. overhang under the Canadian 115-ft. span, and an overhanging point directly adjacent to and north of this. The 8-ft. overhang under the 115-ft. span on the American end was also removed. The yardage was not a large total, but the rock had to be broken up into less than one-man stone before casting it over at the Canadian end, and before hoisting at the American end, on account of the electric railway down in the Gorge. The skewbacks and tracks were well protected by plank aprons. The rock was drilled in rows of holes for one cut, using hand air (or plug) drills, and the face finally left was practically smooth and vertical, but all the great superimposed weight was taken off and no future falls are expected.

Should future conditions warrant further protection, it is proposed to construct just above the skewbacks on either side a rock-catching abutment which will catch and retain a large quantity of small rock before a cleaning out would be necessary, and in the case of a large fall, would break its force and prevent its bouncing on to the steelwork. Such a device might be found useful in many similar locations where protection from rock falls is necessary.

\section{Masonry Repairs.}

The repair of existing masonry is usually more troublesome than building new; especially is it difficult to decide on a sure cure for trouble. This is usually due to the impossibility of knowing the condition of the interior of walls or masonry masses, except as its solidity may be learned from borings, and this method of testing is often far from satisfactory. Added to this difficulty, there was at Niagara the old suspension bridge abutments and anchorages in use for the abutments of the railway viaducts. These were built of limestone in 1855, making them 64 years old, and there were no plans in the files from which to determine their thickness and the character of construction.

Fortunately, the writer found at Van Nostrand's one of the original Roebling monographs on the Suspension Bridge, published in England, and in this were plates giving the masonry details. The front walls of the abutments which carried the girder spans were found to be about $9 \mathrm{ft}$. thick at the ground line; and this was later checked up when weep-holes were bored through them with a Burley drill carrying a 5-in. drill bit, in which to insert 4-in. steel drain pipes that 
were also to extend through the new concrete face wall, which is described later.

The old suspension bridge towers, as has already been mentioned, were replaced with steel by Mr. L. L. Buck, and when the stonework was torn out from between the new steel members of the towers, the rock was found to be completely shattered or broken up in the interior. The abutment wall under the girders at the Canadian end was quite shattered from frost and traffic combined, so that it worked under passing trains and was considered to be unsafe. A heavy timber bent was erected to carry the traffic, and the face of the wall barred out to a depth of more than $1 \mathrm{ft}$., or to where it was quite compact under pressure. Forms were then built of 2-in. surfaced lumber and a new concrete face wall or carrying abutment was constructed. The girders were carried on this abutment using new cast-steel shoes, with new stiffeners riveted on the girders above the new support and on the webs between this and the first old pair, to care properly for the shear. The old end of the girder had the bearing-plates removed and now carries the track as a cantilever for the distance from the new bearing to the old back-wall.

The stone pedestals removed from beneath the viaduct columns on account of being cracked were found to be badly shattered, much the same as noted for the old towers and the old abutments. This led to devising a thorough method of protection of the skewback masonry of the arch from weathering, as it had only begun to show the effects of 22 years of exposure to the rigorous climate. The original scheme adopted had been simply to coat the limestone courses below the granite copings with a cement-gun finish, but on the developments in regard to the other masonry, it was decided to armor all four of the skewbacks as shown in Fig. 23, which also shows the thrust wall between them, which is described later.

The armor was shot on with a cement gun, the proportions of the coating being one of cement to one and one-half of clean sharp sand, with an air pressure of $40 \mathrm{lb}$. This coating was about 6 in. thick at the top, and more than $12 \mathrm{in}$. at the bottom of each skewback, as was necessary to get a regular batter line. The coating was reinforced by a triangular wire mesh which had first been fastened closely over the old stonework by spikes driven into the cement joints. This mesh had No. 9 longitudinal wires 4 in. apart and No. $12 \frac{1}{2}$ cross-wires 8 in. apart. 
Just below the old coping a new coping was shot on, reinforced by a bowed-out strip of wire netting. The old coping therefore appears as a pedestal block.

The stone skewbacks were quite high and slender, especially on the American side, and under the most severe assumptions as to stresses from wind on the unloaded bridge, which is exceptionally high and exposed, it was found desirable to carry the directly applied stresses from the new sway bracing down to the solid rock foundation strata. The drilling of any holes through the skewback masonry for efficient tie-rods seemed undesirable, and, therefore, the skewbacks were connected by the thrust-walls shown in Fig. 23. These walls were $4 \mathrm{ft}$. thick, with a plain coping, and arched at the bottom to allow falling rocks and débris to pass through or be cleaned out, so that they would not eventually become retaining walls. Footings were built next to the skewbacks to carry each end of a wall. The reinforcing consisted of sixteen 1-in. deformed bars in diagonal lines from the top of one skewback to the bottom of the other, each bar being placed 6 in. into the masonry at each end in holes drilled with the plug drills. These holes were put into the tops of the high American skewbacks, slanting downward, so as to afford some tension anchorage. Each set of sixteen rods was hooped into a column as shown. The arched bottom was reinforced to act in conjunction with the shear rods, simply to prevent cracks in the wall.

The thrust-walls and the armor coating not only serve perfectly the structural purposes for which they were intended, but as may be seen from Fig. 23, they add much to the appearance of the structure, especially as to solidity and stability. They are also designed to serve as part of the enlarged skewbacks that will eventually be needed to carry additional ribs for a four-track bridge.

\section{Deductions.}

The data given as to increase of locomotive and train loads, supplemented by such other like data as have been published and which can easily be obtained, should be made the basis for negotiations by the Society with the leading railway societies and with locomotive and car builders as to the allowable increases for a reasonable time in the future. This would make it possible to plan more definitely than could otherwise be done for the strength of future bridge construction. The great 
requirements for steel in all classes of work in which iron and steel are utilized makes it certain that from every viewpoint raw supplies for the manufacture of iron and steel structures must be conserved.

The information presented as to the great diversity of possible bridge loadings now in use, and the distribution of stresses occurring in structures as compared to calculated stresses, indicates the great futility of over-refinement. Although the system of composite loading proposed may prove to be no more than tentative, it is certainly to be hoped that it will be made the basis by the Society, and others interested for the adoption of a comprehensive, logical, and simple system. This can certainly be done, and be a credit to that branch of engineering which lays claim to being the most scientific of the many specialties now comprised under the general head of Civil Engineering.

The strain-gauge results obtained, while not perfect, certainly indicate the necessity of making both dead load and live load readings of representative members of all important structures. The gauge points should be permanent, put on the members and read before erection, to the end that the bridge engineer may at any time easily make a check of actual stresses and their distribution, as caused by standard trains. Should such a scheme be instituted by the large railway systems, it would then be possible, with the aid of the United States Bureau of Standards, to obtain extensive and conclusive data as to impact on bridges, as to secondary stresses, as to distribution of stress over the cross-section of members, and, finally, to obtain much valuable data as to the strength of compression members and members undergoing reversal of stress. The needed information to supplement this kind of data on compression members could also be easily obtained if each railway would substitute for full-sized eye-bar tests, the testing of one or two compression members for each important structure. This would probably corroborate recent data from tests that indicate the need of better compression member details, rather than any change in the sections themselves or in their make-up.

The stress readjustment carried out in the Niagara Arch, by using toggles to change the center shim, is seldom possible of attainment in the ordinary structure, but it is not too much to say that there is a logical way possible for the revision of most large structures, and the strain gauge would play no small part in accomplishing the desired result. The great lesson to be learned from this Niagara revision and 
the examples of the first Quebec and the Blackwell's Island Bridges, together with the success obtained for the Hell Gate Arch, is that the real design of a structure does not lie entirely in computing stresses and designing details, but in the greater problem of the most fitting general design for a given location and as a general scientific problem. The writer does not hesitate to repeat a statement often made heretofore, that engineers cannot properly design a bridge unless they have made every effort to give it the proper æsthetic consideration, with the assurance that in so doing they need not violate the principles of scientific design, nor of the truest economy.

The investigation at Niagara emphasizes the need for the engineer of any important structure to leave the most complete data possible in the files of the owners. This should not merely include blue prints and specifications, but copies of all computations, stress sheets, and data as to the construction, and of practical details of the work. Such information is not only of value as relating to the particular bridge, but will result in more exact scientific data being obtained whenever such a bridge is under investigation.

The scientific investigation of the Niagara Arch was made financially possible through the courtesy of George L. Burrows, Assoc. Am. Soc. C. E., President of the Niagara Falls International Bridge Company, and Charles Riordon, President of the Niagara Falls Suspension Bridge Company, joint owners of the bridge. The field and office work was carried out with the assistance, during 1918 and 1919, of C. T. Morris and A. H. Fuller, Members, Am. Soc. C. E. The Resident Engineer on construction was H. A. Reid, Assoc. M. Am. Soc. C. E. ; and acknowledgment is also made for the assistance rendered by F. L. C. Bond, Chief Engineer, and H. B. Stuart, Structural Engineer, of the Grand Trunk Railway, and by P. L. Wolfel, M. Am. Soc. C. E.; also to H. G. Dickinson, Superintendent for the Bridge Companies; and to The Terry and Tench Company and the Lackawanna Bridge Company, contractors for construction and fabrication, respectively. 


\section{I S CUSSIO N}

Mr. Ammann.

O. H. Ammann,* M. Am. Soc. C. E.-The author deserves much credit for the careful and thorough manner in which the revision of the Niagara Bridge has been carried out, as well as for the elaborate experimental investigation conducted in connection therewith. The redesigning and reinforcing of the bridge is in accordance with the most advanced practice and should give the structure an additional useful life equal to that of a new one.

Experimental investigations such as those made on this bridge are most valuable in giving engineers knowledge of the exact stress conditions, and for this purpose cannot be too strongly encouraged nor too painstakingly carried out. The knowledge gained, however, must be applied in a broad sense and above all with a view to the improvement of the excellence of the design rather than to economy by excessive refinement.

Bridge building is still an art, and as such its success depends largely on broad vision and judgment in the combination of the many intricate and changeable elements which enter into the design and which cannot, by themselves, and still less in their combined action, be determined exactly by scientific laws. A liberal margin in the selection of these elements therefore is justified. From this point of view, the speaker takes exception to some of the suggestions for revision in bridge design made by the author.

The author proposes the abandonment of Cooper's engine loading and the substitution therefor of the composite moment and shear curves or tables derived from some of the recent heaviest locomotives.

Although Cooper's loading is not an ideal one for all cases, it covers, probably more than any other loading proposed, the widest variety of engine and train loads. It has become a standard with which other loadings, past and present, are comparable in weight and axle loads, as well as moments and shears produced. Compromise moment and shear curves do not allow as simple and tangible comparison, because they do not represent any particular loading; and what guarantee is there that such curves may not, within a short time, become even less representative of actual loads than Cooper's loading? They at least are not representative of the large number of engine loads which are still prevalent on many roads and which must be taken into consideration in establishing a general representative loading.

Even if only the four extreme actual loadings selected.by the author are taken as a basis, the speaker would consider Cooper's E-66 fairly representative, because the greatest excess of moments and shears from these extreme loads over those from E-66 would not be more than $15 \%$ and this only in very short spans. This is not excessive, con-

* South Amboy, N. J. 
sidering that the moments and shears from the four locomotives differ as much as $40 \%$ among themselves.

Mr. Ammann.

The author's composite moments are in excess of those from the actual loads by amounts up to $30 \%$, not considering the additional $25 \%$ allowed for future increase of the loads; and inasmuch as this excess would affect the great number of small spans, it would not seem to be conducive to good economy.

For spans greater than about $250 \mathrm{ft}$., Cooper's loading appears to give excessive results. It must be considered, however, that the excess is not due so much to the engine loads as it is to the train load behind the engines. This load is more apt to increase in the future than the average weight per foot of the engine. Moreover, in longer spans, an excess in the live load produces a proportionately much smaller excess in the total stresses or sections than in smaller spans.

The speaker, therefore, believes that there is not sufficient ground for the abandonment of Cooper's loading, but that, on the contrary, it will become, even to a wider extent than in the past, the standard loading for designing railroad bridges.

The author introduces a new impact formula based on the train speed. Although in isolated cases it may be justified to design a bridge for limited speed, as was done in the case of the Niagara Arch, it is questionable whether a formula can be established which would be generally applicable, because impact is dependent on many factors other than speed.

In the Niagara Bridge the impact for various speeds was determined from careful readings, and there can be no doubt that the curve thus established is correct and justified a reduction in the impact allowance in redesigning the bridge. For other bridges the curve may be entirely different, mainly because the critical speed causing maximum impact is dependent on the type of bridge, span length, dead weight, and even on the live load itself. Only extensive series of tests would shed further light on this question, and for lack of additional data it is safer to design bridges with full impact allowance.

The author's adoption of high permissible unit stresses of about two-thirds of the elastic limit and his application of them to the combined stresses from all sources, is a step in the right direction. In the speaker's opinion, it would not have been necessary, however, to include the secondary stresses in the maximum stresses, because they are nowhere excessive except in a few members, which, for constructive reasons, have an excess section.

In general, secondary stresses may be assumed to be safely covered by the one-third margin of safety below the elastic limit, provided care has been taken in the design to avoid large secondary stresses. It is safe to say that, by reason of greater rigidity and superior details, 
Mr. bridges designed according to good modern practice and in which Ammann. excessive secondary stresses are avoided, have a greater margin of safety than former bridges in which the secondary stresses were not even investigated.

The author's compression formula is well chosen in view of the experimental data gained during the past few years and, as a simple straight line formula, deserves general adaption in cases where high unit stresses are chosen.

Recent attempts to introduce apparently more refined formulas are not warranted. What engineers need more than an ideal formula is improved practice in designing compression members, so that they will develop the full strength attributed to them.

Mr.

Bentham.

C. Bentham,* EsQ.-The author states that the bridge was constructed of what is termed in the United States as medium steel, and that the rivets are of soft steel; he also mentioned that some of the rivets came loose. This may be due to a number of causes. In bridge construction in England, especially over tidal waters, trouble has been experienced with the rivets in steel bridges, and it has been thought that electrolytic action between the rivets and plates when of different material is intensified by the salt water. In the Forth Bridge, numerous rivets have been replaced because corrosion has occurred between the plate and the head of the rivet. Corrosion of the plates appears to be more intense with those of modern steel than with those of wrought iron. The bottom parts of the tubular supports of the Forth Bridge are rusting away because of waves beating over them.

In answer to the question as to whether the renewal of the girders was on both the railroad decking and the road decking, the author states that only the girders on the railway deck were renewed as the salt water from the refrigerator cars did not get down to the lower deck. One of the photographs shows the bridge with all the track removed and all the girders exposed, and yet the author states that the work continued without interference with traffic, explaining that in a double-track bridge, one track was kept clear while the other was being renewed. The floor-beams, he states, extended across the width of the bridge, and the engineers shored up and took the cover-plates off the floor-beams without interference with traffic.

This point is not quite clear to the speaker because it looks, from the photograph, as if the whole deck had been taken off. In regard to this loading weight, it has been found that many of the earlier English bridges are far too weak, according to the present-day formulas. A number of them have been stiffened, but there is one bridge in particular, constructed by Brunel at Chepstow, about 1840, where it was found that the stress was above the elastic limit of the wrought iron

* Manchester, England. 
used in the construction. That bridge stood for forty years. It has been stiffened, because the weights have been increased; with the loads as calculated, however, it should have broken down many times in those years, but it did not do so. As the weight of the locomotives increased, the speed was reduced to a limit of 10 miles per hour over the bridge. Presumably, this is partly what was done at Niagara before the bridge was stiffened, the speed of the trains being gradually decreased as the train loads were increased.

The critical speed of the average train in relation to any particular bridge is an important factor, because, when ascertained, the members of the bridge may be safely stressed more nearly to their elastic limit if this particular speed can be avoided.

The author has mentioned the greater utilization of the water power of the Rapids, and he is probably aware of what is now being done. The Ontario Hydro-Electric Commissioners are at the present time carrying out a scheme which utilizes the entire head of the water with the exception of that which is necessary for hydraulic flow. The water is being used up to a head of about $300 \mathrm{ft}$., whereas at the existing power stations the head is about $160 \mathrm{ft}$. The benefit of the Rapids below the Falls in addition to the Rapids above the Falls, is being obtained.

J. A. L. WADDELL,* M. AM. Soc. C. E. (by letter).-This paper is 'Mr. one of the most interesting and instructive treatises on bridgework Waddell. that has appeared in a long time. The labor involved in its preparation must have been very great, and the author deserves the hearty thanks of the Engineering Profession in general, and of bridge specialists in particular, for his able efforts on behalf of his brother engineers. The historical features of the paper are specially interesting and valuable, because far too little is either recorded or generally known concerning the history of engineering. Again, the dissertation on live load augmentation is most instructive. The writer agrees with Mr. Fowler that the time for abandoning the Cooper type of loading has arrived, but thinks that curves of equivalent uniform live loads should be given in specifications for design, rather than the irregular concentrated loads. These curves should not follow exactly the equivalents for any particular locomotives, but should envelop on the diagram most of the plotted points for the equivalent uniform loads of a number of modern or possible future engines. In predictions concerning future live loads, it must not be forgotten that for the roadbed the present style of track is loaded about all it will stand, so that any seriously greater burden will have to be distributed in some more uniform manner than is attainable by the arrangement of rails and ties used generally in America. 
Mr. In pointing out "the need of better compression member details, Waddell. rather than any change in the sections themselves or in their make-up", Mr. Fowler has struck the keynote in reference to the proportioning of struts, concerning which there has been so much discussion of late; and it is evident that, like the writer, he does not see any real raison d'être for the panic about the alleged weakness of the old standard compression formulas initiated by the Society's Special Committee on Steel Columns and Struts in its final report.*

The writer is in accord with the author also when the latter says that "the real design of a structure does not lie entirely in computing stresses and designing details, but in the greater problem of the most fitting general design for a given location", and also when he states that a proper consideration of æsthetics will not violate the principles of scientific design nor those of the truest economy.

Bridge designers in general, and especially young men who are studying the specialty, will do well to hearken to these words of wisdom from one who, by years of experience in designing and construction, deep study of theory and principles, and the writing of standard works, has established himself as one of the highest authorities in bridgework.

Mr. Theodore Belzner, $\nmid$ Assoc. Am. Soc. C. E. (by letter).-The Belzner. author is to be congratulated in presenting to the Engineering Profession, and to the members of this Society in particular, such an interesting and important paper.

In reference to the comparative readings to determine the respective accuracy of the Berry, Howard, and Fuller-West strain gauges, it would be of interest to the writer to know the relative accuracy of the Howard gauge for static load readings, as compared with the other two instruments.

During the strengthening of the end spans of the Williamsburg Bridge some years ago, the Department of Bridges of the City of New York, in co-operation with the United States Bureau of Standards, under the auspices of James E. Howard, Engineer Physicist, conducted a comprehensive series of extensometer investigations on the important truss members at the main towers of that bridge and on the legs of the Brooklyn intermediate towers.

The writer had the good fortune of being assigned to these investigations by the late Austin Lord Bowman, M. Am. Soc. C. E., then Chief Engineer of the Department of Bridges. He also had the pleasure of being associated with Mr. Howard from the beginning to the completion of this work, and became thoroughly grounded in the importance of precision in such work in order to secure the best results.

* See p. 1583.

$\dagger$ Brooklyn, N. Y. 
A 20-in. Howard extensometer was used throughout the entire Mr. investigation, and the precision attainable with the strain gauge and its reliability in measuring stresses proved it to be an invaluable aid to the Bureau of Design of the Bridge Department in arriving at the conclusions on which the successful issue of the work was based. Its merits were illustrated in certain vital operations, especially in connection with the various stages of the wedging operation, and in the transferring of stresses from the old to the new diagonal members of the end trusses. The accuracy of these results has been discussed by Isidore Delson,* Assoc. M. Am. C. E., Assistant Engineer, Department of Bridges.

D. B. Steinman, M. Am. Soc. C. E., in his exceedingly valuable paper entitled, "Stress Measurements on the Hell Gate Arch Bridge", $\uparrow$ has described the Howard strain gauge so fully, the methods of its operation, and the precaution required in its use for precise work, that little can be added, except, possibly, a few references to methods of making the measurements. After the preliminary work on the members to be measured, the most important point to be considered is in obtaining consistent measurements, and this point cannot be emphasized too strongly. In order to secure such results, which are absolutely essential, persistent patience and painstaking thoroughness, combined with good judgment on the part of the observer, are required until he gains perfect control of the instrument, after which he will experience little or no difficulty; and it is upon the observer that the value of such measurements will depend.

Another fact to be remembered is that all measurements should be taken during the early morning hours, preferably before sunrise in summer, and on cloudy days, in order to eliminate any possible internal temperature strains in the members.

The writer's experience with the operation of the Howard extensometer, extending over a long period of measurements, has been that the use of the inside milled head is preferable, on account of the sensitiveness of touch for contact, and he agrees with Dr. Steinmant that it "is probably the simplest and most accurate field instrument for measuring strains."

It may be of interest to state that, in September, 1913, during the stress investigations on the Williamsburg Bridge, Mr. Howard tried out, on the stiffening trusses, a new strain gauge which he had designed for measuring live load stresses. This instrument is about $3 \mathrm{in.} \mathrm{long}$ and $1 \frac{1}{4} \mathrm{in}$. wide, and might be properly termed a "scissors-gauge". This gauge has been fully described in an article entitled "A New Strain Gauge for Live Load Stresses".§

* Transactions, Am. Soc. C. E., Vol. LXXXII (1918), p. 1087.

$\dagger$ Transactions, Am. Soc. C. E., Vol. LXXXII (1918), p. 1040.

¥ Transactions, Am. Soc. C. E., Vol. LXXXII (1918), p. 1051.

$\S$ Engineering News, October 9th, 1913, p. 701. 
Mr. F. E. Schmitr,* M. Aм. Soc. C. E. (by letter).-As the first schmitt. instance of large-scale bridge reinforcement on the basis of thorough analysis by measurement of stresses, the work described by Mr. Fowler is not only notable in itself, but also presents a valuable model for future work in this field. The revision was greatly simplified by the excess of strength originally provided in the arch rib, which made it unnecessary to add material to the arch members. Nevertheless, the impressive fact is made known by the author's account that the operations described extend the life of the Niagara Railway Arch indefinitely, without impairment of efficiency in the utilization of its material. This is a new achievement, and one of great importance. It is particularly noteworthy because it is based on investigations which are truly scientific, including separate studies of condition and behavior of structure, nature of service, and capacity of material. Since these studies were essential to the results, it is fair to assume that similar investigations, at least for service stresses, will be found necessary in future cases of reinforcement of steel structures, if the results are to measure up to the possibilities.

The reinforcement of large bridges has been undertaken but rarely. In large part this must be charged to the fact that bridge practice progressed continuously, and that when a bridge was outgrown by the traffic loads it was almost necessarily replaced by a new one of better type. In the railway bridge field, conditions have changed sufficiently to eliminate this necessity, so far as structures of recent date are concerned. As bridges are built to-day, they may be considered virtually proof against "wearing out" or obsolescence of like character. Change in amount and kind of loading is the chief future contingency, and this may be dealt with by reinforcement. Therefore, less bridge replacement and more reinforcement work would appear to be in order for the future.

Bearing directly on this question is the remarkable demonstration of the longevity of well-built and well-maintained steel bridges afforded by the Niagara Arch. After having done service for more than twenty years, the bridge proves to have been essentially free from deterioration in its primary parts. Steel bridges have been regarded as inherently short-lived, but the Niagara example makes this view untenable. It shows that steel bridges may be made permanent structures, the original investment in which is a fixed asset. To realize permanence it is necessary, however, that the designer exercise sufficient foresight to guard against destruction of service value by obsolescence, that maintenance be attended to, and that a high degree of thought and skill be applied to reinforcement (when this is called for), perhaps 
even greater skill than is ordinarily applied to bridge construction and $\underset{\text { Schmitt. }}{\mathrm{Mr}}$. replacement.

In connection with the first of these requirements, it is pertinent to remark that, since designing for indefinite future increase of loading is usually impossible, attention at the time of original design to the likelihood of future reinforcement should be worth while. It is safe to say that few if any bridges have been planned with this point in mind, but there is no reason why the design should not be worked out so as to simplify reinforcement at a later period. An incidental advantage would be gained, which is by no means negligible: When the planning of a bridge is guided by the purpose of producing a permanent structure and providing in advance for future operations to adapt it to changed service, a design of far higher character will result than when the controlling thought is that the structure will have only a moderate life, on account of deterioration or change of service requirements.

To make reinforcement ideally efficient, both old and new materials must be utilized to full capacity. Something has been done in developing methods to secure this object. The remarkably well conceived crown-shim readjustment to distribute the dead load stresses of the arch more favorably, and the toggle device used in reinforcing the posts of the Niagara truss spans, as well as the successful use at Poughkeepsie of heating in attaching reinforcing plates, fall in this category, and deserve high appreciation on the score of simplicity and effectiveness. However, there can hardly be a doubt that methods to accomplish equal division of service between old and new material will be developed much more extensively in the future than in the past. In work so variable and so dependent on the engineer's resourcefulness as bridge reinforcement, it seems to be inevitable that a much broader range of available methods must be worked out to meet the many complex sets of conditions arising in practice. It may be expected therefore that with the expansion of reinforcement work the development of the structural art will enter on a new phase.

As the first step in reinforcement work, or even in the preliminaries leading up to a decision on the question of replacement or reinforcement, is the determination of actual effects of service, the relation between calculation and measurement of stresses calls for consideration. In the writer's opinion there is usually enough uncertainty about the distribution of stress in a structure, particularly in one that has been long in service, to make strain-gauge measurements indispensable to a satisfactorily thorough knowledge of service effects. Relatively few comparisons of calculated and measured stresses have been made, from 
Mr. which a good judgment of the relation between them could be formed; but these indicate that even with respect to primary stresses the check is only approximate, especially under moving loads, while stress variations over the cross-sections of members, and numerous other auxiliary effects, create very serious divergences between measurement and calculation. In considering questions of reinforcement, the measured stresses will naturally be accorded determinative weight, and calculation will be regarded only as a check. It is thus possible by means of measurement to adapt the distribution of material in a structure much more closely to the actual stresses developed in service than is possible in constructing a new bridge, a point worth special consideration as suggesting that a distinctly higher efficiency can be reached in reconstructing an existing bridge than in building a new one.

With regard to the use of strain gauges for the measurement of live load stresses, the fact is not very prominently dwelt on by the author that even in a constrained structure, such as the Niagara Arch, these stresses are as definitely calculable as in simple structures, except for two factors: The influence of details and possible looseness at a support. The latter can be determined and evaluated by inspection; the influence of details, on the other hand, is likely to be difficult to estimate, because of the lack of suitable data. Deflection observations on bridges of either simple or constrained type would supply such data, but observations of this kind are rare.

Apart from the question of influence of details, the primary live load stresses in the Niagara Arch should have been determinable as accurately by computation as in any type of bridge. The results of the measurements and comparisons make it clear, however, that secondary and impact effects are of such magnitude as to give them an importance from the designer's viewpoint equal to that of the primary stresses; and very obviously, according to the results, these secondary and impact effects must be measured by the strain gauge rather than be approximated by rule-of-thumb formulas which were framed to provide allowances suitable in new design.

Dead load stresses appear not to have been a matter of much concern in the Niagara case. It is to be considered, however, that where such service is placed on metal as in the revised Niagara Arch, in other words, where a high efficiency of utilization of material is aimed at, the dead load stresses should be known quite accurately. The crown jacking which was done to give a datum point for the calculation of dead load stresses supplied no further information than that it removed the statical uncertainty due to constraint. It did not give fuller knowledge of actual dead load stresses than is available in the case of a simple structure without any measurement whatever. It is of some interest to speculate on what methods might have been used, and at 
what cost, to make direct measurements of the dead load stresses existing in one or two important members. The writer, however, believes the case is most valuable in again directing attention to the proposal made some years ago by $\mathrm{Mr}$. James E. Howard, that gauge points for measuring stress deformations be provided on the members of important structures before erection. When such points are placed, in permanent fashion, and initial measurements are made, stresses can be measured in a reliable manner at any time during the life of the structure. The measurements made by Mr. Howard on the Armour-SwiftBurlington Bridge, at Kansas City, and on one or two other bridges, besides several buildings, constitute a thoroughly practical demonstration of what may be done in this direction. The importance of his suggestion and its practical demonstration do not seem to have been fully appreciated. Renewed reference to Mr. Howard's work is believed to be justified by the fact that, in so important an undertaking as the Niagara revision, a distinct uncertainty surrounds the dead load stresses which constitute a very respectable proportion of the total stresses and hence of the utilized strength of the members.

With regard to the whole subject of the permanence of bridges, the facts brought out in the paper as to the condition of the floor-beam flanges and the stringers are highly significant. The figures given as to deterioration of the floor are in alarming contrast to the statements as to the excellent condition of the primary members of the bridge. Although it is true that floor material usually can be renewed without great difficulty, yet the rapid loss of strength due to corrosion would make it seem a desirable safeguard and economy to attempt to provide better protection for floors than is given by the ordinary undrained, opentie, floor construction which is virtually standard in railway bridge practice. The Niagara drip-plate protection is an ingenious and praiseworthy solution of the problem encountered there, but its value for general use is likely to depend on the maintenance which it requires. Experience with these drainage plates will need to be awaited as to this point. Although the last report of field tests of the Committee on Corrosion of the American Society for Testing Materials, made public after the presentation of the author's paper, indicates that copper-bearing steel is distinctly more resistant to corrosion than noncopper-bearing steel, yet the differences are not large enough to make the plates give promise of anything beyond a very short life. However, in spite of the use of thin steel plates in a substantially horizontal position, and wooden packing blocks which are also likely to be subject to rapid deterioration, the arrangement adopted has the great advantage of protecting thoroughly all the carrying parts of the structure and concentrating the deterioration in easily renewable parts, where ordinary maintenance can take care of them and continue the protection of the structure unimpaired. 
Mr. Besides bringing to the front important matters concerning bridge reconstruction, however, the paper raises numerous open questions and doubtful points in bridge design. Among these are railway loadings, impact effects, permissible unit stresses, the importance of secondary stresses, the suppression of vibration, etc. The vital way in which these points were involved in the Niagara work seems likely to open up anew a discussion on various phases of bridge construction, which by many have been regarded as practically settled. It is hoped, therefore, that full discussion of the matters in question will develop, and that the experience and opinions of practical bridge engineers may be brought out in a representative way. Although the paper gives only a small range of data on some of the matters concerned and most of these data are of quite inconclusive character, the method of attack used was effective and satisfactory, and (since sound and serviceable results were obtained) the data given in so far as they bear on bridge design are entitled to careful consideration.

The wide departure of the procedure followed in the Niagara work from that prescribed in standard bridge specifications suggests that a committee of this Society on bridge specifications, as recently proposed, would find ample work to do. One point with which such a committee might have to concern itself is unfortunately passed over in the paper without discussion, namely, the treatment of reversed stresses. In consequence, it is not very easy to determine the relative margins of safety in the main chord members and the web of the structure. According to the prevailing design practice of to-day, members subject to stress reversal are proportioned with increased section and still further increased connections, but there appears to be no agreement as to whether this is done because stress reversal has an injurious effect on the metal or its connections, or whether it is a contingency allowance for change in loading (in view of the fact that increased loading has most unfavorable effect on these particular members). The writer knows of no data from test or service observations to support the view that stress reversal, such as occurs in bridges, has any effect on the metal aside from that measured by the maximum stress. If reversed stress clauses are really intended to provide for load increase, this purpose might be expressed more properly in the wording of the clause. In any event, reversed stresses are not likely to have the same meaning in reconstruction as in new design.

Two points bearing on design requirements will be commented on here, namely, reduction of vibration and the selection of a loading system for design.

So far as the paper gives information, it is not possible to judge whether the reported virtual elimination of sway and vibration by putting in rigid bracing between the arch posts was due to the increased section of bracing thereby provided, or to the fact that the new brac- 
ing is of the rigid type. Conceding that prejudice against light rod $\mathrm{Mr}$. bracing is well founded, one may fairly ask if any data exist to show ${ }^{\circ}$ whether rod bracing of more ample proportion, well detailed, and properly adjusted, may not make a structure fully as rigid as stiff bracing. On this matter of rigidity, existing specifications fail to give any useful advice. Some guidance seems desirable, however, for there is a wide interval between the extremely light sway rods of former days and the surprisingly massive bracing found in many modern bridges. The best practice may lie between these extremes. Further, considering rigid bracing, it is proper to take note of the lateral secondary stresses which it induces in the main members; the effect of these secondaries is beneficial in only a very minor degree, and, on the other hand, may be distinctly harmful, particularly in tension members.

Whether or not the adjustment of the sway rods by the strain-gauge check carried out in 1918 was of service in stiffening the bridge, is not explicitly stated by the author, but it may be inferred that some decrease of side sway was thought to have resulted. Was the author able to form any specific opinion on the degree of initial stressing and the ratio between the sway-rod section and the main section, which will tend to assure that the bracing will be taut and the structure rigid under all service conditions? Also, in dealing with the old rod sways between the long posts, did he observe anything that would tend to show whether ordinary loop ends are too yielding for efficient service of sway rods fitted with such ends?

Commenting on the author's recommendation of a composite load system, selected to correspond to the maximum of various modern traffic loads, O. H. Ammann, M. Am. Soc. C. E., dissented from the view that Cooper's system of loading should be discarded, and referred to the moment curve in Fig. 4, as demonstrating the satisfactory character of the Cooper loadings. This diagram shows clearly, however, that the old system has a marked deficiency when applied to moderate span lengths, and an even more marked excess when applied to long spans. Practical considerations would counsel an opposite relation. In any event, it is plain from the diagram that maximum present-day traffic is not represented by any one Cooper loading for all spans. To produce a bridge of uniform strength under modern traffic, it is necessary to design the floor for one Cooper loading, the chords for another, and the web members for one or more other loadings; and in the case of a multi-span bridge, different spans must be designed for different sets of Cooper loadings. Thus, the Cooper class name is no longer a designating index number of the capacity of a bridge; calling a bridge an E-55 structure does not mean that it is adequate to carry a certain class of modern traffic. This is a practical disadvantage the importance of which the bridge engineer is more apt to underrate than the bridge user. 
Mr.

A load system more in accord with present-day railway practice

Schmitt: would avoid this disadvantage. It is not wholly clear, however, that the substitution of another system which also requires a group of loadings to represent a single weight of traffic, as proposed by the author, would be an improvement. It should be possible to discover a suitable single loading, whether of the wheel load or of the uniform-load type; such a system should have more regard for probable future development in load distribution than for present-day loading.

Before a load system is finally formulated, it might be proper to take note of what was shown by the earliest work* of the Special Committee on Stresses in Railroad Track, namely, that the weight of a group of concentrations on an ordinary roadbed is distributed to such an extent that the effect of the individual wheels virtually disappears. It may be that a similar distribution of load effect occurs when the track is supported by a bridge floor, and some of the author's statements indeed suggest this fact. In that event, the problem of representing train effect by a conventionalized loading system would be much simplified.

In regard to the behavior of bridges, it is necessary to take careful note of one surprising fact reported by the author: That after the readjustment of the dead load stress in the arch at the crown, the completion of the readjustment after the change of shims occurred very gradually. It would appear from this observation that even in a bridge of fully elastic type, inelastic elements have an unexpectedly large influence. Without knowing more about the circumstances than is reported in the paper, one can only judge that the floor stringers, and, perhaps, in some small degree, the rails, were responsible for the lag in adjustment. In any structure likely to be affected by similar inelastic lag, it would evidently be necessary to take particular precautions in conducting a deflection test, in order to obtain a true reading of elastic deflection.

Taken as a whole, the facts developed in Mr. Fowler's investigation, and throughout the subsequent revision of the structure, constitute a most gratifying testimonial to the excellence of the design embodied in the original bridge. It does not seem to be extravagant to say that the design was a generation ahead of its time.

Mr. P. G. Lang, Jr., $\nmid$ Assoc. M. Am. Soc. C. E. (by letter).-The author states that "the logical procedure for new bridges, however, seems to be to abandon the Cooper loading entirely."

The use of the Cooper loadings has been the subject of much discussion. The engines shown in Columns 1, 2, 3, and 4 of Table 1 cover moments for engines of the Mallet and Santa Fé types only. If a careful study is made of all the various types of engines in use on the railroads to-day, and these engines are compared with the

* Transactions, Am. Soc. C. E., Vol. LXXXII (1918), p. 1191.

$\dagger$ Baltimore, Md. 
Cooper series of loadings, the fact will become apparent that the $\mathrm{Mr}$. Cooper loadings reflect the composite of all types of engines for all ${ }^{\text {Lang. }}$ span lengths more nearly than any other typical loading which may be used. This matter has been very fully discussed in a paper* written by Mr. W. S. Bouton and H. T. Welty, M. Am. Soc. C. E.

In regard to the new railway floor, the statement is made that plates and angles, originally from $\frac{3}{8}$ to $\frac{1}{2}$ in. thick, were wasted away on an average of $50 \%$, and that, in extreme cases, only a thickness of from $\frac{1}{8}$ to $\frac{1}{16}$ in. remains.

The writer's wide experience in the inspection and observation of old bridges inclines him to the belief that this statement, in the form published, conveys an impression at variance with that intended by the author. It appears to be improbable that a plate $\frac{3}{8}$ in. thick would be reduced, by corrosion, to a thickness of $\frac{1}{16}$ in. The writer's observation of such cases has practically always indicated that plates and angles corrode when placed in a horizontal plane, and that the corrosion begins at the edge. In the case of the horizontal leg of an angle, for example, the edge may be corroded to a thickness of $\frac{1}{16}$ in., but, at the root, the original thickness is obtained.

In regard to the highway floor, data concerning the axle loads and wheel spacing of the 15-ton motor truck used in the design would be a matter of much interest. For a bridge of this character, on an international highway, a 15-ton motor truck is, it would seem, not an excessive live load to use in designing the floor.

In a bridge carrying both railroad and highway traffic, it appears somèwhat inconsistent to design the roadway floor for a 15-ton motor truck and the railroad structure capable of carrying Cooper's E-80 loading. That is, in the design of the highway structure, the margin of increase over actual current requirements appears small when compared with the greater allowance made in the case of the railroad bridge. It may be, however, that the highway floor has an ultimate capacity considerably in excess of a 15 -ton motor truck. In this connection, it would be interesting to know the maximum load which may be passed over the highway floor.

James E. Howard, $\uparrow$ EsQ. (by letter).-It is gratifying to have another example presented of the use of the strain gauge on so important a piece of work as the Niagara Railway Arch Bridge, conducted in so satisfactory a manner. It has seemed that the Engineering Profession at large has not adequately realized the practical advantages which the use of the strain gauge affords. In the hands of those skilled in the making of refined measurements, and applied generously to

* Appendix D, Bulletin No. 223, Am. Ry. Eng. Assoc.

$\dagger$ Washington, D. C. 
Mr. ellgineering works of magnitude, no errors of computation, fabrication, Howard. erection, or subsequent use could reasoubly escape detection.

Reference marks established on permanent structures can be reexamined; exact information on the distribution of stresses in the primitive loading of the structures and on their subsequent endurance of dead loads can be obtained; the re-distribution of stresses after repeated live loads have been received can be ascertained; and modifications in built-up members resulting from exposure to thermal changes, if such occur, can be determined.

It is a refined method of examination. The strain gauge as an instrument is a simple one, its adaptability of wide degree. The manipulative skill requisite to obtain reliable results is not in the possession of all. Fully realizing the care which must be exercised in its use, the strain gauge which bears the name of the writer was devised with the view of minimizing personal and instrumental errors. It has so chanced, however, that certain details of design which were carefully avoided have been used in other gauges where they appear to be held in esteem, as constituting the meritorious features of the modifications.

It is believed to be desirable to use a rectilinear movement in an instrument of this kind, and this was provided in the present form of gauge designed for field use, but which is merely a modification of an extensometer designed by the writer and first used some thirty-five years ago. The prototype of the present instrument is still being used for strain-gauge purposes, and is adapted for any gauged length between $1 \mathrm{in}$. and $30 \mathrm{in}$. The usual range for a 20 -in. strain gauge is $\frac{1}{2}$ in. with zero line at mid-stroke. The readings of a rectilinear instrument are reliable at all parts of its stroke, which is limited only by the capacity of the micrometer screw used, which if desired may have a range of $1 \mathrm{in}$. or more.

On measured strains in steel members, a limited range only in ' capacity of the gauge is essential. On other classes of strain-gauge work, $\frac{1}{2}$-in. capacity has not been found to be too great.

On horizontal surfaces the gauge is self-centering. On other surfaces it must be firmly held against the measured member and micrometer readings taken by a second party. The pressure applied in so doing should be directly over the contact points. If so applied, there will be no springing of the parts of the gauge. Overhanging handles were not considered in designing the instrument.

In respect to the choice of material, steel was used. Its advantages are a high modulus of elasticity and high elastic limit. Some authorities give high nickel alloys - 35 to $38 \%$ nickel-an elastic limit above 60000 lb. per sq. in. The writer's tests on a $30 \%$ nickel alloy showed 
an elastic limit of less than $20000 \mathrm{lb}$. per sq. in., with a modulus of Mr. elasticity about 7000000 lower than that of steel.

Howard.

The strain gauge is a transfer instrument. Hence, its coefficient of expansion is a negligible matter provided changes in length do not occur with rapidity. No more than 5 sec. need elapse between readings on the measured member and on the standard bar, to which all readings are referred. Within this interval of time the change in length of the strain gauge is not a sensible amount.

A standard bar of annealed steel, with planed.surfaces, is used. Forged and rolled shapes commonly retain internal strains of considerable magnitude. They may be nearly coincident in value with the elastic limit of the metal, in which case the shape of the bar is not as stable as desired.

The preparation of the drilled and reamed holes used to define the extremities of the gauged lengths on the measured members is conducted in the manner described in "Notes on the Construction of Ordnance," April, 1887. Strain-gauge measurements made at that early date demonstrated their possibilities as an accurate method of investigation. The results were checked on work, published in June, 1886, having reference to changes in diameters at different depths in the walls of a thick hollow cylinder, in comparison with a mathematical analysis of the expected strains, a rigid check on experimental work which the strain gauge successfully met.

Clyde T. Morris,* M. Am. Soc. C. E. (by letter).-In connection Mr. with the work which Mr. Fowler has described in this paper, there are several points which stand out as notable advances in structural engineering:

1st.-The determination of the existing dead load stress in a redundant member (the center top chord in this case) of a statically indeterminate structure, thus determining the true dead load stresses in all the members.

2d.-The re-distribution of the dead load stresses in the entire structure to help equalize the unit stresses, by changing the length of the redundant member and thus changing its dead load stress.

3d.-The adjustment, to a uniform initial stress, of the rod bracing by the use of the strain gauge.

The use of the strain gauge in measuring live load stresses in structures is not new, and its adaptation to the revision of this structure has been fully described by Mr. Fowler. There is no doubt that many bridges in use to-day, which are overloaded, could be reinforced so as to give service for many years to come, at a cost of but a fraction of the amount required for a new structure, if proper stress investigations were made and revisions worked out. 
Mr. A little more detailed description of the application of some of the Morris, strain-gauge measurements may not be out of place here.

Sway-Rod Adjustment.-The adjustment of the sway and lateral rods is an operation which is necessary every few years in all structures with adjustable bracing, and the results by the use of the strain gauge are so much more reliable than judgment by sounding with a hammer, that it should always be used in important structures.

In the preparation of the gauge holes for this work the extreme care used in the other parts of the structure was not found necessary, due to the fact that the whole operation for one pair of diagonals would be completed by one observer, with a single instrument, within a period of perhaps an hour. For the same reason no temperature corrections were made.

The gauge holes were made with a center punch ground to a slightly sharper angle than the points of the strain gauge. After a little experience these were found to be quite satisfactory for temporary use.

After the gauge holes were prepared, a set of initial readings would be taken on the two diagonals of a panel and then the turnbuckles slacked off until there was no stress in the rods. This could be determined by observing when the point was reached where further slackening produced no further change in the gauge reading. This reading was taken as a zero reading and then the turnbuckles were tightened until the desired reading on the gauge was obtained. A 20-in. Berry gauge was used. The tension put in the rods was about $7000 \mathrm{lb}$. per sq. in. In tightening up the rods care was used to draw up both diagonals evenly so that the symmetry of the panel would be preserved.

The adjustment of the ninety-six sway rods occupied about four days. The writer took two bridge men with him to operate the turnbuckles. No staging was found to be necessary.

Floor-Beam Stresses.-Stress measurements were made with an 8-in. gauge, on both flanges of a floor-beam, at a number of points from the center out, and also on the curved brackets at the ends, and down the posts, to determine the variation in unit stress. Readings were also taken on the post below the highway deck to determine what effect would be carried down from the bending of the railway floorheams. The results for the post $\mathrm{U}_{2} \mathrm{~L}_{2}$ are given in Table 4 , and show that below the highway floor, the unit stresses at Corners 1 and 2 are equal and those at Corners 3 and 4 agree within one division of the gauge. This proves that there was little or no transverse bending carried below the highway floor-beams. It was decided therefore that the reinforcement of the railway floor-beams and vertical posts could be determined by calculating the stresses due to floor-beam bending in the quadrangle frame formed by the two posts, the railway floor-beam, and the highway floor-beam. The variation in the measured unit stresses, 
and those calculated by this method agreed very well. The measured Mr. unit stresses at the tops of posts $\mathrm{U}_{2} \mathrm{~L}_{2}$ and $\mathrm{U}_{6} \mathrm{~L}_{6}$ are shown in the Morris. diagrams of Fig. 6.

The reinforcement of the floor-beams on the 115-ft. approach spans was also figured in this manner, although it is probable that the kneebraces there do not have as much stiffening effect on the floor-beams as the very heavy curved brackets of the main arch span.

Almon H. Fuller,* M. AM. Soc. C. E. (by letter).-The writer Mr. has found much of interest in the Niagara Arch revision itself, but that interest has been greater, due to the fact that he went through the fundamental stress work as a thesis at Cornell University in 1898, just after the original structure was completed. He was told by the college authorities that very few structures of that nature had been rigidly analyzed and that the applications of the available theories were not generally understood. R. S. Buck, M. Am. Soc. C. E., makes the statement that the sections used were means between those given by theory and those required for a three-hinged arch; the statement is repeated in different words by the late L. L. Buck, M. Am. Soc. C. E. The computations in the writer's thesis brought out the fact (now generally recognized) that the successive approximations in stress work and design tend to distribute the material from the upper chords and web members to the lower chords.

The situation in regard to the original design of the Niagara Railway Arch is that an excess of material was put into the upper chords and web members due to too few approximations in the stress work and that the light bottom chords of the original design were detected by the "eternal fitness of things" and increased as stated. The designers "builded better than they knew", as has already been stated by the author, and the structure contained more material than was needed to satisfy the specifications. This is one of the principal reasons why it was possible to increase the present capacity so readily, and, at the same time, it is the reason why such a close scientific study was justified and demanded. These facts were known by the writer and by the author before the revision was made, but it was not known in advance how the excess material was distributed. The determination of this distribution and the re-arrangement of stresses to meet it by means of the toggle adjustment were early recognized by the author and became leading features of scientific interest.

The author's suggestions in regard to wheel loads and column formulas are interesting and valuable. Previous discussion makes it evident that many able supporters will be found for both and just as evident that neither will be adopted without a struggle. Is it not per-

- Ames, Iowa.

† Transactions, Am. Soc. C. E., Vol. XL (1898), p. 137.

$\ddagger$ Transactions, Am. Soc. C. E., Vol. XL (1898), p. 160 . 
Mr. tinent to suggest, therefore, that the discussion makes it evident that

Fuller. both are live issues and that the interests of the profession will justify the appointment, by this Society, of special committees to consider them? It is gratifying to note that Mr. Schmitt's discussion also suggests committee action on the entire subject of bridge specifications.

In this connection, it is interesting to note Mr. Ammann's reference to secondary stresses. Very few men are as well qualified by ability and accomplishments as Mr. Ammann, to discuss this perplexing subject. It seems surprising, therefore, to have him take the position that secondary stresses should be included only in the general factor of safety. Designers in general do not have the insight that Mr. Ammann does into the intensity and distribution of secondary stresses. Even if they did, it would certainly be more scientific and more practical as well, as experience is multiplied, to reduce the element of ignorance in the factor of safety and not only have the assurance that the higher unit stresses urged by the author may safely be used, but the added assurance that the material would be more logically distributed.

Mr. Belzner's inquiry concerning the respective accuracy of the Berry, Howard, and Fuller-West strain gauges is a reminder of $\mathrm{Mr}$. Fowler's request to the writer to present the conclusions from the Niagara work and the subsequent comparison made at Lafayette College. The new instrument which Mr. Fowler has called the F'ullerWest gauge, was developed in the shop of the Civil Engineering Department at Lafayette College, as a result of the Niagara work and the discovery of the "Last Word" dial. Such a large proportion of the development, as well as the excellent workmanship, was contributed by Mr. M. L. West, Mechanician for the Department, that the writer has designated it by the simpler and, he thinks, the more appropriate name of the West strain gauge. In speaking of the Howard instrument, Mr. Belzner says:

"In order to secure such results, which are absolutely essential, persistent patience and painstaking thoroughness, combined with good judgment on the part of the observer, are required until he gains perfect control of the instrument, after which he will experience little or no difficulty; and it is upon the observer that the value of such measurements will depend."

This also applies to both of the others, but apparently to a somewhat lesser degree. In other words, the limited experience of the writer in the use of the Howard gauge suggests that greater care in manipulation is required for the same precision than with either of the other instruments and that less speed is probable. He believes, therefore, that most observers would secure results of greater value in a given time with either of the other instruments. The writer prefers the Berry gauge for some work and the West gauge for other. In general, he, and the students he has broken in, will get results of 
apparently the same precision in a shorter time with the West gauge; $\mathrm{Mr}$. but no doubt those observations have been obscured somewhat by local prejudices. He feels, however, an added security in the work when one is used as a check against the other, and would feel just a little safer with both of them on an important piece of work.

The indication, mentioned on page 1938, that the stress in tension members was greatest toward the center, was also noticed in a thesis investigation made under the direction of the writer by four seniors (Messrs. R. S. Gutelius, F. H. Krick, R. H. Moyer, and J. J. Waters), at Lafayette College in the spring of 1920 . The bridge, in this investigation, was a multiple-span, double-track, riveted structure which had just been completed over the Delaware River between Easton, $\mathrm{Pa}$, and Phillipsburg, N. J., by the Central Railway of New Jersey. The data are insufficient, of course, to conclude that these peculiarities in distribution always exist, but they suggest that they may be present and that attention might well be given to such detailing as will insure a more even distribution.

The thesis on the bridge mentioned also brings out the double secondary stresses, as illustrated for the Niagara Arch, on page 1936, but the variation is much smaller; in other words, the distribution is more nearly uniform. Does it not seem probable that the approach to uniformity of distribution in the newer structure is influenced favorably by the exceptionally rigid sway and lateral bracing? The values given on page 1936 for the fiber stresses in each plane at Niagara are evidently the averages of two values. It is apparent, therefore, that greater stresses exist on single corners, and it would be interesting, and, perhaps, valuable, to have them given.

The writer regrets that it has been impracticable for him to make the close study of Mr. Fowler's paper and his own notes which he had intended. As he gets further away from field and office work, the possibilities seem to grow, and he feels that the data gathered at Niagara have values even beyond those which have been brought out, and that they comprise a storehouse which may be drawn on as need develops for that particular kind of information.

Charles Evan Fowler, M. Am. Soc. C. E. (by letter).-The Mr. writer has been much surprised to find how little use, comparatively, Fowler. has been made of the strain gauge in bridge examination and revision. This is no doubt due to the facts that recent instruments of comparative simplicity have not been extensively tried out in practical work, and that the methods to be followed in order to cbtain results are not understood to be only common-sense ones after all. One recent report on the strain-gauge measurements of a structure calls attention to the inaccuracy of readings due to rusting of the gauge 
Mr, holes, whereas the simple expedient of greasing them would have Fowler. obviated the trouble.

The use of a mirror instrument is not necessary for the required practical accuracy, provided the observer has the necessary experience, backed up by the proper personality for careful and painstaking work. Although it is much easier for the engineer to tell the owner that his bridge is worn out or has been outgrown by the traffic, often he has no excuse for belonging to the Profession if he allows a good bridge to go into the scrap heap.

The analysis of railway bridge loading is valuable in indicating that it is probably now possible for an agreement to be reached with locomotive builders as to the future limiting weights; having in mind that this may not deter a railway manager from adopting a type of locomotive that is several degrees heavier than the traffic calls for. This is evident from one case where heavy Mallet locomotives were adopted for a low-grade line; when a Mikado with not more than $50000 \mathrm{lb}$. on the drivers would have been sufficient.

The scheme of bridge loading proposed by the writer to take the place of the obsolete Cooper system has been somewhat misunderstood, and it was based on the data gathered by Messrs. Welty and Bouton for the American Railway Engineering Association, which were plotted in percentages, as shown in Plates XXXVIII and XXXIX. The calculations were made by including nearly thirty of the very heaviest locomotives of each type in use, and the writer in Table 1 refers to only four of these, or those giving the heaviest moments for each length of span. Thus, no "hand-picking" was done as Mr. Ammann seems to suppose, and it would seem that this scheme would answer the requirements of Dr. Waddell by simply plotting an equivalent load curve based on the same moments. Should any one have the temerity to build a locomotive giving heavier moments, the curve of moments or of equivalent loads could readily be revised from time to time. At any rate, the operating departments of the railways would know at once that no loads now in existence would be too heavy for bridges built for such a loading.

That many of the railway companies are not satisfied to start a design for a bridge with an initial error of from 10 to $15 \%$ in the live load stresses, is shown by the fact that Cooper's E-70 loading is being used by many since the adoption of E-60 loading in the new or 1920 American Railway Engineering Association specifications. This is certainly nearer the truth than E-60, being only $5 \%$ too light for short spans, but there will probably be considerable metal wasted in spans from 150 to $300 \mathrm{ft}$. long. Everything developed since 1885 in train loadings has shown the futility of the ultra-refinement of bridge calculation for wheel loads. Moving the locomotives used at 


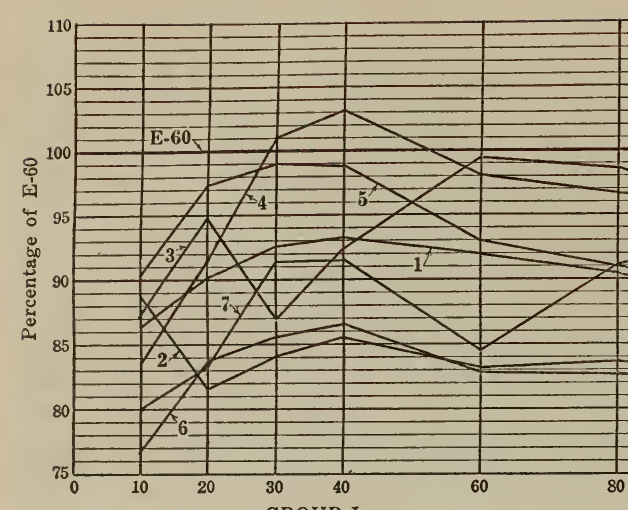

GROUP I

1-U. S. Standard 4-8-2-B and $210000-\mathrm{lb}$. cars. $2-$ U. S. Standard $4-6-2-B$ and $210000-1 \mathrm{lb}$. cars. $3-$ U. S. Standard 2-6-6-2-B and $210000-1 b$. cars. $3-U$. S. Standard $2-6-6-2-B$ and $210000-\mathrm{lb}$. cars.
4-U. S. Standard $2-10-2-\mathrm{B}$ and $210000-\mathrm{lb}$. cars.

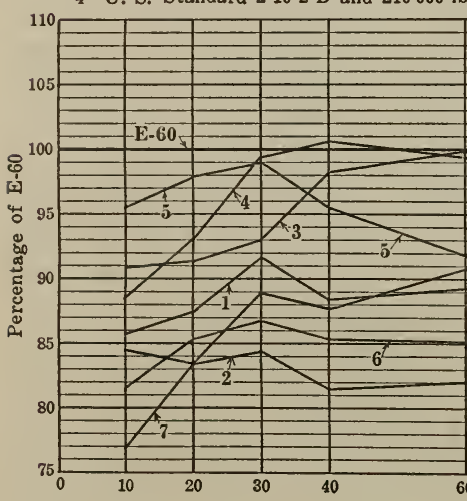

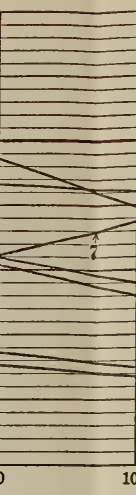

Span. in Feet.

4A-U. S. Standard 2-10-2-B and $6000-\mathrm{lb}$, per lin. $\mathrm{ft}$. uniform load.

$7 \mathrm{~A}-\mathrm{Santa} \mathrm{Fe}$ Type 2-10-2 and $6000 \cdot \mathrm{lb}$. per lin. $\mathrm{ft}$. uniform load.

Engines 1, 2, 4, 4A, 5, 6, 7, and 7A double-headed; Engine 3 single-headed.

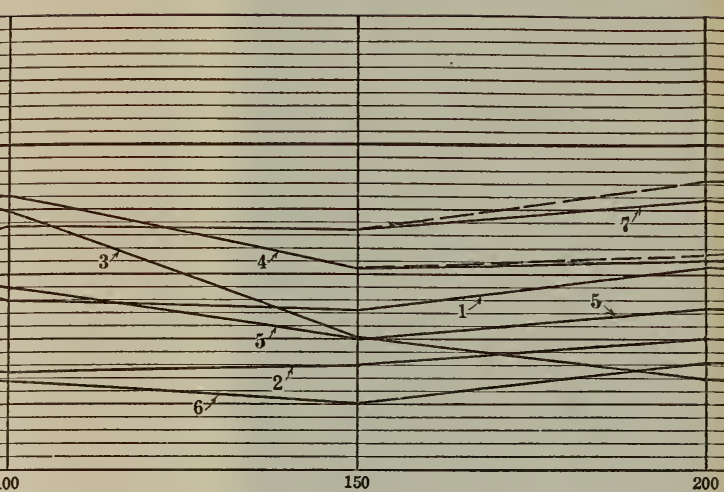

200

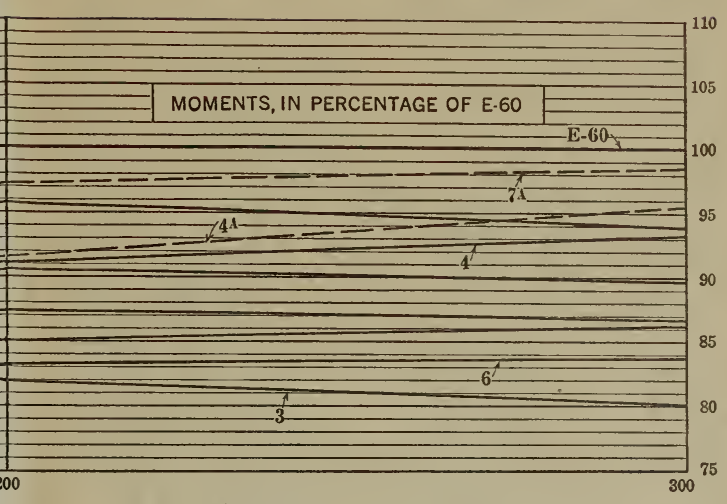

GROUP I (Continued)

$5-N$. Y. C. R. R.-Mikado-H7A-2-8-2 and 210000-lb. cars.

$6-$ U. S. Standard 2-8-2 and $210000-\mathrm{lb}$. cars.

6enta Te Type 2-10-2 and $210000-1 b$.
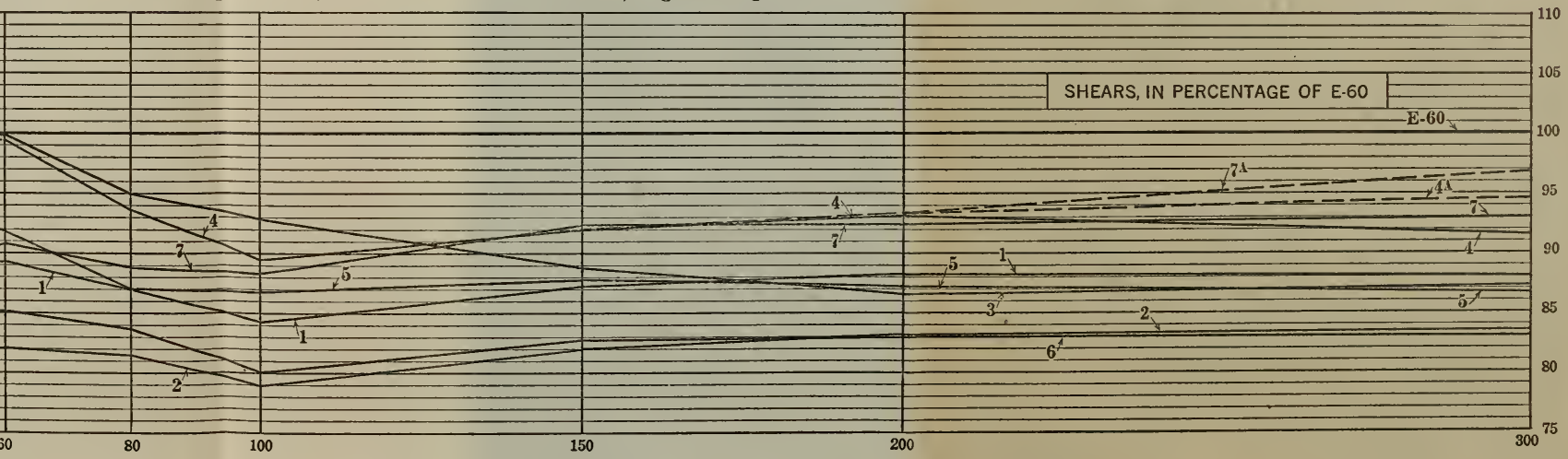

Span, in Feet. 


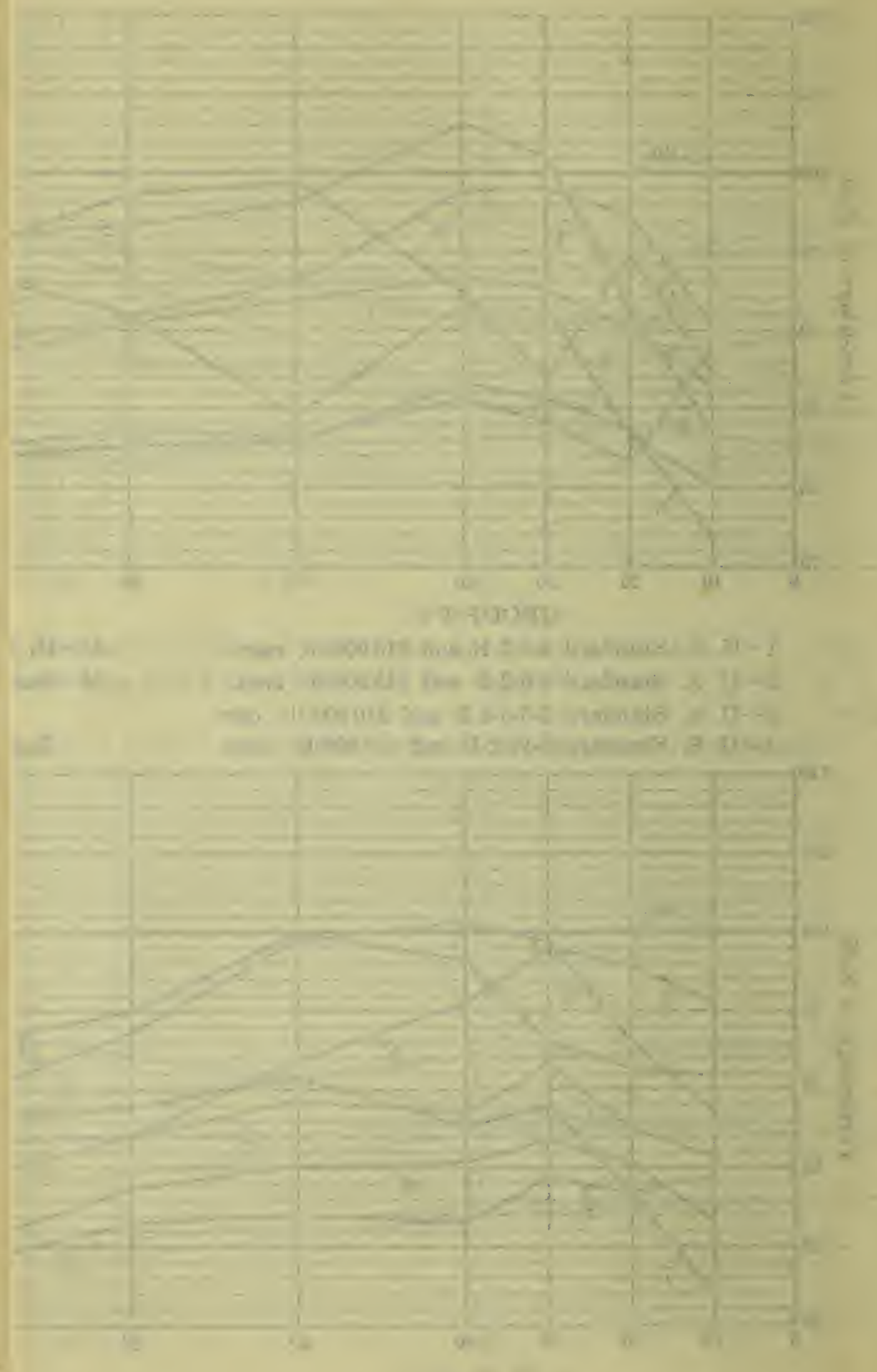


Niagara from having the first driver over the point, to the second Mr. driver, the third driver, or the fourth driver, gave little appreciable Fowler. difference in truss stresses. Yet, with all said, it is certain that any engineer would soon discontinue the services of an assistant who constantly made direct errors in calculations of from 5 to 15 per cent.

Mr. Ammann's criticism with regard to impact allowance is well taken, from his point of view, but the speed on the Niagara Arch Bridge, had not been gradually decreased as the bridge became more heavily loaded. The speed on the Roebling Suspension Bridge had been limited in the contract with the railway company to 5 miles per hour, and this was still in force on the Arch. However, by sufferance, speeds up to 25 to 30 miles per hour had been allowed. Thus, it was a question as to how much of an increase beyond 5 miles per hour should be allowed in the new contract; and the readings showed that 17 miles was the maximum increase allowable if the bridge was to be brought up fully to E-60 capacity. Due to the condition of the structure and to yard conditions at both ends, it was out of the question to run up to test speeds that would determine the critical speed on the Arch. However, it was certain that at some speed beyond 24 miles, the impact would reach a maximum, then probably drop off, and in the writer's opinion possibly increase at a higher speed up to a second maximum. This would be dependent on many other things than speed, notably the type of bridge and panel length. The data on impact gathered by the American Railway Engineering Association are sufficient, no doubt, to make possible the derivation of a formula for the calculation of the critical speed for ordinary types of bridges, and it is interesting to note that a recent review of these data confirms the findings at the Niagara Arch, except that after reaching a maximum at about 50 miles per hour, the curve drops off and does not again rise for the quite high speeds of the tests. The Profession would be greatly benefited if these were developed fully and published. However, the formula given in the paper may be used with confidence in cases where it is necessary to determine the reduction in speed which is necessary on an old structure.

The writer does not agree with Mr. Ammann as to the omission of secondary stress from the total stresses. The great advantage in calculating the secondary stresses in a new truss design is to determine the worth of the scheme under consideration, and when they are excessive, the design should be modified, if possible. The writer has had numerous verbal discussions which confirm him in the belief that all stresses must be included in the total stresses and that one must gradually approach the elastic limit of the material used for unit stresses, but not go beyond, as some have advised-arguing that the secondary stresses would disappear by adjustment and readjustment. 
The column formula used for the Niagara Arch is well on the safe side, but the writer agrees with Dr. Waddell and Mr. Ammann that further study of the subject is advisable; nothing better can be done than has been done until a thorough study and review have been made of all the column tests made during the last thirty years. Indications are that the opinion expressed to the writer recently by George H. Pegram, Past-President, Am. Soc. C. E., is correct, that when this is completed we will return to a formula of the Gordon type as most nearly representing test values for unit stress. This seemingly accords with the findings of O. E. Hovey, M. Am. Soc. C. E., with regard to the report of the Special Committee on Steel Columns and Struts of the Society. Recent specifications do not do justice to the American bridge engineer, who has long prided himself as being thoroughly scientific and not in favor of compromises.

The point made by Mr. Ammann with regard to column design is well taken, and much could be gained by more study in the designing and detailing of columns. The recent column tests by the U. S. Bureau of Standards emphasize the fact that a great difference in column strength is obtained in the arrangement of lacing, as was pointed out long ago by John E. Greiner, M. Am. Soc. C. E., in his study of secondary stresses in columns due to the arrangement of lacing bars. The fact noted by Mr. Schmitt with regard to the Niagara Bridge design being a generation ahead of its time, is especially true of the columns and built tension sections and their detailing, and they are entitled to much study by the present generation of designers.

The comparison of the strain gauges used at the Niagara Bridge was not carried far enough to give conclusive data in answer to $\mathbf{M r}$. Belzner, but without any reflection on either of the three types that were tried out, it may be said that although the Howard gauge is highly satisfactory for static work as regards final results, it is not at all possible to use it where moving loads are constantly passing over a bridge, nor for impact readings. Neither is it as easy to use as either of the other types. The Berry gauge was highly satisfactory for the dead load readings and for the static live load, but for impact work the vibration of the needle of the Ames dial made the readings too large, which, of course, was on the side of safety. The Fuller-West instrument was, in the writer's opinion, the best for all classes of work, and the only one that was really accurate for impact, as there was no disconcerting vibration of the needle of the "Last Word" dial. For the work done it was more satisfactory than a deflectometer.

The great care necessary in drilling the holes for the gauge points and in holding the strain gauge perpendicular to the member was a vital point, and necessitated a large number of check readings. The new scheme devised by Professor Fuller's mechanician, Mr. 


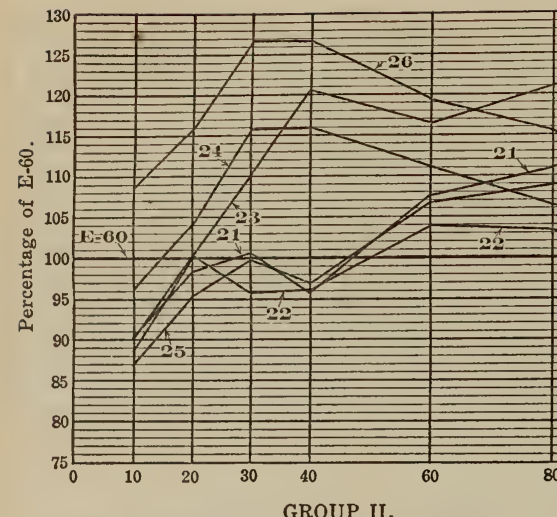

21-The Virginian Ry. 2-8-8-2 and $210000-\mathrm{lb}$. cars. $22-$ The L. S. \& M. S. Mallet $0-8-8-0$ and $210000-1 \mathrm{~b}$. cars. 23-The Virginian Ry, 2-10-10-2 and 210 000-lb. cars. 24-Erie Engine 2-10-2 and 210000-lb. cars.

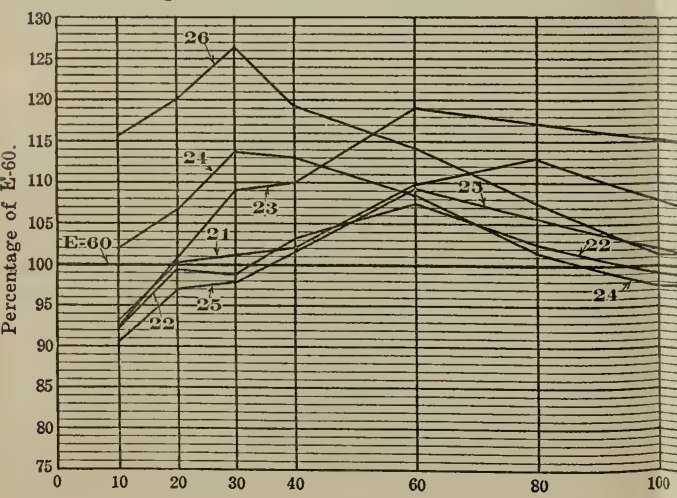

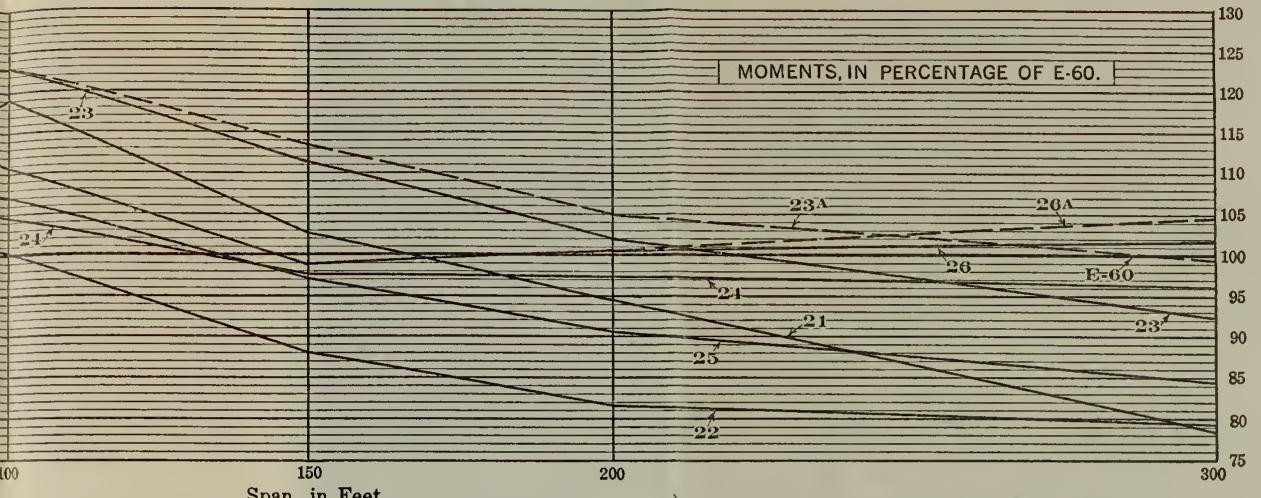

Span, in Feet.

33A-The Virginian Ry, 2-10-10-2 and $6000-\mathrm{lb}$, per lin $\mathrm{ft}$ un (Continued). $\begin{array}{ll}23 \mathrm{~A}-T h e \text { Virginian Ry. } 2-10-10-2 \text { and } 6000-\mathrm{lb} \text {. per lin. } \mathrm{ft} \text {. uniform load. } & 25-\mathrm{U} \text {. S. Standard 2-8-8-2-B and } 210000-\mathrm{lb} \text {. cars } \\ 26 \mathrm{~A}-\mathrm{Pennsylvania} \text { Ry. NIS 2-10-2 and } 6000-\mathrm{lb} \text {. per lin. ft. uniform load. } & 26-\text { Pennsylvania Ry. NIS } 2-10-2 \text { and } 210000-\mathrm{lb} \text {. cars }\end{array}$ Engines 21, 22, 23, 23A, and 25, single-headed; Engines 24 and 26, 26A double-headed.

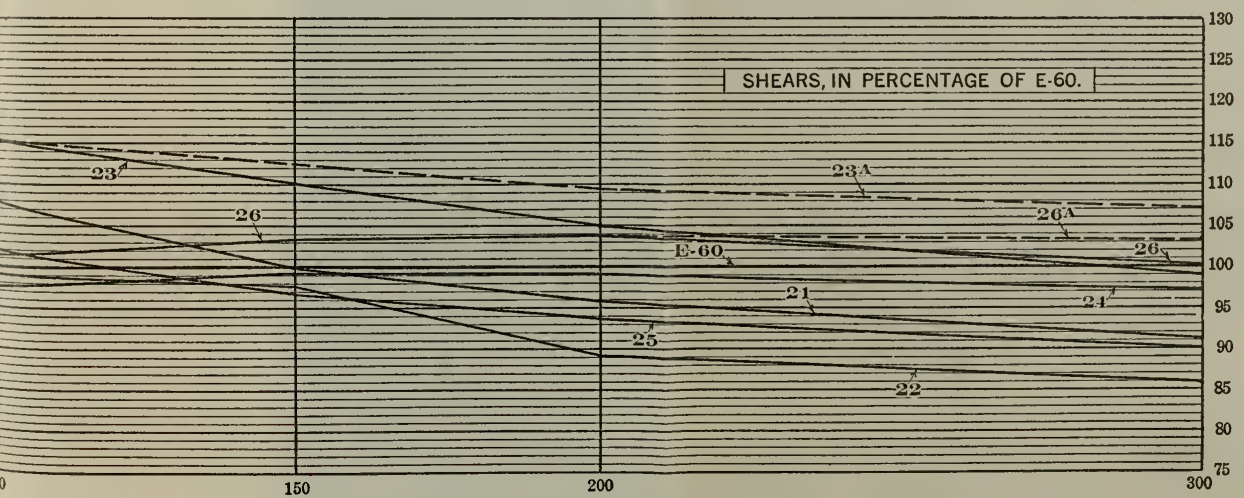



West, is one of the greatest improvements yet made for strain gauge $\mathrm{Mr}$, work. This consists in drilling the small holes and then setting into Fowler. them a small ball-bearing ball, as in Fig. 24. The leg of the instrument, instead of being pointed, has a conical recess to set on the projecting half of the ball. The instrument thus gives perfect readings when the legs are considerably out of plumb, and thus a great number of check readings are not required.

Early morning readings before the sun heats up the steel, are not necessary if proper temperature readings are made and the corrections calculated. In fact, it is next to impossible to get test trains except during regular working hours. The advisability of permanent gauge points on important structures mentioned by Mr. Howard should be taken to heart by all builders of big bridges, as the cost would be small, and the gain to the owner beyond question, to say nothing of the scientific data that would eventually be gained. The cost need not exceed $\$ 2$ per pair of points even if the large holes and the tapping

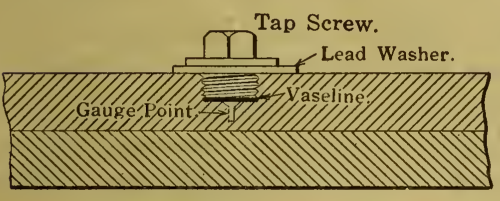

PERMANENT GAUGE POINT.

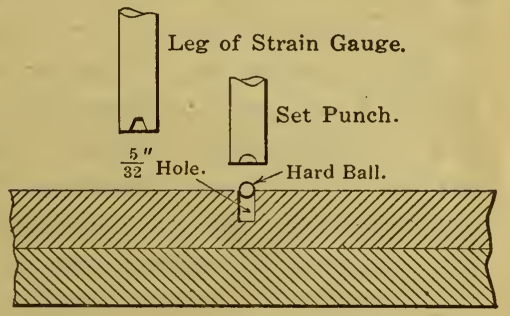

BALL BEARING GAUGE POINT.

FIG. 24.

are done with a breast hand drill; thus, the points on 150 members of a long span would cost about $\$ 300$. (Fig. 24.)

The many points raised by Mr. Schmitt are quite vital in the consideration of general and detail design. There can be no question but that the designer in endeavoring to make up his sections for easy future reinforcement will get a much better average make-up of sections; and he should also endeavor to design members that can easily be repainted and re-riveted in the field. One vital point, as brought out by results at the Niagara Bridge, is that all plates and shapes should be thickened about $\frac{1}{32}$ in. for each 20 years of the proposed life of a structure; and where there is apt to be excessive corrosion, then this amount should be doubled. Thus, the exposed top plates or angles of beams and stringers, and the horizontal coverplates or exposed angles should be increased more than $\frac{1}{8}$ in. for an assumed life of 40 years. The extra good care given the Niagara Arch was very exceptional. 
Mr. Fowler.

The methods used in the placing of reinforcing on members subjected to dead load stress were certainly superior to any such method as heating which might injure the steel and could not possibly be uniform throughout the length of a member, nor during the time required for the operation. The erratic distribution of stress over the cross-section of a truss member serves to make uncertain the realization of the computed unit stresses, and points anew to the necessity for a careful consideration of all kinds of secondary stresses. The writer cannot agree that the calculation of the stresses for such a two-hinged arch or other form of indeterminate structure is of necessity obviously correct, or as surely correct as for a simple structure, and it is certainly making assurance doubly sure to measure the dead load stresses as was done initially at the Hell Gate Arch and, latterly, at the Niagara Arch. The general run of the results of the latter for static live load was corroborative of the dead load stresses in other members than the center top chord where the dead load stress was actually measured. This could easily have been proven by using a toggle on some other member, at, however, a much greater cost.

The examination of the copper steel salt-water floor this summer (1920) has happily confirmed the reasons for the use of copper steel and of the enamel coating. The repair of some bad spots in the coating did not comprise more than about $5 \%$ of the top area, and was practically the only maintenance cost on the bridge for the year. The copper steel, where exposed, had not rusted to any such degree as is usual with ordinary carbon steel. The recent publication of the good condition of copper steel tie-plates, as compared with ordinary tie-plates, was another pleasing confirmation of the wisdom of the experiment. The cost of renewing some of the troughs, if necessary some years from now, will be only a fraction of the cost of renewing top flanges of beams and stringers at a cost of probably $\$ 30000$. The low first cost of such a floor and the saving in dead load on the structure should recommend a similar design for new bridges.

The question as to the rod bracing allowing more vibration in the Arch than would be the case with stiff bracing was carefully studied. It is true that the adjustment of the rods by using the strain gauge did add to the stiffness, as some of them were stressed to the elastic limit and undoubtedly gave more or less under lurching trains, but there was a general swing to the long rods which was accentuated by the inertia of the pin and eight loop eyes at the center crossing. The new stiff bracing, of course, was made heavy enough to allow for the future four-tracking of the bridge, but while the gusset connections may induce some secondary stresses in the truss members, it is also true that in the final analysis they serve to shorten in a 
degree the length of the main members and to bind the entire struc- ${ }_{\text {Fowler. }}^{\mathrm{Mr} \text {. }}$ ture more firmly together.

The slowness of the center top chords to take full stress after the change of the shims certainly was due largely to the compressive stress that was taken by the tight stringers, by the $100-\mathrm{lb}$. rails with tight joints, and, lastly, to a certain readjustment of the center bottom joints, where the gussets had been curved out and som rivets cut out, as was shown by the check strain gauge readings. Certain it must be that there were infinitesimal elastic adjustments at other truss joints, and this may still be slowly going on.

The riveting done during 1918 and 1919, referred to by Mr. Bentham, was not because of overload, or train vibration, except as found in some joints in the northwest quarter of the arch, which gets more traffic due to yard switching, but was largely due to poor field riveting when the bridge was built. This was not to be avoided when driving 1-in. rivets by hand, as had to be done in 1896-97. Had they been tested with an 8-lb. sledge, as the writer once knew an inspector to do (!), it could have been found at the time. Redriving them with long gun air riveters, drew the plates more firmly together and loosened adjacent rivets to the extent that in some cases all of the 250 or more rivets in a joint would have to be redriven. The low unit stress first used, $6500 \mathrm{lb}$. per sq. in., had prevented the joints from working. Many of the hand-driven rivets had never been upset to fill the holes, and were rusted inside from end to end, although this did not show outside, around the heads, the rivet heads in all cases being tight against the member or plate.

The writer has already replied to Mr. Ammann and others in regard to the query of Mr. Lang, pointing out that the Welty-Bouton data prove more conclusively against the retention of Cooper's loadings, than for their continuance as the standard. The writer has seen too many such questions answered by "time" in the past thirty years, not to await "time's" verdict in this case.

The wasting away of the plates from salt-water currosion was quite uniform over the entire surfaces, whole layers or laminations being removable; for angles, however, it was in patches and depressions, but also over the entire exposed surfaces.

The careful reader will certainly find the matter of highway loads fully covered under the head of "Highway Floor." The 15-ton truck was of the standard type as to the spacing of axles, wheels, and loads. The writer is not aware of any statement to the effect that the bridge had been revised for E-80 loading, having been made in the paper.

Replying to Mr. Bentham's query about keeping trains going: Only one track was removed at a time; when the first track was complete, traffic was shifted and the other track torn up. The only work extend- 
Mr. ing across under the track in use was the replacement of the top Fowler. floor-beam cover-plates. This reduction in strength of beams was made up by shoring and slow speed of trains.

The writer would feel sure, after the experiences with salt-water corrosion at Niagara, that it would be a reasonably simple matter to correct the effects of salt-water corrosion on the lower parts of the Forth Bridge, and to protect it against further corrosion. Whether or not the rusting has been severe enough seriously to endanger the structure would be interesting to know, but it is to be presumed that the data regarding the original design of the bridge, which have never been made public, would make this a matter to be easily determined.

The whole of the Niagara Bridge investigation and revision, and the discussion of this paper, makes one quite certain that engineers cannot now stop, self satisfied, with the present status of bridge design. There is little incentive, it is true, for anything except machine-made plans; but with the data available from which to formulate a real specification why is it not incumbent upon the Society to fix a standard as high as the materials specifications of the American Society for Testing Materials? 






\section{SpCl \\ $F C$ \\ $316^{\circ}$ BROCK UNIVERSITY}

.67 ST. CATHARINES, ONTARIO

$$
\begin{aligned}
& N 54 \\
& 1920
\end{aligned}
$$

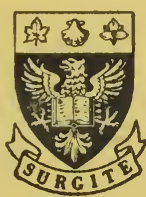

\section{LIBRARY}


